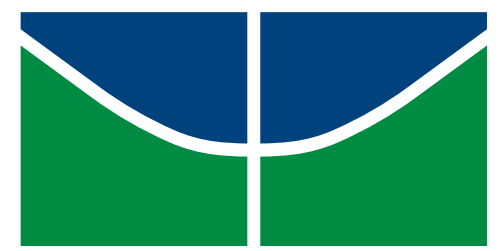

Universidade de Brasília (UnB)

Faculdade de Economia, Administração, Contabilidade e Gestão Pública (FACE)

Programa de Pós-graduação em Administração (PPGA)

\title{
INOVAÇÃO, DESEMPENHO E COPRODUÇÃO NO SETOR FINANCEIRO: ESTUDO DE COMPANHIAS BRASILEIRAS DE CAPITAL ABERTO
}

CHAEL LUIGI DE SOUZA MAZZA

Orientador: Prof. Dr. Antonio Isidro-Filho

Tese de Doutorado 
Universidade de Brasília (UnB)

Faculdade de Economia, Administração, Contabilidade e Gestão Pública (FACE)

Programa de Pós-graduação em Administração (PPGA)

\section{Brasília-DF}

\section{INOVAÇÃO, DESEMPENHO E COPRODUÇÃO NO SETOR FINANCEIRO: ESTUDO DE COMPANHIAS BRASILEIRAS DE CAPITAL ABERTO}

\section{CHAEL LUIGI DE SOUZA MAZZA}

Tese submetida ao Programa de Pós-Graduação em Administração (PPGA) como requisito parcial à obtenção do grau de Doutor em Administração.

Banca Examinadora:

Prof. Dr. Antonio Isidro-Filho, Universidade de Brasília.

Orientador

Prof. Dr. Herbert Kimura, Universidade de Brasília.

Examinador Interno

Prof. Dr. Tomás de Aquino Guimarães, Universidade de Brasília.

Examinador Interno

Prof. Dr. André Luiz Marques Serrano, Universidade de Brasília.

Examinador Externo

Prof. Dr. Marcelo Gattermann Perin, Pontifícia Universidade Católica do Rio Grande do Sul. Examinador Externo

Prof. Dr. Rafael Barreiros Porto, Universidade de Brasília.

Suplente 
MAZZA, Chael Luigi de Souza.

Coprodução, Inovação e Desempenho no Setor Financeiro: Universidade de Brasília - UnB, 2017, 136 p.

Tese de Doutorado em Administração

Orientador: Prof. Dr. Antonio Isidro-Filho

1. Inovação

2. Desempenho

3. Coprodução

4. Setor Financeiro 


\section{DEDICATÓRIA}

Aos meus pais, Jeanne Alves de Souza Mazza e Emanuel Mazza de Castro, pelo amor incondicional e por minha eterna gratidão.

A todos aqueles que me ajudaram a remar para frente, pois neles pude encontrar suporte, força e determinação para seguir adiante.

A todos aqueles que tentaram me fazer remar para trás, pois por intermédio deles pude testar minha vontade e alcançar a superação. 


\section{AGRADECIMENTOS}

Considero esta a parte mais difícil de escrever, pois entre tantos que colaboraram de forma direta ou indireta para o aprendizado e consecução deste trabalho, apenas tenho a dizer que sem vocês e sem tudo isso eu não teria conseguido.

Agradeço primeiramente a Deus, onipresente em todas as etapas, onisciente em toda Sua sabedoria e onipotente em todos os caminhos que Ele escolheu designar a mim. Nesses anos foram tantas bênçãos e realizações que tenho apenas a agradecer a vida que me foi dada.

Agradeço aos meus pais pelo tempo dedicado, pela companhia, pelos sorrisos, conselhos e aprendizado. Afinal, quando todo o céu vem a desabar, são nos nossos pais que sempre encontramos refúgio e fortaleza. Da mesma forma agradeço à minha família, em sentido amplo e estrito, pois familiares não são apenas aqueles com laços sanguíneos, mas sim aqueles que escolhem correr ao nosso lado. Agradeço também a todos os meus amigos pelos depoimentos, críticas, sinceridades, momentos, lembranças e saudades. Apenas eles têm a incrível capacidade de estar sempre disponíveis, mesmo longe, e sempre dispostos a fazer loucuras, mesmo sãos.

Devo um agradecimento especial ao professor, mentor e amigo, Antonio Isidro, pela paciência infinita em ver e criticar meus erros (e acertos) e ser uma luz nesse imenso túnel de aprendizado. Gosto de brincar que, às vezes, o orientador mais desorienta que orienta, mas em sua sabedoria ele compreende que nos fazer pensar é sempre mais importante que dar respostas prontas, e nos ensinar a construir resultados é mais importante que fazê-los por nós.

Um agradecimento especial também ao professor André Serrano, pelas valiosas dicas e conselhos e principalmente pela consideração. Agradeço também a todos os membros da banca examinadora pela disponibilidade, atenção, pareceres, críticas e por terem me permitido seguir em frente.

Agradeço ao amor da minha vida, Dyhesca, por me proporcionar uma felicidade tão única que não conseguiria descrever em palavras.

Finalmente, agradeço ao pequenino sabiá que todo dia de manhã cedo canta na minha janela e é meu companheiro de escrita e inspiração, tanto nos dias de sol, quanto nos dias de chuva. A ele agradeço por me lembrar todo dia das pequenas belezas da vida, que são as que realmente importam. 
EPÍGRAFE

Toda manhã, na África, uma gazela desperta. Sabe que deverá correr mais depressa do que o leão, ou será morta.

Toda manhã, na África, um leão desperta. Sabe que deverá correr mais do que a gazela, ou morrerá de fome.

Quando o sol surge, não importa se você é um leão ou uma gazela: é melhor começar a correr.

(Provérbio Africano) 


\section{RESUMO}

A presente tese teve como objetivo explicar as relações entre inovação, desempenho e coprodução no setor financeiro. Com base no levantamento bibliométrico realizado, verificouse que produtos e serviços financeiros são processos formados por competências, características e entregas. Dessa forma, a inovação é resultante de modificações em tais elementos, a coprodução é a mobilização de competências entre instituições, parceiros e clientes e o desempenho é determinado com base na conversão dos vetores em entregas. Portanto, argumentou-se que o ambiente tem relação direta com inovação e coprodução, que a inovação tem relação positiva com a coprodução, e que ambas têm relação positiva com o desempenho. Posto isso, realizaram-se dois estudos a fim de validar empiricamente estas afirmações. $\mathrm{O}$ estudo I, qualitativo e transversal, procurou caracterizar a relação entre inovação, desempenho e coprodução no setor financeiro brasileiro. A técnica utilizada foi a análise de conteúdo, elaborada com base nos formulários de referência de vinte e nove instituições financeiras brasileiras listadas na bolsa de valores. Os constructos analisados foram os tipos e as lógicas de inovação, tipos e parceiros na coprodução. Os resultados demonstraram que no âmbito do setor financeiro brasileiro a inovação e a coprodução, no geral, têm relação positiva com o desempenho, e que inovação e coprodução apresentam relação positiva entre si. Contudo, tais relações são mediadas e moderadas por fatores internos e externos à organização. Na sequência, o estudo II, quantitativo e longitudinal, utilizou a análise por envoltória de dados (DEA) em painel para determinar o impacto da inovação e coprodução no desempenho bancário. O modelo considerou três entradas (inovação, coprodução e rede de atendimento) e duas saídas (geração de valor e adimplência) e a investigação baseou-se nas demonstrações financeiras dos bancos brasileiros de capital aberto no período de 2008 a 2015. Os resultados demonstraram que o modelo DEA-BCC é mais adequado para analisar o desempenho de bancos brasileiros e que o modelo Malmquist-DEA é apropriado para quantificar melhorias de produtividade no setor. Ainda, verificou-se que a produtividade do setor bancário brasileiro declinou no período, mas que a maioria dos bancos apresentaram boas médias de eficiência global e melhoria de produtividade. Nesse contexto, a inovação e a coproducão mostraram-se bons estimadores de desempenho.

Palavras-Chave: Inovação; Coprodução; Desempenho; Setor Financeiro; DEA. 


\begin{abstract}
The main objective of this thesis was to explain the relationships between innovation, performance and coproduction in the financial sector. The bibliometric survey showed that financial products and services are processes comprised of competences, characteristics and deliveries. In this way, an innovation is the result of modifications in such elements, coproduction is the competences mobilization between companies, partners and customers and the performance is determined by the conversion of the vectors into deliveries. Therefore, we argue that environment is directly related to innovation and coproduction, innovation is positively related to a coproduction, and that both have a positive relationship with performance. After that, two studies were carried out to empirically validate these statements. The Study I, qualitative and transversal, sought to characterize the relationship between innovation, performance and coproduction in the Brazilian financial sector. We performed a content analysis technique based on the activities report of twenty-nine Brazilian financial institutions listed on the stock exchange. The constructs analyzed were the types and logics of innovation and partners and types of coproduction. The results showed that in the Brazilian financial sector, innovation and coproduction have a positive impact on performance, and that both have a positive relation between them. However, these relationships are mediated and moderated by internal and external factors. Subsequently, the Study II, quantitative and longitudinal, applied a panel envelopment data analysis (DEA) to determine the impact of innovation and coproduction on banking performance. The model considered three inputs (innovation, coproduction and bank network) and two outputs (value generation and compliance) and the investigation was based on the analysis of the financial statements of the biggest Brazilian banks from 2008 to 2015 . We demonstrated that DEA-BCC model is more adequate to analyze the performance of Brazilian banks and that the Malmquist-DEA model is appropriate to quantify productivity improvements in the sector. Also, we verified that the production of the Brazilian banking sector declined in the period, but that the majority of banks presented good averages of global efficiency and productivity improvement. In this context, innovation and coproduction proved to be good performance estimators.
\end{abstract}

Keywords: Innovation; Coproduction; Performance, Financial Sector; DEA 


\section{SUMÁRIO}

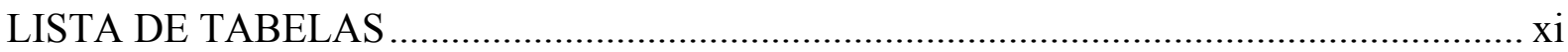

LISTA DE QUADROS..............................................................................................

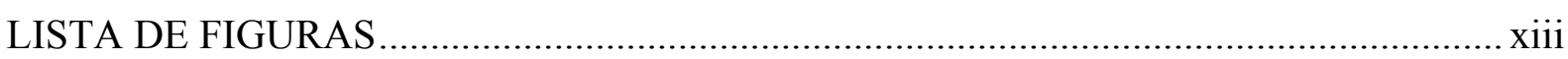

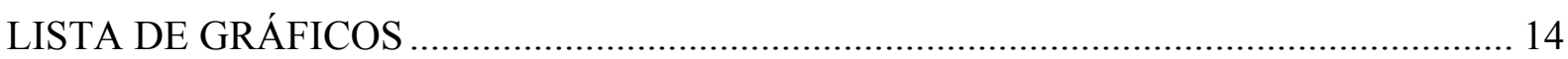

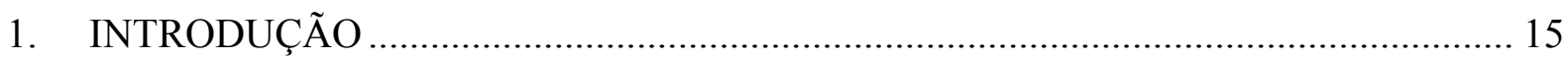

1.1. Problema de Pesquisa, Descrição Geral e Relevância do Trabalho.................................. 15

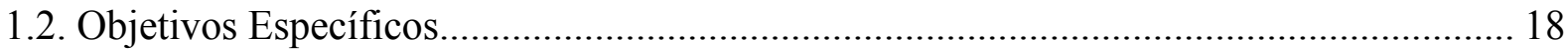

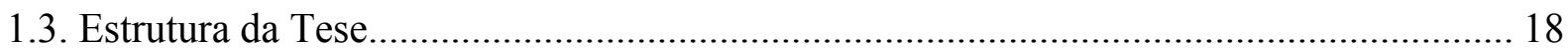

1.4. Descrição e Procedimentos Metodológicos do Estudo I................................................... 19

1.5. Descrição e Procedimentos Metodológicos do Estudo II ........................................... 21

2. INOVAÇÃO, DESEMPENHO E COPRODUÇÃO NO SETOR FINANCEIRO:

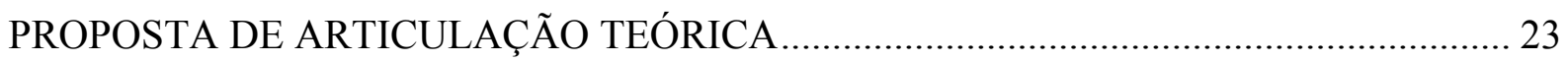

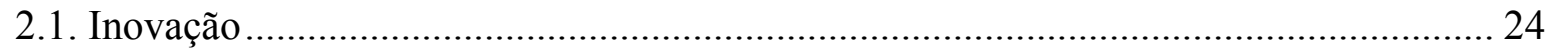

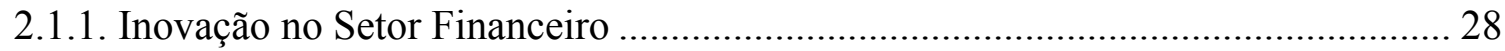

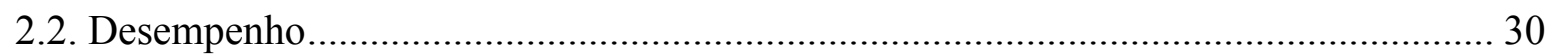

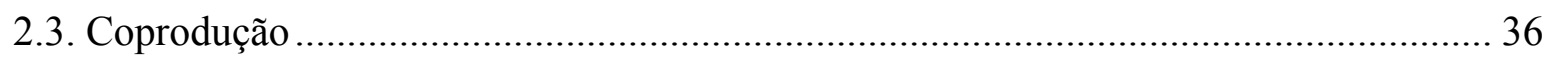

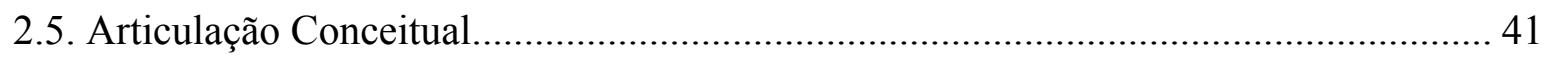

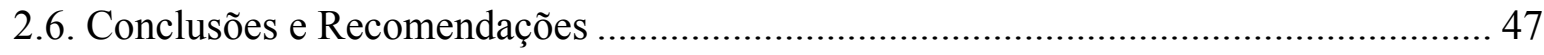

3. ESTUDO I: INOVAÇÃO, DESEMPENHO E COPRODUÇÃO NO SETOR FINANCEIRO BRASILEIRO: UM ESTUDO EXPLORATÓRIO DE COMPANHIAS DE CAPITAL

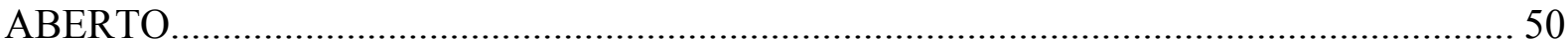

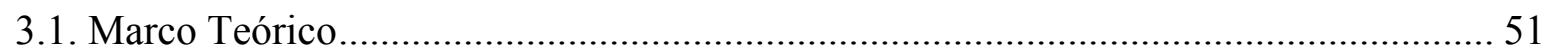

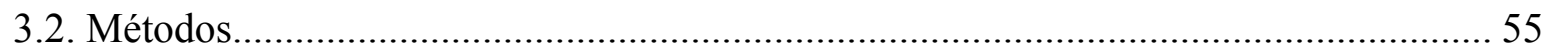

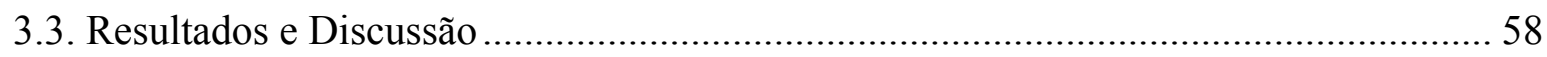

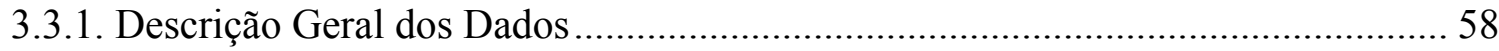

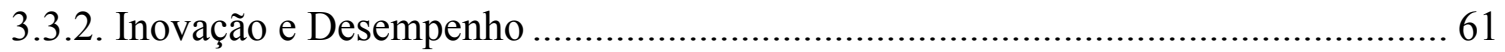

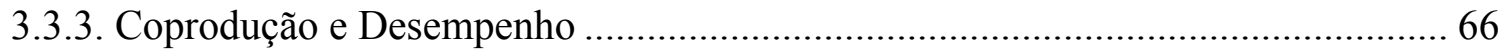

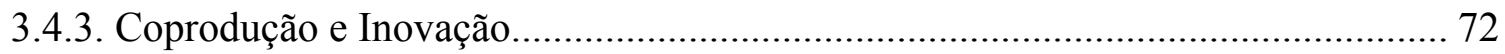

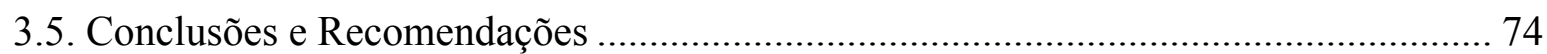

4. ESTUDO II: APLICAÇÃO DE DEA BASEADA NO ÍNDICE DE PRODUTIVIDADE DE MALMQUIST: MENSURAÇÃO DO DESEMPENHO DE BANCOS BRASILEIROS c COM BASE NA INOVAÇÃO E COPRODUÇÃO 


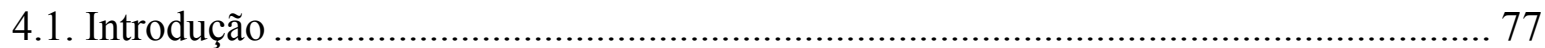

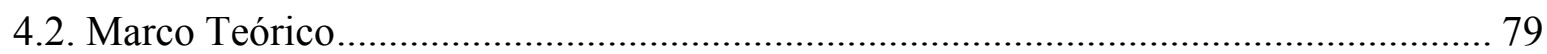

4.2.1. Inovação e Coprodução no Setor Financeiro ....................................................... 79

4.2.2. Desempenho Bancário e Inadimplência................................................................ 81

4.2.3. Articulação e Hipóteses de Pesquisa......................................................................... 83

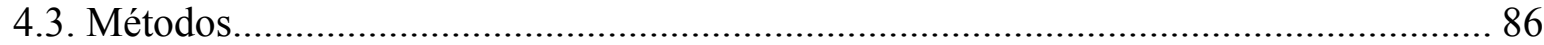

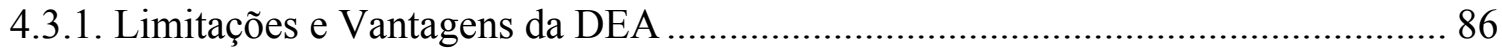

4.3.2. Modelo DEA baseado no Índice de Produtividade de Malmquist......................... 87

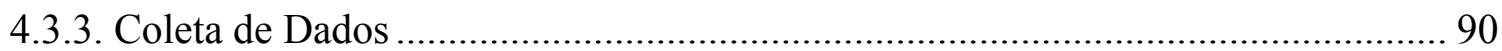

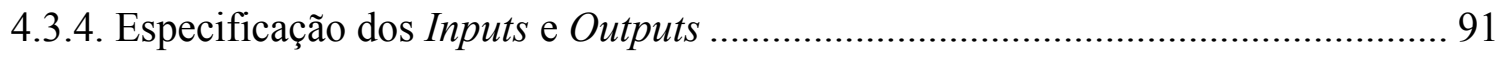

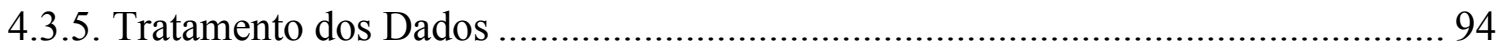

4.3.6. Parâmetros para Análise dos Dados....................................................................... 95

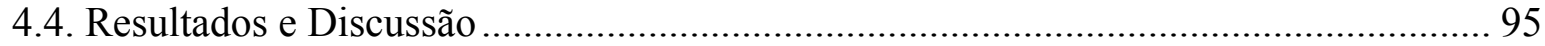

4.4.1. Panorama Geral do Setor Bancário Brasileiro no Período 2008-2015 .................. 95

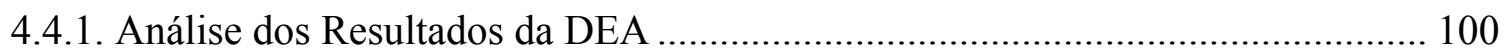

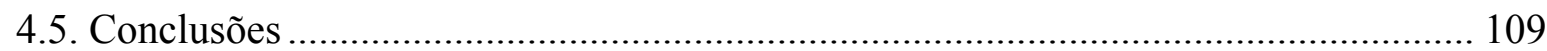

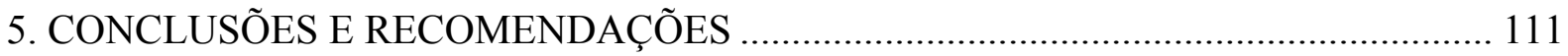

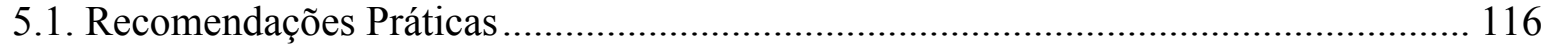

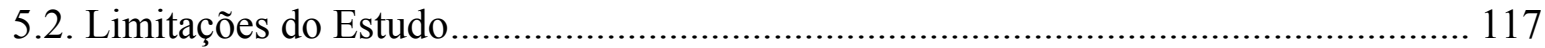

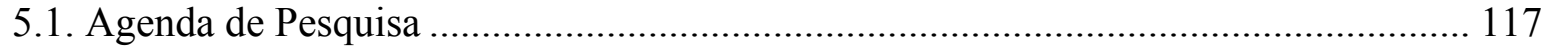

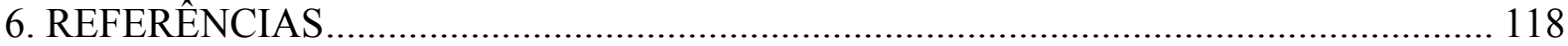

ANEXO 1 - PROTOCOLO PARA ANÁLISE DE DADOS SECUNDÁRIOS (NINE-UNB)

ANEXO 2 - ANÁLISE DA MELHORIA DE PRODUTIVIDADE, EFICIÊNCIA TÉCNICA E TECNOLOGIA DOS BANCOS BRASILEIROS DE CAPITAL ABERTO NO PERÍODO DE 2008 A 2015. 128 


\section{LISTA DE TABELAS}

Tabela 1. Quantidade de indícios de inovações e coproduções de cada empresa da amostra. 59

Tabela 2. Porcentagem de tipos e lógicas de inovação mapeadas. 60

Tabela 3. Tipos e dimensões de coproduções mapeadas. 61

Tabela 4. Inovação, coprodução e desempenho do setor bancário brasileiro. 96

Tabela 5. Escores médios de eficiência das DMUs de acordo com os modelos CCR e BCC, considerando o período 2008-2015.

Tabela 6. Escores médios de eficiência das DMUs de acordo com os modelos CCR e BCC, considerando o período 2008-2015... 102

Tabela 7. Índices de produtividade no setor bancário brasileiro no período de 2008 a 2015.103

Tabela 8. Média de produtividade do bancos brasileiros no período de 2008 a 2015. 108

Tabela 9. Eficiência das DMUs - Modelo CCR. 128

Tabela 10. Eficiência Global das DMUs - Modelo CCR 129

Tabela 11. Eficiência das DMUs - Modelo BCC. 130

Tabela 12. Eficiência Global das DMUs - Modelo BCC. 131

Tabela 13. Índice Malmquist de Produtividade (MPI) de cada DMU - Modelo BCC 132

Tabela 14. Mudança de Eficiência (OEC) de cada DMU - Modelo BCC. 133

Tabela 15. Mudança de Tecnologia (OTC) de cada DMU - Modelo BCC. 134 


\section{LISTA DE QUADROS}

Quadro 1. Tipos de inovação de acordo com a abordagem integradora (Gallouj \& Weinstein, 1997).

Quadro 2. Tipos de coprodução de acordo com Edvardsson et al. (2010). 40

Quadro 3. Amostra de Pesquisa. 56

Quadro 4. Finalidades da inovação no setor financeiro brasileiro. 62

Quadro 5. Fatores que impactam o Sucesso da Inovação. 64

Quadro 6. Benefícios da inovação no setor financeiro. 65

Quadro 7. Formatos de Coprodução no Setor Financeiro 67

Quadro 8. Principais fatores que impactam a coprodução no setor financeiro. 68

Quadro 9. Riscos associados ao processo de coprodução 69

Quadro 10. Benefícios da coprodução no setor financeiro. .70

Quadro 11. Proposta de tipologia de coprodução. 72

Quadro 12. Características da relação entre inovação e coprodução. 72

Quadro 13. Operacionalização das variáveis de pesquisa. 94

Quadro 14. Parâmetros para análise dos resultados DEA. Fonte: Wang \& Lan (2011). .95

Quadro 15. Protocolo para Análise de Conteúdo de Dados Secundários (NINE-UnB). 127 


\section{LISTA DE FIGURAS}

Figura 1. Processo de inovação de acordo com a abordagem integradora. Adaptado de Gallouj e Savona (2010) e Gallouj e Toivonen (2011).

Figura 2. Proposta de articulação entre inovação, desempenho e coprodução no setor financeiro. 44

Figura 3. Modelo de pesquisa. 


\section{LISTA DE GRÁFICOS}

Gráfico 1. Inovação e geração de valor no setor bancário brasileiro ..................................... 97

Gráfico 2. Coprodução e geração de valor no setor bancário brasileiro................................. 98

Gráfico 3. Rede de atendimento e geração de valor no setor bancário brasileiro.................... 99

Gráfico 4. Inovação, coprodução e adimplência média no setor bancário brasileiro. ........... 100

Gráfico 5. Produtividade do setor bancário brasileiro no período de 2008 a 2015 .............. 107 


\section{INTRODUÇÃO}

\subsection{Problema de Pesquisa, Descrição Geral e Relevância do Trabalho}

Em setembro de 2008, a quebra do banco americano Lehman Brothers simbolizou o início da maior crise econômica desde a grande depressão de 1929 (Delimatsis, 2012). As raízes da crise foram os instrumentos financeiros, pois, por muito tempo, houve uma super oferta de crédito aos consumidores no setor imobiliário. Empréstimos subprimes foram feitos àqueles que não teriam como pagar, uma vez que a valorização dos imóveis cobriria as perdas, e foram divididos em produtos financeiros complexos e opacos, onde o verdadeiro valor estava mascarado (Hutton \& Lee, 2012; Ozbay, Dinçer \& Hacioglu, 2011). Com o início da falência do mercado imobiliário americano, o sistema começou a entrar em colapso. Os direitos de propriedade sem valor tornaram os bancos insolventes, o que acarretou a quebra de confiança no sistema e o consequente encerramento de empréstimos interbancários, impedindo a solvência do fluxo de caixa diário. A crise levou a uma redução considerável de liquidez, que passou dos bancos para as empresas, o mercado imobiliário e os consumidores, fato esse que expôs a fraqueza de uma economia endividada e a convicção do governo nas taxas pagas pelas instituições financeiras (Ozbay, Dinçer \& Hacioglu, 2011). Seguiu-se, então, uma recessão global e perda geral de confiança (Hutton \& Lee, 2012).

A crise financeira global incluiu a desaceleração incisiva das atividades econômicas, e muitas das grandes economias sofreram recessões consideráveis. Nesse contexto, foram reveladas inúmeras falhas na regulação prudencial e supervisão do setor financeiro, que estão relacionadas não apenas às instituições individuais, mas também ao sistema financeiro como um todo. Estruturas regulatórias e o paradigma neoliberal predominante mostraram-se incapazes de atuar de forma efetiva em termos de prevenção, gerenciamento e resolução de crises financeiras (Caselli, 2010; Delimatsis, 2012; Rossignoli \& Arnaboldi, 2009). Depois de oito anos, o tumulto financeiro ainda se mantém acelerado após a reviravolta da crise (Delimatsis, 2013). Tais eventos levantaram questões acerca da correta aplicabilidade das práticas de desregulação durante três décadas de ortodoxia neoliberal do setor financeiro. A crise levou à revisão de vários princípios fundamentais e práticas cruciais das políticas financeiras e ao reconhecimento de que se fazem necessárias mudanças de estrutura e supervisão do sistema financeiro global (Delimatsis, 2012; Hutton \& Lee, 2012; Ozbay, Dinçer \& Hacioglu, 2011). 
Tal conjuntura resultou na reformulação de toda a dinâmica do setor financeiro. Houve um aumento significativo da competitividade após a entrada de empresas estrangeiras e concorrentes de outros setores, além de novos modelos de negócio, de forma que se tornou difícil identificar os atores do mercado, o escopo de atuação de cada um deles e o grau de fiscalização e regulação a que estão submetidos (Delimatsis, 2013; Hoffmann, Post \& Pennings, 2013; Rossignoli \& Arnaboldi, 2009). Além disso, os governos estão ainda em discussão sobre a correta aplicabilidade dos mecanismos regulatórios, tendo em vista o paradoxo regulaçãodesregulação, que afirma que após os tumultos há uma tendência de enrijecimento dos normativos e do fortalecimento da supervisão, o que acaba sendo afrouxado nos períodos de crescimento (Caselli, 2010; Rossignoli \& Arnaboldi, 2009). Ademais, novas tecnologias vêm influenciando significativamente a forma como as transações financeiras são realizadas e as demandas dos clientes por novos instrumentos, visando a explorar as deficiências de mercado e a estabelecer padrões de fluxo de caixa específicos. Da mesma forma, vêm moldando a forma como as instituições financeiras atuam e interagem (Rossignoli \& Arnaboldi, 2009; Shahrokhi, 2008).

Nesse contexto, a inovação, foi considerada por diversos autores como a principal causa da crise (Delimatsis, 2012; Delimatsis, 2013). Tais estudos destacaram que a inovação no setor financeiro está diretamente atrelada à fragilidade financeira, ao mascaramento de riscos e à supervalorização de seguranças (Delimatsis, 2012; Gai, Kapadia, Millard \& Perez, 2008; Hutton \& Lee, 2012; Lenzer \& Zhao, 2012). Tal fato se justifica porque os empréstimos subprimes foram frutos diretos de inovações que negligenciaram os riscos a fim de maximizar os lucros, sem haver garantias de mercado válidas para tais instrumentos. Dessa forma, essa vertente de estudos destaca que a inovação é capaz de gerar riscos sistêmicos e que, por sua vez, tem impacto negativo no desempenho do setor (Mullineux, 2010).

Por outro lado, diversos estudos destacam os benefícios da inovação, uma vez que esta está relacionada ao crescimento econômico, ao atendimento das necessidades específicas dos investidores, ao desenvolvimento de novos produtos e serviços, à diversificação dos instrumentos financeiros e riscos, à redução dos custos de transação e geração de valor social (Delimatsis, 2012; Johnson \& Kwak, 2012; Tufano, 2003). Tal vertente "otimista" busca enfatizar o impacto positivo da inovação no setor financeiro, uma vez que a inovação é mecanismo fundamental de adaptação por meio do qual as instituições fazem frente a um ambiente dinâmico e complexo (Bos, Kolari \& Lamoen, 2013; Delimatsis, 2013; Frame \& White, 2004; Rossignoli \& Arnaboldi, 2009). 
Ainda, argumenta-se que a inovação financeira contribuiu significativamente para o aumento das interações e a interconectividade entre os diversos atores do sistema (Delimatsis, 2012). Isso se deve ao fato de os mais importantes depósitos de conhecimento para a inovação residirem, na própria instituição, nos parceiros e clientes, além de aproximadamente metade das inovações no setor financeiro serem geradas com base em interações com parceiros do mesmo grupo ou conglomerado ou com os demais parceiros externos (Martovoy, Mention \& Torkelli, 2015). Portanto, a literatura defende que a coprodução, definida como todos os formatos de cooperação que objetivam agregar valor para as partes, impacta positivamente o bem-estar econômico e social (Chen, Tsou \& Ching, 2011; Cheung \& To, 2011; Mende \& Doorn, 2014; Wu \& Lin, 2013; Vargo \& Lusch, 2004).

Nesse contexto, diversos estudos apontam que a coprodução tem impacto positivo na inovação, visto que cooperações de negócio e parcerias e alianças contribuem para o desenvolvimento da capacidade de inovação à medida que o aumento das interações gera insumos para o desenvolvimento de novos produtos e serviços (Chen, Tsou \& Ching, 2011; Tsou \& Chen, 2012). Além disso, verifica-se que o desempenho das instituições financeiras é influenciado fortemente pelo grau de confiança dos atores e investidores que, por sua vez, é resultante dos formatos e mecanismos colaborativos entre instituições financeiras, parceiros e clientes (Martovoy, Mention \& Torkkeli, 2015; Mende \& Doorn, 2014). Ainda, o papel crescente dos parceiros e clientes como participantes ativos e mandatórios da dinâmica é cada vez mais evidente em um contexto onde os atores redefinem as regras do jogo a partir do momento que se tornam mais interativas e aumentam as demandas por responsabilidade e transparência (Mende \& Doorn, 2014).

Face ao exposto, resta ainda em aberto a questão: a inovação e a coprodução possuem impacto positivo no desempenho das instituições financeiras? Em meio a esse debate, cabe destacar que pouco foi realizado no sentido de elucidar e validar empiricamente a relação entre inovação e desempenho, e muito menos no sentido de caracterizar o próprio processo de inovação no setor (Delimatsis, 2012; Delimatsis, 2013; Gai, Kapadia, Millard \& Perez, 2008; Meng \& Guo, 2013; Mullineux, 2010; Stevens \& Dimitriadis, 2005). Além disso, destaca-se que, apesar de a literatura destacar o papel ativo dos parceiros e clientes no contexto do setor financeiro pós-crise, há poucos estudos que equacionam a coprodução com o desempenho ou com a inovação (Akamavi, 2005; Boor, Oliveira \& Veloso, 2014; Chen, Tsou \& Ching 2011; Edvardsson et al.; 2010; Martovoy, Mention \& Torkkeli, 2015; Mende \& Doorn, 2014; Zhaoquan, Chen \& Xiande, 2013). 
Posto isso, e tendo como base o contexto e as questões apresentadas, o presente trabalho tem como objetivo explicar as relações entre inovação, desempenho e coproducão no setor financeiro. Tal questão não está clara uma vez que ao mesmo tempo em que a inovação e coprodução contribuem para o aumento do risco sistêmico, falhas regulatórias e falta de liquidez, também são responsáveis pela redução de custos e riscos, bem como pelo crescimento econômico.

Do ponto de vista teórico, esta investigação permitiu testar as relações acima elencadas e caracterizar os elos entre inovação, coprodução e desempenho no âmbito do sistema financeiro nacional. Tais contribuições servem para mitigar em parte as lacunas apresentadas e aprofundar os estudos sobre a natureza do fenômeno no contexto brasileiro. Adicionalmente, do ponto de vista prático, os resultados da presente tese contribuem para o planejamento de metas e projeção do desempenho das instituições financeiras com base na proposta de inserção da inovação e coprodução nos modelos de tomada de decisão.

\subsection{Objetivos Específicos}

Para a realização desta pesquisa, são delineados os seguintes objetivos específicos:

1. Discorrer sobre a relação entre inovação, desempenho e coprodução no setor financeiro e propor um modelo de articulação conceitual;

2. Caracterizar a relação entre inovação, desempenho e coprodução no setor financeiro brasileiro;

3. Mensurar a mudança de desempenho no setor financeiro com base nos investimentos em inovação e coprodução;

\subsection{Estrutura da Tese}

A presente tese está estruturada em seis capítulos, sendo o primeiro destinado a esta introdução. O capítulo 2 apresenta um ensaio teórico que articula inovação, desempenho e coprodução no setor financeiro sob uma óptica de processo e apresenta um modelo para discussão de pressupostos e proposições teóricas. A construção deste capítulo foi realizada com base em levantamento bibliométrico da literatura dos constructos mencionados segundo a produção nacional e internacional.

O capítulo 3 trata do Estudo I, que tem como objetivo caracterizar a relação entre 
inovação, desempenho e coprodução no setor financeiro brasileiro. Para tal estudo foi utilizado o protocolo de análise de dados secundários, construído e validado no âmbito do Núcleo de Inovação e Estratégia (NINE-UnB) como instrumento de coleta de dados, e, na sequência, utiliza-se a análise de conteúdo para investigar os formulários de referência de 29 companhias de capital aberto do setor financeiro brasileiro. Ademais, o trabalho descreve a operacionalização da inovação e coprodução em variáveis qualitativas e apresenta uma nova proposta de tipologia de coprodução.

O capítulo 4 descreve o marco teórico, métodos e resultados do Estudo II, que tem como objetivo determinar e comparar o desempenho de bancos brasileiros em função dos investimentos em inovação e coprodução. Para tal, foram levantados os demonstrativos contábeis-financeiros dos últimos 8 anos de Bancos brasileiros de capital aberto e utiliza-se a análise por envoltória de dados (DEA) para analisar o desempenho de tais instituições, e verificar a melhoria de eficiência com base na inovação e coprodução. Adicionalmente, o capítulo sugere uma forma de operacionalização quantitativa da inovação e coprodução e mensura a relação entre tais constructos e o desempenho.

No Capítulo 5 são consolidadas as conclusões, contribuições e limitações da pesquisa, bem como as recomendações de cunho teórico e prático e se propõe uma agenda de pesquisa. Finalmente, no Capítulo 6, estão elencadas as referências bibliográficas que embasam este estudo.

\subsection{Descrição e Procedimentos Metodológicos do Estudo I}

O estudo I foi desenhado para atender o objetivo específico de caracterizar a relação entre inovação, desempenho e coprodução no setor financeiro brasileiro. Tal problemática é evidenciada pela literatura da área, onde há diversos relatos sobre a necessidade de estudos e evidências empíricas sobre a relação entre inovação e desempenho, inovação e coprodução e coprodução e desempenho, além do que existem poucos estudos que equacionam tais elementos no setor financeiro e menos ainda no âmbito do sistema financeiro brasileiro.

O estudo baseou-se na análise de conteúdo para buscar evidências e respostas às questões levantadas a partir dos documentos emitidos pelas instituições financeiras brasileiras. A amostra foi constituída aleatoriamente por vinte e nove instituições financeiras brasileiras listadas na BMF\&Bovespa em virtude da representação e volume financeiro movimentado pelas companhias de capital aberto, bem como pela disponibilidade dos dados e acessibilidade a relatórios de atividades. Os documentos selecionados para compor a análise foram os 
Formulários de Referência relativos ao ano de 2015, que representam o principal informe de comunicação e de prestação de contas da companhia com a descrição detalhada das atividades realizadas no período.

O instrumento de coleta de dados foi o protocolo validado pelo Núcleo de Estudos em Inovação e Estratégia (NINE-UnB) para análise de dados secundários (Anexo 1). Tal instrumento foi construído para padronizar e validar a coleta de informações baseada em dados secundários, e propõe uma forma de categorização dos constructos de interesse por meio da especificação dos constructos, definições, referências, forma de detecção, identificação no texto e palavras-chave. Dessa forma o constructo de inovação foi decomposto em duas dimensões: tipos - radical, melhoria, incremental, adhoc, recombinação e formalização (Gallouj \& Weinstein, 1997); e lógicas - extensiva, intensiva, regressiva e de combinação (Djellal \& Gallouj, 2005). Paralelamente, a coprodução foi operacionalizada em função das dimensões (coprodução com parceiros - B2B, com clientes - B2C e com parceiros e clientes - B2BC), bem como em função dos tipos desenvolvedor, codesenvolvedor e provedor de informação (Edvardsson et al., 2010). Ainda, o desempenho de cada empresa foi classificado tendo como base os lucros e prejuízos, bem como impactos positivos e negativos dos constructos investigados. A coleta de dados ocorreu no período de maio a junho de 2016.

A análise dos dados foi efetivada por meio da análise de conteúdo conforme (Bardin, 2011), veiculada por meio do software de análise qualitativa NVivo, e envolveu as seguintes fases: (1) pré-análise, (2) exploração do material e (3) tratamento dos resultados, inferência e interpretação, sendo a primeira subdividida em cinco etapas: (a) leitura flutuante; (b) escolha dos documentos; (c) formulação de hipóteses; (d) referenciação dos índices e formulação de indicadores; e (e) preparação do material. Dessa forma, a pesquisa iniciou-se com o levantamento de documentos e mapeamento das informações e categorias de informações. A formulação de hipóteses se deu com base na literatura e no modelo proposto no ensaio teórico, a saber: a inovação tem relação positiva com o desempenho; a coproducão tem relação positiva com o desempenho; e a inovação tem relação positiva com a coproducão. $\mathrm{Na}$ sequência, a indexação se deu com base nas categorias de análise delineadas no protocolo.

A exploração do material envolveu a organização das evidências de acordo com as palavras-chave e as variáveis elencadas, onde se construiu uma base de dados com as informações de cada evidência mapeada. Nesse ponto, buscou-se em cada evidência, com o auxílio do software, delinear as categorias de análise e isolar os impactos positivos e negativos da inovação e coproducão, bem como os fatores que moderam e medeiam a relação com desempenho. Finalmente, os dados categorizados foram validados, as inferências e 
interpretações foram feitas e o fenômeno foi caracterizado, tendo como base o cruzamento das informações levantadas com a literatura sobre o tema.

\subsection{Descrição e Procedimentos Metodológicos do Estudo II}

O Estudo II teve como objetivo determinar o impacto da inovação e coprodução no desempenho bancário. Tal questão é ressaltada por diversos autores como essencial para mensuração de desempenho, gerenciamento de riscos, estabilidade financeira, crescimento econômico, inadimplência e prevenção de crises. Além disso, a literatura reforça a necessidade de estudos empíricos sobre o tema e o estudo promove tal análise no contexto do mercado financeiro brasileiro. Para tal utilizou-se a Análise por Envoltória de Dados (DEA) para comparar o desempenho de bancos brasileiros, usando como insumos os investimentos em inovação e coprodução, o que constitui uma contribuição para a literatura, uma vez que não foram encontradas na literatura evidências da inserção dos constructos de inovação e coprodução na análise de desempenho bancário.

Trata-se de um estudo quantitativo, longitudinal e de natureza explicativa, que utiliza a DEA para testar as hipóteses apresentadas de que a inovação e a coprodução possuem impacto positivo no desempenho. A DEA é um modelo de programação linear que estima a fronteira de produção eficiente tendo como base os dados de um conjunto preestabelecido de Unidades Tomadoras de Decisão (DMUs) e, dessa forma, identifica as unidades eficientes, constitui benchmarks de referência e verifica a melhoria de eficiência de cada unidade em virtude das entradas e saídas que utiliza (Charnes, Cooper \& Rhodes, 1978; Paradi \& Zhu, 2013; Resti, 1997). Comparou-se o modelo CCR (Charnes, Cooper \& Rhodes 1978) com o BCC (Banker, Charnes \& Cooper, 1984), ambos orientados para outputs, a fim de verificar se os retornos de escala interferem na análise e qual é mais aderente ao setor financeiro brasileiro. Além disso, o modelo foi baseado na análise do Índice de Produtividade de Malmquist (MPI) (Wang \& Lan, 2011).

A amostra foi constituída pelos bancos brasileiros de capital aberto listados na Bolsa de Valores de São Paulo (BM\&FBovespa) e o horizonte de tempo para a pesquisa abrangeu o período de 2008-2015, com o intuito de melhor explorar o cenário do sistema financeiro pós-crise. Os documentos utilizados para a coleta de dados foram as Demonstrações Financeiras Padronizadas (DFPs) anuais de cada banco e a Relação de Agências, Postos e Filiais de cada instituição financeira disponibilizada pelo Banco Central do Brasil. Quanto à especificação de entradas e saídas, o estudo adota a abordagem de produção, que considera 
bancos como unidades prestadoras de serviços para os clientes. O modelo DEA considerou três entradas (inovação, coprodução e rede de atendimento) que, conjuntamente, produzem duas saídas (geração de valor e adimplência). A coleta de dados foi realizada no período de junho a setembro de 2016.

A variavel inovação foi construída com base no somatório dos ativos diferidos e ativos intangíveis, desconsideraddas as amortizações, de acordo com o normativo IAS38 das Normas Internacionais de Contabilidade (IFRS) e o Pronunciamento Técnico CPC $\mathrm{n}^{\mathrm{o}} 4$ do Comitê de Pronunciamentos Contábeis (CPC). Na sequência, a variável coprodução foi construída tendo como base a diferença entre o valor ativo e o valor passivo da conta relações interfinanceiras, em acordo com o disposto no Plano Contábil das Instituições do Sistema Financeiro (COSIF). Enfim, a última entrada foi operacionalizada a partir do somatório do número de agências com o número de Postos de Atendimento (PA), o que representa a medida de relacionamento com o cliente, tanto para a inovação quanto para a coprodução. No que tange às saídas, a geração de valor foi representada com base no Valor Adicionado Bruto (VAB), e a adimplência foi caracterizada como a razão entre as Perdas Estimadas em Créditos de Liquidação Duvidosa (PECLD) e o saldo total das Operações de Crédito, sob a óptica da abordagem de provisão (Annibal, 2009; Costa \& Blum, 2008).

A aplicação da DEA demandou o tratamento dos valores negativos e nulos, visto que a existência de tais valores inviabiliza a análise. Os valores negativos foram transformados em positivos baseados no somatório do valor mais negativo da variável, e os valores iguais a zero foram substituídos por 0,001 . A análise dos dados foi veiculada por meio do software MaxDEA e utilizou como parâmetros a mensuração do índice de desempenho geral, bem como o índice Malmquist de produtividade (MPI), mudança de tecnologia (OTC) e mudança na eficiência técnica (OEC), para cada um dos anos no período de 2008 a 2015. 


\section{INOVAÇÃO, DESEMPENHO E COPRODUÇÃO NO SETOR FINANCEIRO: PROPOSTA DE ARTICULAÇÃO TEÓRICA}

Nos últimos anos, o setor financeiro passou por mudanças significativas em âmbito global em virtude principalmente da recente crise de 2008 (Delimatsis, 2012; Hutton \& Lee, 2012; Ozbay, Dinçer \& Hacioglu, 2011). Regulação e desregulação, internacionalização de instituições financeiras, indefinição de fronteiras, fusões e aquisições e o surgimento de novas tecnologias e demandas contribuíram para o aumento de competitividade, as pressões de mercado e a necessidade de diferenciação (Caselli, 2010; Delimatsis, 2012; Hoffmann, Post \& Pennings, 2013; Rossignoli \& Arnaboldi, 2009; Shahrokhi, 2008). Essas mudanças resultaram em uma virada estratégica no setor, onde as organizações tornaram-se aptas a ampliar a base de clientes, construindo relacionamentos e ofertas de produtos e serviços modernos, de forma que estão mais eficientes, flexíveis e adaptáveis às novas condições de mercado (Hutton \& Lee, 2012). Observa-se, portanto, um papel cada vez mais central da inovação e coprodução na dinâmica e no desempenho do setor (Delimatsis, 2012; Hutton \& Lee, 2102; Martovoy, Mention \& Torkkeli, 2015; Mende \& Doorn, 2014; Meng \& Guo, 2013).

No que se refere à inovação, a literatura sobre o tema se divide, visto que, por um lado, a inovação no setor financeiro está relacionada à fragilidade financeira, alienação e negligência das ameaças reais, supervalorização das seguranças, falta de liquidez e riscos elevados (Gai, Kapadia, Millard \& Perez, 2008; Hutton \& Lee, 2012). Por outro lado, diversos autores argumentam que a inovação está diretamente associada ao crescimento econômico de longo prazo, que tem como objetivo a redução de custos, o atendimento das necessidades específicas do mercado e a transformação de ativos em oportunidades de diversificação (Bos, Kolari \& Lamoen, 2013; Delimatsis, 2012; Delimatsis, 2013; Frame \& White, 2004; Rossignoli \& Arnaboldi, 2009). Apesar de críticas recentes acerca de determinadas inovações, os benefícios da diversificação de risco e o incremento dos instrumentos de financiamento são geralmente reconhecidos (Delimatsis, 2013). Entretanto, a literatura traz poucos estudos que equacionam tal constructo com o desempenho das organizações e do setor financeiro como um todo, bem como trabalhos que caracterizam o próprio processo de inovação (Delimatsis, 2012; Gai, Kapadia, Millard \& Perez, 2008; Meng \& Guo, 2013; Mullineux, 2010; Stevens \& Dimitriadis, 2005).

Paralelamente, cabe destacar que o desempenho do setor financeiro é influenciado diretamente pelo grau de confiança entre os atores do mercado, posto que todas as transações 
financeiras e decisões de investimento são realizadas tendo como base relações interativas fundamentadas em segurança e credibilidade (Hutton \& Lee, 2012; Martovoy, Mention \& Torkkeli, 2015; Mende \& Doorn, 2014). Tal confiança é construída com base nos relacionamentos duradouros entre instituições, parceiros, clientes, governo e sociedade, que estabelecem relações de coprodução a fim de agregar valor como consequência das sinergias existentes (Akamavi, 2005; Martovoy, Mention \& Torkkeli, 2015). Além disso, no setor financeiro, o papel dos parceiros e clientes é crescente, posto que atuam como participantes ativos e mandatórios da dinâmica em um contexto onde as regras do jogo são redefinidas em ambientes colaborativos e as demandas por responsabilidade e transparência se tornam cada vez mais evidentes (Mende \& Doorn, 2014). Ao analisar a literatura, o que se observa é que, apesar da relevância do tema, há escassez de trabalhos que tratam do impacto da coprodução no desempenho ou na inovação, e menos ainda no setor financeiro (Akamavi, 2005; Boor, Oliveira \& Veloso, 2014; Chen, Tsou \& Ching 2011; Edvardsson et al., 2010; Martovoy, Mention \& Torkkeli, 2015; Mende \& Doorn, 2014; Zhaoquan, Chen \& Xiande, 2013).

Portanto, tendo como base as considerações apresentadas, o presente capítulo tem como objetivo discorrer sobre a relação entre inovação, desempenho e coproducão no setor financeiro e propor um modelo de articulação conceitual. Para tal, foi realizado um levantamento bibliográfico de periódicos nacionais e internacionais de impacto na área de administração e economia e com foco nos constructos de inovação, desempenho e coprodução no setor financeiro. As bases de dados consultadas foram: SAGE Journal online; SPELL; JSTOR; SpringerLink; Emeraldand Oxford Journals; PROQUEST; Scielo; e Periódicos da Capes.

Argumenta-se que as lacunas teóricas delineadas devem ser mais bem exploradas, e que novas críticas acerca do processo sejam construídas, com o intuito de promover o debate sobre o fenômeno e compor uma estrutura que explique adequadamente a dinâmica do setor com base nas mudanças recentes de contexto. Em síntese, a contribuição deste capítulo reside na articulação dos constructos apresentados, que consistirá em um ponto de reflexão e direcionador de estudos futuros sobre o tema.

\subsection{Inovação}

A inovação em serviços é um tema transversal em pesquisas na área de administração e seu conceito é plural e multifacetado. O recente destaque para os estudos no setor justifica-se em virtude do crescente papel dos serviços no desenvolvimento econômico e 
no direcionamento da produtividade, na geração de conhecimento, promoção da inovação e empregabilidade (Salunke, Weerawardena \& McColl-Kennedy, 2011). Em economias baseadas em serviços, companhias líderes, consultores e pesquisadores tendem a substituir o foco do produto para o serviço (Djellal \& Gallouj, 2005), uma vez que a inovação em serviços molda a criação de valor e incrementa o desempenho de mercado, eficiência e valor para o cliente (Thakur \& Hale, 2013). A inovação em serviços é um fenômeno multidimensional, de forma que o nível e o padrão de atividades inovativas dependem das características das firmas de serviço (Hertog et al., 2010; Sundbo, 1997). Até mesmo as empresas de manufatura expandiram seus negócios e transformaram-se de fornecedoras de produtos tangíveis a garantidoras de serviços intangíveis, o que indica um foco diferenciado para atividades de inovação nesse ramo (Hsieh, Chiu, Wei, Yen, \& Cheng, 2013).

De forma sistemática, a literatura sobre o tema abarca três abordagens (Gallouj \& Savona, 2009): assimilação, derivada dos modelos industriais, que argumenta que a inovação em serviços é resultante da criação e implementação de novas tecnologias; demarcação, que foca nas especificidades intrínsecas dos serviços e objetiva estabelecer um modelo próprio de análise; e integração, que propõe uma articulação entre produtos e serviços sob a égide da mesma óptica. Enquanto os primeiros estudos tecnicistas surgiram no fim da década de 1980 e representam o maior volume de trabalhos publicados sobre o tema, os estudos da segunda abordagem se fortalecem segundo as perspectivas do marketing do final da década de 1990, e os de integração adquirem forma a partir do início dos anos 2000. A abordagem integradora adquiriu destaque uma vez que apresenta um modelo analítico mais abrangente e um viés processual da inovação, o que torna os serviços mais tangíveis e a caracteriza como a mais promissora em termos de avanço teórico (Gallouj \& Savona, 2009).

Do ponto de vista acadêmico, a abordagem tecnicista é a que apresenta maior volume de estudos, tendo em vista o destacado papel do avanço tecnológico como objeto de estudo de inovações na segunda metade do século XX (Gallouj \& Savona, 2009) e o caráter pioneiro da proposta. O principal argumento dessa vertente é o de que as indústrias de serviço cada vez mais incorporam capital e tecnologia, de forma que a inovação em serviços é direcionada pelos padrões de adoção de tecnologias e pelos recursos de capital. A abordagem considera ainda que inovações não tecnológicas são apenas residuais (Gallouj \& Savona, 2009). O introdutor dessa abordagem foi Barras (1986), que desenvolveu o modelo do ciclo de vida reverso onde relaciona os determinantes tecnológicos que permitem a inovação no setor de serviços, e organiza-os em três estágios: inovação incremental, radical e de produto (serviço). Barras descreve o ciclo de inovação em serviços como o reverso do ciclo industrial tradicional, 
e a inovação surge baseada em mudanças causadas pela introdução desses sistemas tecnológicos, que se efetivam pela implementação de diversos tipos de processos de aprendizagem (Barras, 1986). Entretanto, o forte viés tecnicista motivou o surgimento de novos modelos de análise do fenômeno.

O segundo grupo de estudos de inovação em serviços refere-se à abordagem de demarcação, que reúne os trabalhos focados nas especificidades do serviço, em uma tentativa de contrabalançar o peso do aspecto tecnológico na abordagem tecnicista, e procura expandir a estrutura de análise de inovação em serviços a fim de incorporar fatores não tecnológicos (Gallouj \& Savona, 2009). Essa vertente baseia-se no pressuposto que os aspectos idiossincráticos de serviços garantem a unicidade dos serviços e impedem que estes sejam analisados da mesma forma que os produtos, e que o caráter relacional entre prestador e cliente é onde residem as principais oportunidades de inovação. Ao incidirem sobre as particularidades dos serviços, os estudos da área trazem a existência de formas de inovação negligenciadas ou ocultas, as quais podem ser identificadas por meio de um foco nas atividades específicas de serviços (Djellal, Gallouj, \& Miles, 2013). Contudo, o forte apego ao caráter separatista e a busca contínua pelas particularidades dos serviços abriu espaço para estruturas conceituais que analisam produtos e serviços de formas mais complementares.

Finalmente, a abordagem de integração é considerada a mais promissora em termo de avanço teórico, uma vez que supera a distinção entre bens e serviços e propõe uma alternativa focada no processo (Gallouj, 2002; Gallouj \& Savona, 2009). O produto/serviço é caracterizado com base em um processo $\left[(\mathrm{C})\left(\mathrm{C}^{\prime}\right)(\mathrm{X})(\mathrm{Y})\right]$, onde o vetor $\mathrm{Y}$ representa as entregas do serviço, o vetor $\mathrm{X}$ representa as características técnicas do produto e os vetores $\mathrm{C}$ e $\mathrm{C}$ ' indicam os conjuntos de competências do fornecedor e do cliente, respectivamente. A inovação é estabelecida após o momento em que um ou mais desses vetores sofrem modificação e ocorre em seis tipos (Gallouj \& Weinstein, 1997): radical, melhoria, incremental, ad hoc, recombinação e formalização. Tal tipologia está esquematizada no Quadro 1. 


\begin{tabular}{|cc|}
\hline Tipo de Inovação & Descrição \\
\hline Radical & Adição/Eliminação/Modificação em todos os Vetores $\left(\left[\mathrm{C}^{*}\right]\left[\mathrm{C}^{*}\right]\left[\mathrm{X}^{*}\right]\left[\mathrm{Y}^{*}\right]\right)$ \\
\hline Melhoria & Modificação de Componentes Dentro de um Determinado Vetor \\
\hline Incremental & Adição/Eliminação de um determinado Vetor (ex: $\left[\mathrm{C}^{*}\left[\mathrm{C}^{\prime}\right]\left[\mathrm{X}^{*}\right][\mathrm{Y}]\right)$ \\
\hline Adhoc & Construção Interativa Prestador-Cliente para Solucionar um Problema \\
\hline Recombinação & Reorganização da Arquitetura do Processo sem Modificar Vetores/Elementos \\
\hline Formalização & Padronização de Procedimentos e Otimização do Processo \\
\hline
\end{tabular}

Quadro 1. Tipos de inovação de acordo com a abordagem integradora (Gallouj \& Weinstein, 1997).

Pesquisas recentes exploraram de forma aprofundada as relações entre os vetores e propuseram novas inclusões ao modelo. Incluiu-se o vetor de características processuais (Z), mantendo-se a divisão prestador-cliente, e o vetor de características técnicas $(\mathrm{X})$ subdividiu-se em dois componentes: características técnicas do cliente ( $\left.T^{\prime}\right)$ e características técnicas do prestador (T) (Djellal \& Gallouj, 2010; Gallouj \& Savona, 2010; Gallouj \& Toivonen, 2011). Tal modelo está esquematizado na Figura 1, e representa a consolidação mais recente para o processo de inovação (Gallouj \& Savona, 2010; Gallouj \& Toivonen, 2011).

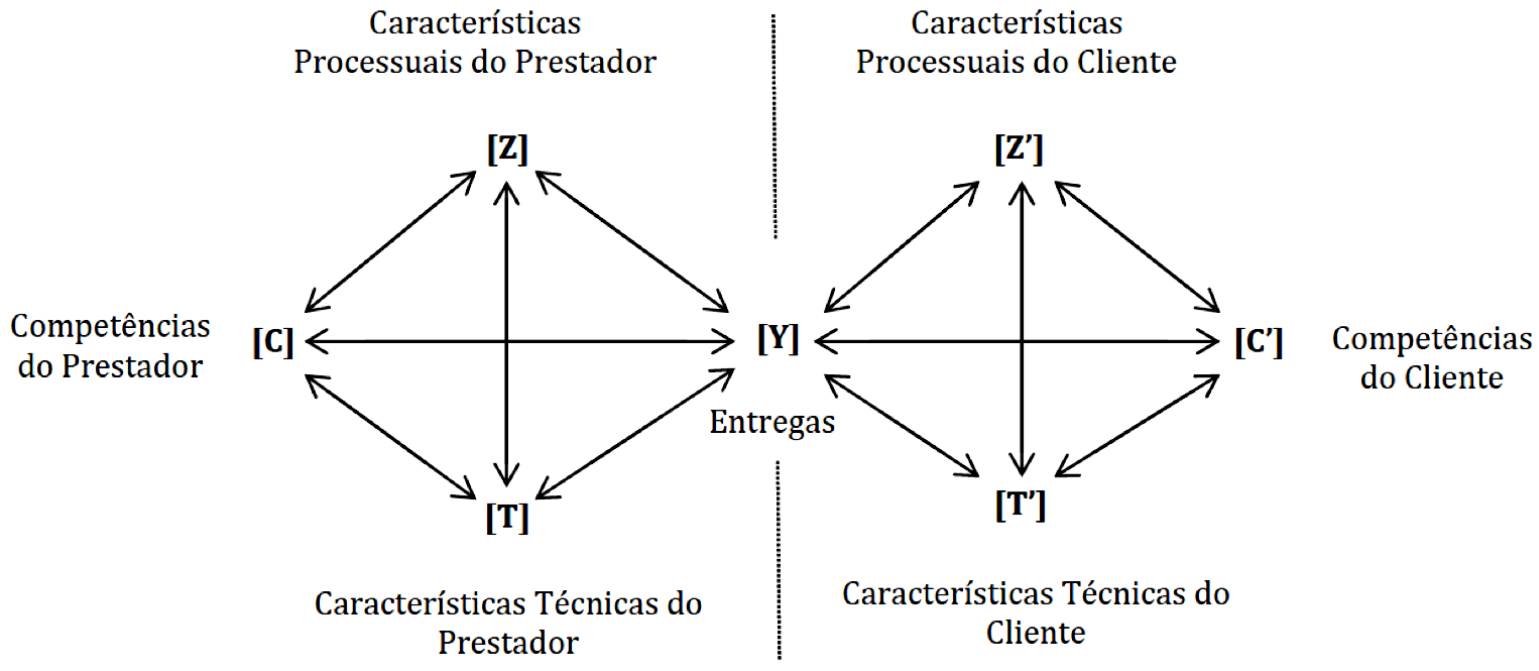

Figura 1. Processo de inovação de acordo com a abordagem integradora. Adaptado de Gallouj e Savona (2010) e Gallouj e Toivonen (2011).

Apesar do recente avanço na literatura sobre o tema, os alicerces teóricos ainda carecem de validação empírica para as três abordagens. Os estudos da área demandam modelos de análise mais robustos e expansão para os diversos setores de serviços. Ainda, o que se 
observa é que no âmbito do mercado financeiro ainda não houve a adoção de um modelo de análise mais consistente com as recentes mudanças do setor. A transposição de uma óptica mais integrada requer adaptações, uma vez que produtos e serviços financeiros são arriscados, complexos e, ocasionalmente, torna-se difícil avaliá-los em termos de qualidade e benefícios (Hoffmann, Post \& Pennings, 2013).

Nesse contexto, a abordagem de integração é considerada a mais promissora em termos de avanço teórico, uma vez que supera a distinção entre bens e serviços e propõe uma alternativa focada no processo (Gallouj \& Savona, 2009). Esta abordagem oferece um novo caminho para envolver as situações que permeiam o processo de inovação, seja na produção de bens, seja na de serviços, pois se entende que há oportunidades para enriquecimento mútuo (Gallouj, 2002). Os autores argumentam que uma integração adequada não deve ignorar as especificidades dos serviços ou interessar-se por aspectos puramente tecnológicos da inovação em serviços, representando uma tendência de direcionamento de pesquisas. Muitos pesquisadores adotam a perspectiva de integração com o intuito de combinar inovação em produtos e serviços ao invés de estudá-las separadamente, o que reflete a essência dos serviços. À medida que as funções do serviço ganham proeminência, torna-se razoável englobar todos os tipos de indústrias e organizações ao se pesquisar inovações em serviços (Hsieh et al., 2013). Fundamentada em tais evidências, a presente pesquisa adota a abordagem integradora como fundamentação teórica para análise da inovação no contexto do setor financeiro.

\subsubsection{Inovação no Setor Financeiro}

O setor financeiro compreende o conjunto de instituições financeiras que asseguram, essencialmente, a canalização da poupança para o investimento nos mercados, por meio da compra e venda de produtos e serviços (Stevens \& Dimitriadis, 2005). Contudo, recentemente o setor passou por mudanças significativas, tais como desregulação, internacionalização dos bancos, fusões e aquisições e surgimento de novas tecnologias, que contribuíram para um contexto de competição desenfreada, pressões por lucratividade e necessidade de diferenciação. Tais mudanças estão diretamente atreladas à crise de 2008 , que promoveu a desaceleração incisiva das atividades econômicas e uma bancarrota generalizada, que demandou resgate por parte do governo por intermédio de assistência e injeções de capital, ao mesmo tempo em que as estruturas regulatórias mostraram-se incapazes de atuar de forma efetiva em termos de prevenção, gerenciamento e resolução de tumultos financeiros (Delimatsis, 2012; Hutton \& Lee, 2012; Ozbay, Dinçer \& Hacioglu, 2011). 
Neste cenário pós crise, a dinâmica do setor é ditada com base em variáveis como regulação (desregulação), indefinição e redesenho das fronteiras, dinamismo e complexidade, competitividade, inovações tecnológicas e demandas por novos produtos e serviços (Blazevic \& Lievens, 2004; Caselli, 2010; Delimatsis, 2013; Hoffmann, Post \& Pennings, 2013; Rossignoli \& Arnaboldi, 2009; Shahrokhi, 2008; Stevens \& Dimitriadis, 2005). Tal contexto se mostra complexo e idiossincrático visto que, apesar da riqueza de dados e informações disponíveis, pouco foi realizado no sentido de elucidar os mecanismos de dinâmica e funcionamento do setor, principalmente no que tange ao aspecto de adaptação às mudanças de contexto. Essa adaptação requer que as instituições financeiras inovem no sentido de internalizar os novos regulamentos, condições, permissões e oportunidades. Neste ponto, a literatura reconhece o papel da inovação, pois instituições financeiras que apresentam a habilidade de desenvolver um constante fluxo de inovações são mais rentáveis no longo prazo (Hutton \& Lee, 2012; Stevens \& Dimitriadis, 2005).

O estudo da inovação no setor financeiro segue uma trajetória de pesquisa própria na economia, independente do estudo no campo da administração, o que caracteriza um empecilho para a adoção de um modelo integrador que possa usufruir dos avanços nas duas áreas. Tal literatura centraliza-se na caracterização do constructo de inovação financeira, definida como processo dinâmico contínuo de criação e disseminação de instrumentos financeiros, tecnologias, instituições e mercados, a fim de reduzir riscos e atender demandas específicas dos investidores por padrões particulares de fluxos de caixa (Bos, Kolari \& Lamoen, 2013; Delimatsis, 2012; Frame \&White 2004; Rossignoli \& Arnaboldi, 2009). Nesse âmbito, os autores apontam que inovações no setor financeiro contribuem para a redução de volatilidade macroeconômica uma vez que permitem mais flexibilidade de escolha das estruturas financeiras e promovem redução de custos de transações financeiras e melhoria no gerenciamento de riscos (Delimatsis, 2012; Delimatsis, 2013; Mullineux, 2010).

Nesse contexto pós-crise, faz-se necessário um olhar crítico sobre a inovação, visto ela ter sido considerada por muitos autores como a raiz e principal causa da crise (Delimatsis, 2012; Delimatsis, 2013). A literatura aponta que a inovação no setor financeiro está diretamente relacionada à fragilidade financeira, uma vez que a negligência de riscos acarreta na supervalorização das seguranças e o otimismo dos investidores fomenta a habilidade dos intermediários de inovar, de forma que se mascara o risco real e os intermediários não apresentam liquidez suficiente para absorver aumentos inesperados de demanda ocasionados por um evento negativo (Lenzer \& Zhao, 2012). Dessa forma, uma vez que o risco é revelado, investidores reagem exageradamente para se livrar dos falsos substitutos das seguranças 
tradicionais, causando uma evasão em massa (Delimatsis, 2012; Gai, Kapadia, Millard \& Perez, 2008; Hutton \& Lee, 2012; Lenzer \& Zhao, 2012). Os autores dessa vertente complementam que tanto investidores quanto intermediários sofrem perdas no caso de ambos os grupos negligenciarem os riscos associados à inovação, de forma que se uma instituição financeira oferece determinado produto ou serviço, deve possuir capital suficiente para cumprir suas obrigações no caso de aumentos súbitos de demanda (Delimatsis, 2012). Ademais, a inovação modifica o perfil de risco dos instrumentos financeiros e incentiva os inovadores a gerarem riscos sistêmicos excessivos a fim de maximizar os lucros, além de possibilitar a criação de um mercado secundário de instituições financeiras não sujeitas à regulação (Mullineux, 2010).

Entretanto, por outro lado, diversos estudos defendem que a inovação é fundamental para o desenvolvimento do setor e o crescimento econômico. Tais autores afirmam que a inovação no setor financeiro é componente essencial para atendimento das necessidades específicas dos investidores, além de ser a força motriz da difusão de produtos e melhoria de serviços e de contribuir para a redução dos custos de transação, financiamento de projetos e otimização do gerenciamento de riscos (Delimatsis, 2012). Ainda, a inovação é responsável pela geração de valor social, dispersão do risco, aumento da resiliência do sistema e geração de benefícios econômicos de forma geral, desde que as ameaças e riscos sejam observados e regulados (Johnson \& Kwak, 2012). Nesse âmbito, a literatura afirma que a inovação no setor financeiro desempenha seis funções principais: atender demandas de mercado; resolver conflitos de agência e assimetrias de informação; minimizar custos de transação; atender demandas regulatórias; reagir ao aumento das interações e riscos do sistema; e responder a inovações tecnológicas (Tufano, 2003; Lenzer \& Zhao, 2012). Dessa forma, tal vertente reconhece o papel da inovação financeira para a redução de custos, riscos e atendimento das demandas específicas dos investidores, além do que é responsável pela melhoria da intermediação financeira e contribui para o crescimento econômico (Bos, Kolari \& Lamoen, 2013; Delimatsis, 2013; Frame \& White, 2004; Rossignoli \& Arnaboldi, 2009). De fato, um dos maiores benefícios da inovação no setor financeiro é o crescimento do mercado, relacionado à transformação de ativos em oportunidades de diversificação.

\subsection{Desempenho}

O problema de mensuração da eficiência ou desempenho é importante tanto para os teóricos econômicos quanto para os formuladores de políticas públicas (Farrell, 1957). Na definição clássica, quando se discute o desempenho de uma firma, deve-se mencionar o sucesso 
de produção de saídas com base nas entradas e, considerando que todas as entradas e saídas são corretamente mensuradas, a utilização de tal indicador seria aceito (Farrell, 1957). Para fins de discussão, primeiramente, faz-se necessário estabelecer uma distinção entre os conceitos fundamentais, a saber: eficácia, produtividade e eficiência (Mello et al., 2005). O conceito de eficácia está relacionado ao que é produzido, sem levar em conta os recursos gastos no processo. Em outras palavras, representa a capacidade de uma unidade atingir a sua meta de produção. Em seguida, a produtividade pode ser obtida com base no valor máximo de uma proporção de saídas em função de um determinado conjunto de entradas (Charnes, Cooper \& Rhodes, 1978; Farrell, 1957; Kopp, 1981; Leibenstein, 1966; Varian, 1990). Finalmente, eficiência é um conceito relativo, posto que compara medidas de produtividade entre unidades e representa o que poderia ter sido produzido dado um conjunto de recursos disponíveis (Mello et al., 2005)

Farrell (1957) apresentou um método para medir duas formas de eficiência produtiva, centrado na hipótese de que a eficiência pode ser dicotomizada em dois subcomponentes que refletem a eficiência física da transformação de insumos (entradas) em produtos ou serviços (saídas), chamada de componente técnica, e a eficiência econômica do fator de alocação ideal dos elementos e função dos preços, caracterizada como eficiência de preço ou eficiência alocativa. A eficiência alocativa envolve a seleção de um mix de entradas que atribui fatores para seus mais altos usos valorizados e, portanto, introduz o custo de oportunidade dos fatores de produção para a medição da eficiência (Kopp, 1981). Pode-se argumentar que as decisões dos agentes econômicos envolvidos em produção são conjuntas; ou seja, decisões que afetam a eficiência técnica também podem ter ramificações alocativas, e vice-versa. A capacidade de desagregar o efeito dessas decisões conjuntas em dois subcomponentes é ideal para medir empiricamente seus efeitos individuais (Kopp, 1981). Na prática, no entanto, os planos de produção observáveis não seguem decisões perfeitamente racionais e eficientes. Pelo contrário, fatores como erros, atrasos entre a escolha do plano e sua implementação, inércia e comportamentos humanos, comunicações distorcidas e incerteza podem acarretar em ineficiência (Leibenstein, 1966; Varian, 1990).

No âmbito acadêmico, diversos estudos trouxeram tal conceito de eficiência para o setor financeiro. A questão sobre o que impulsiona o desempenho está no topo das mentes dos gestores e decisores políticos, como o primeiro passo para a compreensão e desenho de um desempenho superior (Soteriou \& Zenios, 1997). Os estudos sobre eficiência e desempenho no setor financeiro iniciaram-se na década de 1960, e ainda são considerados uma área de pesquisa relevante, de um ponto de vista tanto micro como macroeconômico (Resti, 1997). A busca pela eficiência tornou-se mais complexa e a abordagem subjetiva carece de suporte formal. No nível 
macroeconômico, a eficiência representa um alvo social ótimo, uma vez que reduz os custos da intermediação financeira. Consequentemente, bancos centrais tornam-se interessados na estruturação de práticas operacionais e no equilíbrio de mercado (Resti, 1997). Além disso, numerosos estudos discutem como a eficiência da intermediação financeira afeta o crescimento econômico, enquanto outros indicam que as insolvências podem resultar em crises sistêmicas que têm consequências adversas para a economia como um todo (Fethi \& Pasiouras, 2010).

A primeira tarefa na avaliação de desempenho de instituições financeiras é separar as unidades de produção, por meio de algum padrão de desempenho, daquelas unidades de baixo desempenho. Isso pode ser feito por intermédio da aplicação de análises paramétricas e não paramétricas no contexto da indústria financeira. A informação obtida pode ser usada para: subsidiar políticas governamentais pelo acesso aos efeitos da regulação, fusões e estruturas de mercado; direcionar pesquisas futuras através da descrição de uma indústria, ranqueamento de firmas ou checagem da relação entre desempenho e diferentes técnicas aplicadas; e melhorar o desempenho gerencial por meio da identificação de melhores práticas e piores práticas associadas à alta e baixa eficiência, respectivamente (Berger \& Humphrey, 1997). Nesse contexto, historicamente pelo menos quatro abordagens diferentes são vulgarmente utilizadas para medir o desempenho no setor financeiro: análise de correlação, análise de regressão, fronteiras de eficiência e outras técnicas de inteligência artificial, tais como redes neurais, processos analíticos de hierarquia e balances corecards (Paradi \& Zhu, 2013). A análise de correlação tem sido a técnica padrão utilizada por reguladores, analistas e gestão do setor para analisar desempenho em todos os níveis. Caracterizam-se por medir a relação entre duas variáveis escolhidas para fornecer insights sobre diferentes aspectos das operações multifacetadas do ramo, como a rentabilidade, adequação de capital, qualidade dos ativos, gestão de riscos, e outros. A análise de regressão, por sua vez, é outro método comum utilizado em estudos anteriores do setor financeiro. A principal vantagem dessa análise é que ela permite a inferência e a medição de erros estatísticos, bem como quantificar a influência de múltiplas variáveis independentes na variável dependente, simultaneamente. Na sequência, a metodologia de fronteira de eficiência permite identificar as melhores empresas a partir do conjunto de dados formado empiricamente e comparadas com a fronteira eficiente ideal. A principal vantagem é que tais técnicas oferecem escores de eficiência numéricos em ambientes operacionais complexos e resume o desempenho em uma única estatística (Paradi \& Zhu, 2013).

Nesse contexto, instituições financeiras estão cada vez mais utilizando técnicas de benchmarking para identificar as operações que necessitam de melhoria comparando o seu 
desempenho com outras empresas do setor (Kopp, 1981; Resti, 1997). Dessa forma, duas metodologias de fronteiras primárias foram desenvolvidas para estimar as eficiências de fronteira: (1) análise de fronteira paramétrica ou estocástica (SFA), que geralmente faz suposições acerca da forma funcional da função técnica e incorpora o erro aleatório a fim de produzir estimativas de eficiência usando técnicas econométricas; e (2) análise de fronteira não paramétrica, sendo a mais proeminente a análise envoltória de dados (DEA), que faz suposições sobre as estimativas de eficiência, utilizando programação linear e outros métodos não paramétricos. Muito foi escrito sobre os méritos relativos das duas metodologias e ambas ganharam uma posição firme na literatura.

Com base em tal levantamento, abre-se espaço para a discussão sobre qual seria o melhor método de fronteira. Nesse contexto, há falta de consenso entre pesquisadores em relação a um método preferido. As abordagens paramétricas apresentam o defeito de impor uma forma funcional particular que pressupõe a forma da fronteira. Se a forma é mal especificada, a mensuração do desempenho pode ser confundida com o erro de mensuração. Por outro lado, os estudos não paramétricos impõem menos estrutura na fronteira, mas apresentam o defeito de não permitir o impacto do erro aleatório e outros erros de mensuração. Se houver erro aleatório, o desempenho mensurado pode ser confundido com tais desvios aleatórios de fronteira de eficiência (Berger \& Humphrey, 1997).

De forma específica, a análise envoltória de dados tem sido bastante utilizada na literatura para se acessar o desempenho de instituições financeiras. A DEA é uma técnica de programação linear onde o conjunto de melhores práticas ou fronteira de observação são aqueles para o qual nenhuma outra unidade tomadora de decisão (DMU) ou combinação linear destas apresenta a mesma quantidade para cada saída ou o menor volume para cada insumo (Berger \& Humphrey, 1997). Trata-se de uma técnica utilizada para medir as eficiências relativas de um conjunto de organizações que consomem múltiplas entradas para produzir múltiplas saídas. A ideia principal é avaliar a eficiência relativa de um conjunto de DMUs homogêneas usando a razão entre a soma ponderada das saídas e a soma ponderada de entradas (Zaher, Zeineldin \& Abdelshafy, 2015). Ainda, a metodologia é uma ferramenta poderosa para avaliar o desempenho das organizações e sua unidades funcionais, pois atravessa os limites de diversas áreas acadêmicas e recebe uma importância crescente para avaliar e melhorar o desempenho de operações e serviços (Zaher, Zeineldin \& Abdelshafy, 2015).

Conceitualmente, a DEA é um algoritmo de programação (Charnes, Cooper \& Rhodes, 1978) onde a fronteira eficiente é constituída com base na constituição não-paramétrica de um envelope de hiperplanos sobrepostos no espaço das combinações de proporções entre 
entradas e saídas do sistema. A distância entre cada plano de produção observado e a fronteira é, em seguida, utilizada como uma medida da ineficiência (Varian, 1990). A técnica de programação foi inicialmente desenvolvida para avaliar a eficiência de organizações governamentais sem fins lucrativos e é capaz de medir a eficiência relativa de cada unidade, sem assumir a priori a função de produção (Luo, 2003). Para isso, ela calcula escores de eficiência relativa de várias unidades de tomada de decisão (DMUs) na amostra. A métrica compara cada elemento da amostra com aquele elemento de melhores práticas e aponta quais DMUs são eficientes e quais não são (Sathye, 2001). A fronteira de melhores práticas é construída por meio de uma combinação linear das partes do conjunto real de entradas e saídas da amostra e a cada DMU é atribuído um escore de eficiência entre 0 e 1 . As pontuações são apenas em relação às DMUs da amostra, com escores mais altos, indicando unidades mais eficientes (Fethi \& Pasiouras, 2010).

A DEA pode ser implementada assumindo retornos constantes de escala (CRS) ou retornos variáveis de escala (VRS). Em seu estudo seminal, Charnes, Cooper e Rhodes (1978) propuseram um modelo que assumia CRS. Este modelo retorna uma pontuação que indica a eficiência técnica global (OTE) de cada DMU. Banker, Charnes e Cooper (1984) sugeriram o uso de retornos variáveis de escala (VRS), que decompõe o OTE em dois componentes, a eficiência técnica pura (PTE) e eficiência de escala (SE). O primeiro diz respeito à capacidade dos gestores para utilizar os recursos disponíveis das empresas, enquanto o segundo refere-se às economias de escala que exploram um ponto onde o fronteira de produção exibe CRS e inclui os retornos variáveis (Fethi \& Pasiouras, 2010). Uma das vantagens da DEA é que ela funciona relativamente bem com pequenas amostras. Outra vantagem é que não necessita de quaisquer suposições sobre a distribuição de ineficiência e não requer uma forma funcional sobre os dados para determinar a eficiência. No entanto, a técnica também está sujeita a algumas limitações. Duas das falhas mais conhecidas são que a DEA não considera os erros de medição e que é sensível a outliers . Ainda, um baixo número de observações para muitas entradas e saídas irá resultar em muitas empresas que aparecem na fronteira DEA, o que pode gerar resultados enganosos (Fethi \& Pasiouras, 2010). Entretanto, a abordagem tem sido utilizada desde que pesquisas recentes afirmaram que o procedimento de programação matemática utilizado na DEA para a estimação de fronteiras eficientes é comparativamente robusto (Seiford \& Thrall, 1990). Adicionalmente, um grande volume de trabalhos estenderam e aplicaram a metodologia (Sathye, 2001).

A validade da técnica DEA está diretamente relacionada à seleção das entradas e saídas que compôem o modelo. Nesse sentido, para a indústria financeira, a definição e 
mensuração de entregas tem sido um assunto central de debate entre os pesquisadores. Existe uma vasta literatura sobre modelos de aferição da eficiência operacional no setor financeiro e, em termos gerais, adota-se uma abordagem de produção ou uma de intermediação. Sob a abordagem de produção, uma instituição financeira é definida como prestadora de serviços para seus clientes, ou seja, elas executam transações em contas de depósito e processam documentos tais como empréstimos. De acordo com tal abordagem, o número de contas e transações relacionadas são saídas, enquanto as entradas incluem o número de empregados e o capital físico (Sathye, 2001; Anthanassopoulos, 1998). Por outro lado, sob a abordagem de intermediação, instituições financeiras convertem a transferem ativos entre unidades superavitárias e deficitárias. Para essa abordagem as saídas são definidascomo depósitos e empréstimos,enquanto as entradas incluem o trabalho, ativos fixos, equipamentos e fundos (Anthanassopoulos, 1998; Sathye, 2001). Cabe ressaltar que nenhuma destas duas abordagens é perfeita, uma vez que não podem capturar totalmente o duplo papel das instituições financeiras como provedoras de serviços e intermediárias financeiras (Fethi \& Pasiouras, 2010).

Independentemente da abordagem escolhida, há uma discussão vigente na literatura sobre o correta definição de entradas e saídas do modelo. Uma vez que os dados sobre quantidades físicas nem sempre são disponíveis, há necessidade de usar fluxos monetários tomados com base nos balanços de ganhos e perdas. Alternativamente, pode-se recorrer ao banco de variáveis tais como a quantidade média de depósitos e empréstimos, uma vez que, continuamente, exigem a produção de serviços de pagamento e de liquidez e o acompanhamento das decisões de crédito (Varian, 1990). Nesse contexto, houve quase tantas hipóteses de entradas e saídas quanto o número de aplicações da DEA e na literatura não há nenhuma escolha definitiva, comumente acordada (Fethi \& Pasiouras, 2010; Luo,2003). As entradas tradicionais são ativos fixos, recursos humanos e, em muitos casos, os depósitos e o capital próprio. Como entradas adicionais ou alternativos verificam-se os depósitos a prazo, a demanda, a poupança, os depósitos fixos e custos totais. (Fethi \& Pasiouras, 2010). A maioria dos estudos com DEA utilizam duas saídas, empréstimos e outros ativos rentáveis. No entanto, alguns estudos desagregam os empréstimos em várias categorias, tais como os empréstimos à habitação, e outros, imobiliários, comerciais, pessoais, curto prazo e longo prazo. Outros desagregam os ativos rentáveis em investimentos, ativos líquidos, investimentos no governo, valores mobiliários e investimentos em empresas públicas e privadas (Fethi \& Pasiouras, 2010).

Apesar das facilidades da DEA, faz-se necessário um destaque chave em tais abordagens não paramétricas. Elas geralmente assumem que não há erro aleatório, ou seja, não há erro aleatório na fronteira; não há elementos temporais que possibilitam algum DMU a ter 
melhor desempenho e não há erro de mensuração criado com base em regras que direcionam as entradas e saídas a elementos não econômicos. Quaisquer erros desses podem resultar em modificações nos scores de desempenho, o que acarreta toda a formulação da fronteira em virtude das combinações lineares que envolvem tal unidade (Berger \& Humphrey, 1997). Além disso, a DEA apresenta uma alta sensibilidade para os dados, uma vez que a metodologia foca em fronteiras ou limites, e, portanto, erros de medição de dados podem causar problemas significativos (Zaher, Zeineldin \& Abdelshafy, 2015).

Apesar disso, a análise envoltória de dados (DEA) vem se destacando como ferramenta de medição de desempenho de instituições financeiras em virtude de sua flexibilidade, aplicabilidade e robustez (Paradi \& Zhu, 2013). A técnica mostra-se adequada para avaliar o desempenho das organizações e sua unidades funcionais, pois atravessa os limites de diversas áreas acadêmicas e recebe uma importância crescente como ferramenta para avaliar e melhorar o desempenho (Zaher, Zeineldin \& Abdelshafy, 2015). Ademais, a pesquisa teórica mostrou que seus estimadores têm boas propriedades estatísticas e podem ser usados para mensurar de forma fiel o desempenho de empresas (Banker, 1993; Banker e Natarajan, 2008; Fethi \& Pasiouras, 2010; Seiford \& Thrall, 1990).

\subsection{Coprodução}

A entrega do serviço é um processo dinâmico e interativo no qual os clientes são participantes vitais que contribuem com ideias valiosas para a melhoria do desenho do serviço. Nesse contexto, os clientes e parceiros coproduzem o serviço por meio de esforços e atenções crescentes ao longo do tempo e, dados tais insumos, os prestadores do serviço são mais capazes de satisfazer as necessidades de negócio (Cheung \& To, 2011). Nesse contexto, a coprodução é definida como a participação construtiva no processo de criação e entrega dos serviços, e engloba todos os formatos de cooperação entre o cliente, os parceiros e o prestador, que têm como finalidade um entendimento mútuo com o propósito de agregar valor (Chen, Tsou \& Ching 2011; Cheung \& To, 2011; Wu \& Lin, 2013).

Cabe destacar que tal constructo é plural e multifacetado, posto que a coproducão se refere à participação dos parceiros e aos clientes no desempenho das diversas atividades do processo produtivo. A coprodução requer contribuições cooperativas e significativas para o processo e favorece um clima de reciprocidade, além do que as organizações coprodutoras movem-se por meio de um entendimento mútuo, que resulta em desempenho positivo (Wu \& Lin, 2013). Para se chegar à essência do construto, faz-se necessário retomar as estruturas 
teóricas que o fundamentam. Nesse contexto, a literatura de coprodução estrutura-se sobre três áreas principais: no contexto da administração pública, focada na participação cidadã e voluntarismo; no âmbito do marketing, fundamentada principalmente na lógica dominante do serviço (SDL); e na literatura de economia dos serviços, caracterizada como o envolvimento do cliente para a geração de novas ideias e consequente inovação.

A primeira vertente de estudos de coprodução se dá no âmbito da literatura de administração pública. Ao se fazer um resgate histórico sobre o construto, verifica-se que o conceito de coprodução surge na década de 1970, com o advento da literatura de serviços. Propôs-se que em sistemas de serviço o cliente aparece duas vezes: uma como consumidor e outra como parte do sistema de entrega do serviço. Os profissionais do serviço comumente desempenham o papel de intermediador que permite ao cliente atuar verdadeiramente sobre o serviço, de forma que o cliente torna-se um coprodutor do serviço (Bovaird, 2007). Esse novo papel do cliente, mais ativo, fez com que outros autores percebessem o potencial da coprodução (Bovaird, 2007). No início da década de 1980, o conceito de coprodução gerou uma profusão de interesse no modo de pensar da administração pública, uma vez que a ideia de envolvimento de pessoas de fora das organizações governamentais na produção de serviços públicos atraía continuamente a atenção da academia (Alford, 2002). O modelo de coprodução foi, então, definido como o grau de sobreposição entre dois conjuntos: fornecedores regulares e clientes. Esse mecanismo representa a produção conjunta do serviço baseada nesses dois grupos e envolve diversas dimensões no processo (Brudney \& Robert, 1983).

O conceito de coprodução foi reformulado à medida que os serviços passaram a ganhar atenção crescente e o papel dos clientes foi revisado. Nesse contexto, Ostrom (1996) apresentou uma crítica acerca das formas tradicionais de práticas profissionais e produção dos serviços e destacou que os serviços na realidade são coproduzidos por participantes ativos que interpretam e atuam sobre as diretrizes políticas e organizacionais. $\mathrm{O}$ autor argumenta que a produção do serviço ocorre em um processo colaborativo onde as contribuições dos clientes não apenas são desejáveis, mas também necessárias e inevitáveis. Portanto, o processo de produção de serviços é complexo e caracterizado por interdependências, negociações avançadas, construção conjunta e coprodução. Além disso, envolve contribuições significativas e capacidades dos clientes e outros participantes (Dunston et al., 2009).

A partir do final da década de 1990, a coprodução adquire novo patamar e o nível de discussão amplia-se para outras áreas de estudo. No modelo de coprodução, os administradores são responsáveis por facilitar o fornecimento conjunto com os cidadãos do desenho e entrega do serviço (Clark, Brudney \& Jang, 2013). As implicações resultantes desse 
reposicionamento do papel do cliente e governo são: a coprodução passa a ser um elemento que fortalece a ponte entre cidadãos e governo apoiada na revitalização da cidadania; a coprodução rompe com a forte barreira existente entre governo e seus cidadãos; trata-se de um mecanismo que define um caminho onde sinergias ocorrem entre aquilo que o governo faz e aquilo que os cidadãos fazem; e os usuários e comunidades podem e devem fazer parte do planejamento e entrega do serviço (Clark, Brudney \& Jang, 2013). Observa-se que o discurso e a prática da coprodução vêm se tornando o paradigma emergente, visto que essa óptica é congruente com muitos direcionadores-chave do setor público, em particular o desenvolvimento de práticas de parceria e de novas formas de participação do cliente. A coprodução é um conceito revolucionário nos serviços públicos uma vez que posiciona os usuários e a comunidade no centro do processo de tomada de decisão (Dunston et al., 2009).

O segundo grupo de estudos é resultante da reformulação da dinâmica dos serviços, e caracteriza-se como a transposição do conceito de coprodução para o marketing, proposto inicialmente por Vargo e Lusch (2004) na lógica dominante do serviço (SDL). De forma abrangente, existem duas perspectivas distintas para caracterizar o processo produtivo: a lógica dominante do produto (GDL) e a lógica dominante do serviço (SDL) (Vargo \& Lusch, 2004). Enquanto a primeira considera as unidades de produção como componente central da troca, a segunda reordena o serviço e o posiciona sobre os produtos. A SDL propõe uma transição e revolução na literatura com base nas seguintes premissas: (1) a aplicação de conhecimento e habilidades específicas é a unidade fundamental de troca; (2) a troca indireta camufla a unidade fundamental de troca; (3) produtos são mecanismos de distribuição para o fornecimento do serviço; (4) o conhecimento é a fonte fundamental de vantagem competitiva; (5) todas as economias são baseadas em serviços; (6) o cliente é sempre um cocriador de valor; (7) a organização pode apenas sugerir proposições de valor; (8) uma perspectiva focada no serviço é orientada para o cliente e relacional; e (9) organizações existem para integrar e transformar competências especializadas em serviços complexos demandados pelo mercado (Lusch, Vargo \& O’Brien, 2007). Reconhece-se, portanto, que existem dois componentes para o valor. O mais abrangente, a cocriação de valor, caracteriza-se como a participação do cliente na concepção inicial do serviço. O segundo componente, a coprodução, envolve a participação no próprio cerne da oferta do serviço (Vargo \& Lusch, 2006).

Diferentemente de tratar valor como um atributo intrínseco do produto no processo de troca, a SDL caracteriza o valor como a criação resultante de interações, onde o cliente se posiciona no processo relacional. Nesse âmbito, as firmas não entregam valor, mas, sim, oferecem proposições que têm potencial de criar valor baseado na parceria com os clientes 
(Vargo \& Lusch, 2008). A SDL resulta em uma inversão fundamental na lógica dominante do marketing por considerar serviços como dominantes e bens, organizações, redes e capital como intermediários. Além disso, a SDL considera que: o desempenho não pode ser aprimorado, mas pode sofrer melhorias graduais; o ambiente externo não é incontrolável, mas, sim, representa um conjunto de recursos que podem ser utilizados como suportes; clientes são recursos operantes que atuam como colaboradores; e o valor de uso é, na verdade, um valor na troca. Entretanto, a SDL não apenas traz o cliente para o processo de cocriação de valor, mas também os parceiros organizacionais por uma rede de criação de valor. Isso ocorre uma vez que a SDL considera o conhecimento como a fonte fundamental de vantagem competitiva e reconhece que o conhecimento não é centralizado, mas, sim, disperso através do mercado e sociedade. Consequentemente, a SDL reconhece que todas as entidades devem colaborar umas com as outras e promover a integração de recursos (Vargo \& Lusch, 2006). Trata-se de uma lógica baseada em um entendimento imbricado de indivíduos e organizações, reunidos em redes e sociedades e especializados na troca e aplicação de competências, diretamente atrelada a um comprometimento com processos colaborativos entre clientes, parceiros e funcionários da organização.

Finalmente, o terceiro grupo de estudos de coprodução se dá no âmbito da economia de serviços, e reúne contribuições de outras áreas para propor uma reformulação do construto. A ideia central é a de que o conceito de coprodução se estende ao longo da cadeia de valor completa do serviço, e envolve todos os mecanismos de interação prestador-cliente. Tal conceito está embutido na própria concepção inicial de serviço (Hill, 1977), que argumenta que um serviço representa uma mudança de determinada condição ou realidade a partir de uma relação de interação entre prestador e cliente. Gadrey (1996) extrapola tal construto, no chamado "triângulo da prestação de serviços", onde um serviço é considerado um conjunto de operações fornecido por um prestador (B) para um cliente (A) em um meio (C), com o intuito de gerar mudança de estado no meio (C). Os serviços, portanto, envolvem necessariamente uma relação entre o prestador e o cliente (Gadrey, 2000). Sob a óptica da abordagem de assimilação, tal relação perde o foco em virtude do papel da tecnologia como direcionadora do processo. Entretanto, com o advento da abordagem de demarcação e da própria SDL, o cliente passa a ter papel central na inovação em serviços. A abordagem de integração explicita tal relação de coprodução a partir do momento que define as competências do prestador e cliente ([C] e [C']) como vetores do processo, de forma que a coprodução representa a união de tais vetores. Verifica-se, portanto, que no contexto da literatura de serviços o papel da interação e o componente relacional estão cada vez mais presentes nos modelos teóricos e estruturas de 
análise (Edvardsson, et al., 2010; Gadrey; 1996; Gadrey, 2000; Gallouj \& Weinstein, 1997; Hill, 1977).

Com base nas considerações levantadas, observa-se que apesar do constructo de coprodução sermultifacetado, os elementos essenciais são mantidos e, consequentemente, há espaço para o aprofundamento e unificação do constructo com base nas contribuições de cada uma das três áreas. Enquanto a administração pública foca nos formatos e determinantes da interação, o marketing enfatiza nos elementos de proposição e geração de valor para as partes e a economia dos serviços traz à tona o papel da mobilização de competências e conhecimento. Argumenta-se, portanto, que a coproducão pode ser considerada como um processo composto por diversos elementos (formatos, determinantes, competências) com o intuito de gerar valor para ambas as partes, e que a disposição de tais elementos depende do tipo de interação. Esta ideia está consonante com o proposto no trabalho de Edvardsson et al. (2010), que propõem uma tipologia de coprodução onde a determinação dos tipos é resultante da definição dos papéis desempenhados pelos atores na relação. Tal construção está esquematizada no Quadro 2.

\begin{tabular}{|cl|}
\hline Tipo de Coprodução & \multicolumn{1}{c|}{ Descrição } \\
\hline Comprador & $\begin{array}{l}\text { Cliente/Parceiro é mero destinatário passivo do produto ou serviço e não } \\
\text { influencia no processo de entrega do serviço. }\end{array}$ \\
\hline Objeto de Interesse & $\begin{array}{l}\text { Prestador aguarda de forma passiva as informações que o Cliente/Parceiro } \\
\text { queira compartilhar. }\end{array}$ \\
\hline Fornecedor de Informação & Prestador capta ativamente informações do Cliente/Parceiro. \\
\hline Codesenvolvedor & Cliente/Parceiro proativo e envolvido diretamente no processo de entrega do \\
& serviço. \\
\hline Desenvolvedor & Cliente/Prestador assume inteira responsabilidade pelo processo de entrega \\
& do serviço. \\
\hline
\end{tabular}

Quadro 2. Tipos de coprodução, de acordo com Edvardsson et al. (2010).

Verifica-se que a utilização da abordagem integrada permite explorar algumas lacunas da literatura e promover a análise mais aprofundada. Essa articulação de constructos pode ser transposta e aplicada ao setor financeiro, tendo em vista se tratar do lócus adequado para a análise do modelo. Sob a óptica da administração pública, o setor envolve agentes governamentais, mecanismos de regulação e fiscalização, formulação e implementação de políticas macroeconômicas e interações com os cidadãos, com foco no desenvolvimento da economia. Do ponto de vista do marketing, o mercado financeiro é complexo, dinâmico, 
imprevisível e abarca os diversos formatos de interação e cooperação para atendimento das demandas de mercado e necessidades dos clientes por rentabilidades específicas. Por fim, o setor financeiro é fundamentado principalmente em serviços, que objetivam orientar o cliente na escolha dos investimentos e na transação de ativos, o que garante um ambiente propício à inovação.

\subsection{Articulação Conceitual}

O setor financeiro se mostra plurifacetado, versátil e complexo e passou por mudanças significativas após a recente crise econômica (Hutton \& Lee, 2012). Nesse cenário, elementos como regulação, fronteiras, dinamismo, competitividade, tecnologias e demandas possuem impacto significativo no desempenho das instituições financeiras (Blazevic \& Lievens 2004; Buzzacchi, Colombo \& Mariotti, 1995; Caselli, 2010; Delimatsis, 2013; Rossignoli \& Arnaboldi, 2009; Shahrokhi, 2008; Stevens \& Dimitriadis, 2005). Contudo, mesmo em face do novo contexto, os modelos de análise para o setor são tradicionais, racionais e tecnicistas, e a forma de abordagem vigente é pautada na economia clássica, à luz de teorias como mercados perfeitos e expectativas racionais (Delimatsis, 2012). O problema é que essa estrutura não apenas é incapaz de explicar a dinâmica do mercado em situações extremas de desequilíbrio, como negligencia em parte os avanços da literatura. Fundamentada nisso, a articulação aqui proposta busca promover um debate acerca da dinâmica do setor financeiro tendo como base os constructos de inovação, desempenho e coprodução.

Inicialmente, no âmbito da inovação, o presente trabalho propõe trazer a abordagem integradora para o contexto do mercado financeiro. Tal fato de justifica tendo em vista que: (1) a abordagem é a mais promissora em termos de avanço teórico (Gallouj \& Savona, 2009); (2) a literatura sugere ampliar o escopo de seu modelo de vetores para outros setores da economia (Djellal \& Gallouj, 2005); (3) tal perspectiva permite analisar produtos e serviços financeiros sob a óptica de um modelo comum, focado no processo de inovação (Gallouj \& Weinstein, 1997); (4) o mercado financeiro é pioneiro em inovação (Barras, 1990); e (5) serviços financeiros são arriscados, complexos e de difícil mensuração bem como a abordagem integradora procura dar mais tangibilidade à análise (Djellal \& Gallouj, 2010; Gallouj \& Savona, 2010; Gallouj \& Toivonen, 2011; Hoffmann, Post \& Pennings, 2013).

Nesse contexto, um produto ou serviço financeiro $(\mathrm{Si})$ pode ser decomposto na forma de processo de vetores constituintes $\left.\left[\mathrm{C}^{\prime}\right] \mathrm{C}^{\prime}\right][\mathrm{T}]\left[\mathrm{T}^{\prime}\right][\mathrm{Z}]\left[\mathrm{Z}^{\prime}\right][\mathrm{Y}]$ (Fig.2), ou, de forma simplificada, $[\mathrm{C}][\mathrm{T}][\mathrm{Z}][\mathrm{Y}]$, onde $[\mathrm{C}]$ são competências, $[\mathrm{T}]$ características técnicas, $[\mathrm{Z}]$ 
características processuais e [Y] entregas (Djellal \& Gallouj, 2010; Gallouj \& Toivonen, 2011; Gallouj \& Weinstein, 1997). Ressalta-se que cada um desses vetores é resultante da interação entre elementos do prestador, parceiros e clientes e que a inovação ocorre quando há modificação em quaisquer desses elementos (Gallouj \& Weinstein, 1997).

Verifica-se que tal modelo não incorpora elementos do ambiente, uma vez que foca nos aspectos internos da organização (competências, características técnicas, características processuais e entregas). Dessa forma, a fim de se transpor para o setor financeiro, argumentase que o modelo deve incorporar as variáveis do ambiente (regulação, fronteiras, dinamismo, competitividade, tecnologias e demandas), visto que são as principais impactantes no processo (Blazevic \& Lievens 2004; Buzzacchi, Colombo \& Mariotti, 1995; Caselli, 2010; Delimatsis, 2013; Rossignoli \& Arnaboldi, 2009; Shahrokhi, 2008; Stevens \& Dimitriadis, 2005). Propõese, portanto, a inclusão do vetor [E], caracterizado como o conjunto de variáveis do ambiente que impactam o processo de entrega do produto ou serviço. Dessa forma, o produto ou serviço financeiro passa a ser descrito na forma de um processo $[\mathrm{E}][\mathrm{C}][\mathrm{T}][\mathrm{Z}][\mathrm{Y}]$. Cabe ressaltar que o vetor [E] não faz parte do produto ou serviço, mas, sim, atua apenas como modificador dos elementos dos demais vetores, de forma que modificações ocorridas exclusivamente nesse vetor não acarretam necessariamente inovação.

Na sequência, ao trazer a concepção de desempenho no setor financeiro descrita anteriormente, argumenta-se que há possibilidade de incremento do modelo. Tal sinergia se justifica visto que ambas as literaturas se fundamentam sob uma óptica de processo. Sob a perspectiva de desempenho, instituições financeiras entregam produtos e serviços a fim de atuarem como intermediários na conversão e transferência de recursos entre unidades superavitárias e deficitárias (Anthanassopoulos, 1998; Fethi \& Pasiouras, 2010; Sathye, 2001; Soteriou \& Zenios, 1997). Nesse âmbito, a medida de desempenho é obtida com base na maximização da proporção de saídas dado determinado conjunto de entradas (Charnes, Cooper \& Rhodes, 1978; Farrell, 1957; Fethi \& Pasiouras, 2010; Kopp, 1981; Leibenstein, 1966; Paradi \& Zhu, 2013; Varian, 1990; Zaher, Zeineldin \& Abdelshafy, 2015).

Ao se extrapolar tal ideia para o modelo proposto, verifica-se que o desempenho é representado como a medida de conversão de $[\mathrm{E}][\mathrm{C}][\mathrm{T}][\mathrm{Z}]$ em $[\mathrm{Y}]$. Em outras palavras, as entradas - ativos fixos, recursos humanos, depósitos, capital próprio, depósitos a prazo, demanda, poupança, depósitos fixos, custos totais (Fethi \& Pasiouras, 2009; Luo,2003) - são elementos embutidos nos vetores [C], [T] e [Z] e são impactadas diretamente por [E], enquanto as saídas - empréstimos, investimentos, ativos líquidos, investimentos no governo, valores mobiliários, investimentos em empresas públicas e privadas, lucros obtidos (Fethi \& Pasiouras, 
2010) - estão representadas no vetor [Y]. Paralelamente, as variáveis que têm impacto direto no desempenho do setor - preços, produtos e serviços ofertados, tamanho, lucros, concentração de recursos, competitividade, passivos, ativos, crédito privado, inflação, valor de mercado, volatilidade, retorno sobre capital próprio, número de empregos do setor, participação do setor no PIB, agregados monetários, crédito privado, disponibilidade de informações, contratos/transações, lastros e alavancagem, empréstimos e adequação de capital (Boyd, Levine \& Smith, 2000; Detragiache, Tressel \& Gupta, 2008; Fraser, Phillips \& Rose, 1974; Graff \& Karmann, 2006; Gropper, Jahera \& Park, 2015; Wang, Lu \& Wang, 2013) - também podem ser inseridas no modelo na forma de elementos constituintes dos vetores.

Finalmente, sob a óptica da coprodução, é possível ampliar o escopo de análise, uma vez que há possibilidade de inclusão de tais elementos colaborativos no modelo. Enquanto a inovação se preocupa com a modificação de elementos dos vetores, a fim de gerar novas entregas, e o desempenho foca na medida de conversão de entradas em saídas, a coprodução permite que a instituição financeira seja caracterizada não apenas com base em fatores intrínsecos, mas também a partir das interações com toda a rede de parceiros e clientes. Tal proposta se justifica visto que a coprodução refere-se a todos os formatos de cooperação e interação entre a organização e seus stakeholders com o intuito de agregar valor (Chen, Tsou \& Ching 2011; Cheung \& To, 2011; Dunston, Lee, Boud, Brodie \& Chiarella, 2009; Ostrom, 1996; Vargo \& Lusch, 2004; Wu \& Lin, 2013) e, no setor financeiro, as transações são realizadas mediante relações de confiança entre as instituições e os investidores, que contribuem entre si para gerar bem-estar financeiro (Martovoy, Mention \& Torkkeli, 2015; Mende \& Doorn, 2014).

A articulação aqui proposta reside no fato de que as abordagens de coprodução se respaldam em uma lógica de serviço, de forma que é possível estabelecer um paralelo com a abordagem integradora da inovação. Ao se trazer as contribuições da administração pública, deve-se considerar a interação entre prestadores, parceiros e clientes, de forma que a coprodução ocorra justamente onde tais grupos se relacionam para contribuir de forma positiva para o desempenho do serviço (Brudney \& Robert, 1983; Dunston et al., 2009; Ostrom, 1996). Da mesma forma, a SDL argumenta que a coprodução ocorre no processo de entrega do serviço, quando o prestador, os parceiros e os clientes interagem para gerar valor (Vargo \& Lusch, 2004). Finalmente, para a economia dos serviços a coprodução está representada na mobilização de competências [C] e [C'] entre prestadores e demais atores do sistema (Gallouj \& Weinstein, 1997; Gallouj \& Savona, 2009). Portanto, o presente trabalho define coprodução como o conjunto de interações no processo de entrega do serviço que envolve a mobilização de 
competências entre prestadores, parceiros e clientes com o intuito de agregar valor. Nesse sentido, tendo em vista que a coprodução pode ocorrer entre o prestador e o cliente ou entre prestador e parceiros, faz-se necessária a inclusão de tais relações no modelo, de modo que, de forma análoga às competências do cliente [C'], sugere-se o acréscimo do vetor [C'’] caracterizado como o conjunto de competências dos parceiros e, paralelamente, teríamos [T'’] e [Z'] como representação das características técnicas e processuais, respectivamente. Posto isso, a coprodução pode ser graficamente representada como a interação dos vetores $[\mathrm{C}]\left[\mathrm{C}^{\prime}\right]\left[\mathrm{C}^{\prime \prime}\right]$ que agregam valor ao vetor $[\mathrm{Y}]$.

A Figura 2 sumariza as ideias apresentadas e propõe um modelo para discussão. Ressalta-se que as considerações delineadas sintetizam a articulação conceitual entre inovação, desempenho e coprodução no setor financeiro e propõem uma nova forma de compreensão do fenômeno tendo como base a visão de processo. Tal concepção é enriquecedora visto que não apenas unifica produtos e serviços sob a mesma óptica de análise, como também permite a ampliação do escopo de forma sistêmica, a fim de incorporar novos elementos.

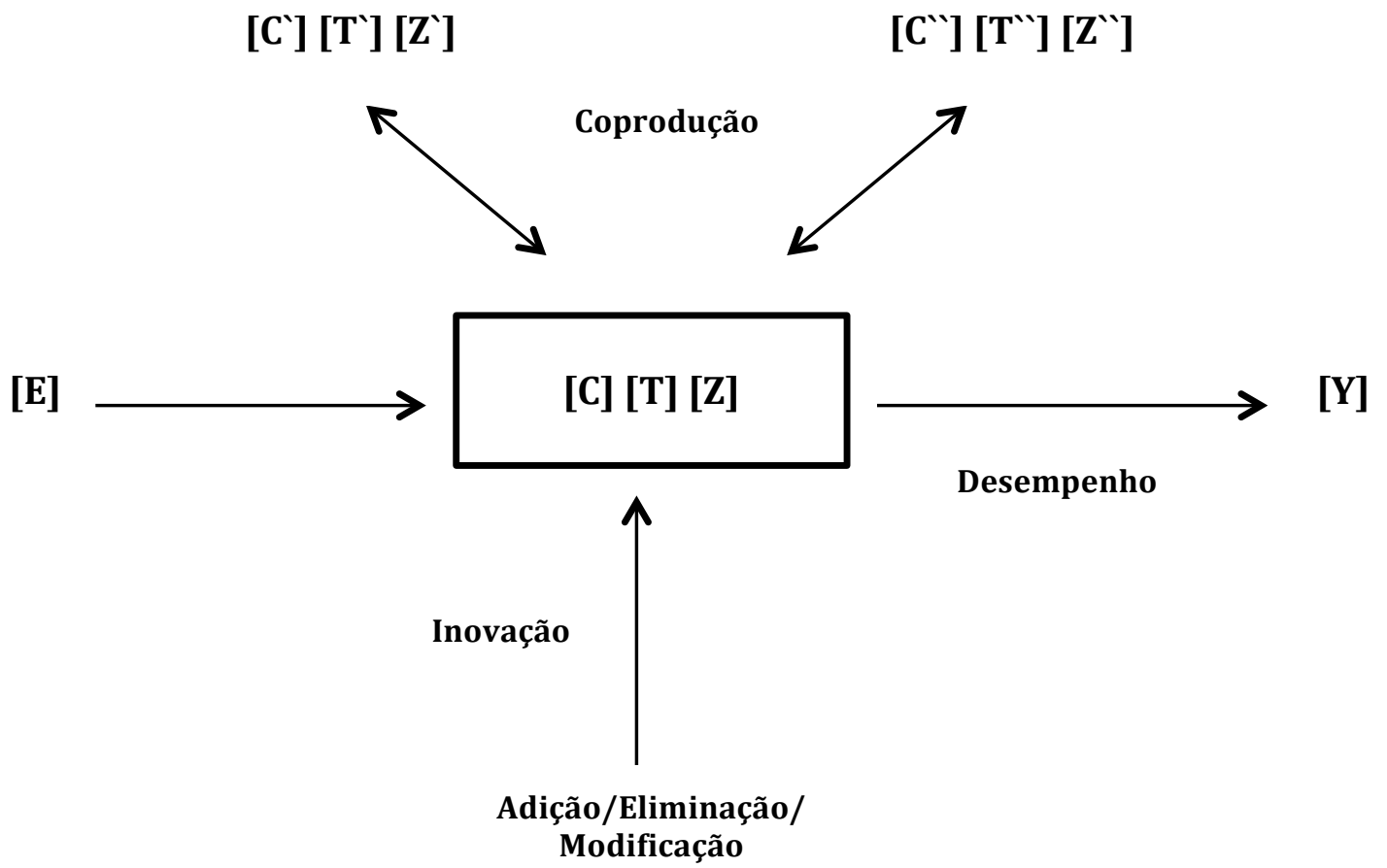

Figura 2. Proposta de articulação entre inovação, desempenho e coprodução no setor financeiro.

Ao se explorar tal modelo, verifica-se que há espaço para discussões relevantes. Primeiramente, dado que a inovação ocorre quando há modificação, acréscimo ou eliminação de um ou mais elementos nos vetores $[\mathrm{C}][\mathrm{T}][\mathrm{Z}]$ a fim de gerar valor $[\mathrm{Y}]$ e que o vetor $[\mathrm{E}]$ tem 
impacto no processo, verifica-se que mudanças no ambiente (regulação, limites, competitividade, dinamismo, tecnologias e demandas) têm relação direta com a inovação. Tal proposição se justifica visto que: (1) padrões de regulação são determinantes da inovação, já que normativos rígidos tendem a impulsionar formas de contorná-los e legislações frouxas geram maior alavancagem e perda de controle do risco subjacente, além do que o grau de regulação define os limites de atuação e estimulam o surgimento de novos formatos, produtos e serviços financeiros (Delimatsis, 2012; Delimatsis, 2013); (2) a nova dinâmica de mercado, caracterizada por regulação forte, competitividade desenfreada, controle justo e transações de grandes volumes em tempo real, estimula organizações financeiras a desenvolverem a capacidade inovativa a fim de sobreviverem e manterem-se competitivas (Blazevic e Lievens, 2004; Hutton \& Lee, 2012; Stevens \& Dimitriadis, 2005); (3) novas tecnologias permitem aumento de volume das transações e agilidade e confiança das operações, o que acarreta o incentivo ao desenvolvimento de novos instrumentos financeiros (Barras, 1990; Shahrokhi, 2008); e (4) a inovação no setor é direcionada com base em demandas particulares dos investidores por padrões de fluxo de caixa específicos (Delimatsis, 2013). Posto isso, delineiase a seguinte proposição de pesquisa:

P1: regulação, limites de atuação, competitividade, dinamismo, novas tecnologias e demandas dos clientes possuem relação direta com a inovação no setor financeiro.

Adicionalmente, posto que o vetor [E] impacta o processo, ele interfere também nos formatos de interação entre $[\mathrm{C}]\left[\mathrm{C}^{\prime}\right]\left[\mathrm{C}^{\prime \prime}\right]$, o que permite inferir que mudanças no ambiente têm relação direta com a coprodução. Tal fato se justifica tendo em vista que os relacionamentos entre atores no mercado financeiro são fundamentados na confiança e orientados para o lucro, e os participantes demandam serviços complexos, interagem frequentemente e estabelecem elos duradouros (Martovoy, Mention \& Torkkeli, 2015; Mende \& Doorn, 2014). Nesse contexto, o ambiente impacta a escolha dos stakeholders e define os mecanismos da articulação dos atores em rede, na busca de superar a autossuficiência e distribuir atividades (Boot \& Thakor, 2000; Caselli, 2010; Martovoy, Mention \& Torkkeli, 2015). Portanto, sugere-se a segunda proposição teórica:

P2: regulação, limites de atuação, competitividade, dinamismo, novas tecnologias e demandas dos clientes impactam diretamente os formatos de coprodução entre os atores do setor financeiro. 
Outra decorrência do modelo é que a coprodução tem relação positiva com a inovação, uma vez que a mobilização de competências $[\mathrm{C}]\left[\mathrm{C}^{\prime}\right]\left[\mathrm{C}^{\prime}\right.$ '] entre prestadores, parceiros e clientes visa a agregar valor à entrega e proporcionar resultados finais $(\mathrm{Y})$ ótimos, ao mesmo tempo que as interações tendem modificar os vetores $[\mathrm{C}][\mathrm{T}][\mathrm{Z}][\mathrm{Y}]$ do processo. Tal fato fundamenta-se uma vez que a prática de colaboração produz sinergias que induzem à melhoria de processos baseados na introdução de novo conhecimento, além do que a coprodução é dependente de fatores como cooperação, alinhamento e expertise, que, conjuntamente, são capazes de promover inovação (Chen, Tsou e Ching, 2011; Edvardsson et al., 2010; Ordanini, Miceli, Pizzetti \& Parasuraman, 2011; Wei, Wang, Tao \& Wang, 2006; Zhaoquan, Chen \& Xiande, 2013). Além disso, no setor financeiro os mais importantes insumos para a inovação residem na própria instituição financeira e na rede interorganizacional e aproximadamente metade das inovações são desenvolvidas conjuntamente com parceiros e alianças estratégicas (Martovoy, Mention \& Torkkeli, 2015). Tais elementos podem ser sumarizados na proposição abaixo:

P3: a coprodução tem relação positiva com a inovação.

Na sequência, uma vez que a inovação representa a modificação de elementos e vetores com acréscimo de valor ao vetor [Y] e que o desempenho está caracterizado como a medida de conversão de insumos $[\mathrm{C}][\mathrm{T}][\mathrm{Z}]$ em entregas $[\mathrm{Y}]$, argumenta-se que a inovação tem relação positiva com o desempenho. Tal fato pode ser corroborado, uma vez que a organização se propõe a adicionar processos e vetores, melhorar elementos existentes e eliminar vetores e elementos ultrapassados no intuito de agregar valor às entregas, o que representa ao mesmo tempo a otimização da conversão de entradas em saídas, posto que a organização produza mais com um determinado conjunto de insumos. Dessa forma, a inovação tende a impactar positivamente o desempenho a não ser que o valor gerado seja inferior ao capital investido para inovar. A literatura encontra respaldo para tal afirmação uma vez que apresenta evidências de que a inovação contribui para a redução de volatilidade macroeconômica, promove redução de custos de transações e melhoria no gerenciamento de riscos, otimiza trocas e meios de pagamento, desenvolve instrumentos e mercados, promove o crescimento econômico e desenvolvimento de mercados e transforma ativos em oportunidades de diversificação (Bos, Kolari \& Lamoen, 2013; Delimatsis, 2012; Delimatsis, 2013; Frame \&White 2004; Mullineux, 2010; Rossignoli \& Arnaboldi, 2009). Sendo assim, a proposição de pesquisa é a seguinte: 
P4: a inovação tem relação positiva com o desempenho do setor financeiro.

Finalmente, tendo em vista que a coprodução visa também a agregar valor às entregas [Y], sugere-se que a coprodução tem relação positiva com o desempenho. Nesse sentido, a partir do momento que a organização interage com parceiros e clientes, gera valor para seus produtos e serviços com poucas modificações em sua base de insumos. Dessa forma, o valor gerado tende a suplantar o valor investido no estabelecimento e fortalecimento destes relacionamentos. Tal argumentação fundamenta-se na ideia de que em um contexto onde o sucesso das transações financeiras depende do comportamento colaborativo entre as partes relacionadas (governo, consultores, clientes, fornecedores, associações profissionais, competidores e investidores), a mobilização de competências caracteriza a transferência de conhecimentos e a consequente vantagem competitiva, o que impacta diretamente o desempenho da organização (Edvardsson et al., 2010; Field, Xue \& Hitt, 2012; Lusch, Vargo \& O’Brien, 2007; Martovoy, Mention e Torkkeli, 2015; Mende \& Doorn, 2014). Além disso, o aumento da interconectividade e interações entre prestadores, parceiros e clientes acarreta a diluição do risco por intermédio da rede de relacionamentos e atendimento a demandas específicas de mercado, o que contribui para a melhoria do desempenho (Delimatsis, 2012; Martovoy, Mentio \& Torkelli, 2015; Mende \& Doorn, 2014; Rossignoli \& Arnaboldi, 2009). Posto isso, apresenta-se a última proposição de pesquisa:

P5: a coprodução tem relação positiva com o desempenho do setor financeiro.

Em síntese, as proposições acima desenvolvidas sugerem novos elementos teóricos para elucidar em parte lacunas da literatura e propor diretrizes de pesquisa. Como consequência delas verifica-se que as instituições financeiras devem realizar investimentos estruturados em inovação e coprodução a fim de agregar valor às entregas e aperfeiçoar o desempenho.

\subsection{Conclusões e Recomendações}

O presente capítulo teve como objetivo discorrer sobre a relação entre inovação, desempenho e coprodução no setor financeiro. Com base no levantamento bibliométrico elaborado, verificou-se que há lacunas teóricas no que tange à integração de tais constructos e, portanto, foi proposto um modelo cujo objetivo é articular tais elementos sob uma óptica de 
processo a fim de promover novos debates sobre o tema. O modelo fundamenta-se no pressuposto de que produtos e serviços financeiros são processos compostos de competências, características técnicas, processuais e entregas. Dessa forma, enquanto a inovação representa modificações em tais elementos, a coprodução é a mobilização de competências entre instituições, parceiros e clientes com o intuito de agregar valor e o desempenho é a medida de eficiência na conversão de tais elementos em entregas.

Nesse âmbito, argumentou-se que o ambiente tem relação direta com inovação e coprodução, no setor financeiro, o que vai ao encontro da literatura (Barras, 1990; Blazevic e Lievens, 2004; Delimatsis, 2012; Delimatsis, 2013; Hutton \& Lee, 2012; Stevens \& Dimitriadis, 2005; Shahrokhi, 2008). Propôs-se que regulação, fronteiras, dinamismo, competitividade, tecnologias e demandas impactam diretamente o processo de entrega de produtos e serviços no setor financeiro (Blazevic \& Lievens 2004; Buzzacchi, Colombo \& Mariotti, 1995; Caselli, 2010; Delimatsis, 2013; Rossignoli \& Arnaboldi, 2009; Shahrokhi, 2008; Stevens \& Dimitriadis, 2005). Na sequência, argumentou-se que a inovação tem relação positiva com a coprodução, o que está de acordo com diversas evidências da literatura (Chen, Tsou \& Ching, 2011; Edvardsson, et al., 2010; Gallouj \& Savona, 2009; Gallouj \& Weinstein, 1997; Hill, 1977; Martovoy, Mention \& Torkkeli, 2015; Mende \& Doorn, 2014).

Adicionalmente, alegou-se que a inovação tem relação positiva com o desempenho, uma vez que a modificação de elementos dos vetores agrega valor às entregas e otimiza a proporção de conversão de entradas em saídas, o que está de acordo com diversos estudos da área (Bos, Kolari \& Lamoen, 2013; Delimatsis, 2012; Delimatsis, 2013; Frame \&White 2004; Mullineux, 2010; Rossignoli \& Arnaboldi, 2009). Desta forma, em meio ao debate acadêmico acerca do impacto da inovação no desempenho do mercado financeiro (Delimatsis, 2012), o presente trabalho posiciona-se na vertente de que a relação é positiva, uma vez que a articulação com a abordagem integradora da inovação (Gallouj \& Savona, 2009) indica que, no geral, a relação tende a ser positiva, desde que o valor gerado supere o capital utilizado para inovar. Finalmente, concluiu-se que a coprodução também tem relação positiva com o desempenho, uma vez que a organização se relaciona para gerar valor e aproveitar sinergias, no intuito de produzir mais com menos, o que vai ao encontro da literatura (Edvardsson et al., 2010; Field, Xue \& Hitt, 2012; Lusch, Vargo \& O’Brien, 2007; Martovoy, Mention e Torkkeli, 2015; Mende \&Doorn, 2014).

Do ponto de vista acadêmico, este trabalho contribui para mitigar em parte algumas lacunas da literatura, principalmente no que tange ao debate sobre o impacto da inovação e coprodução no desempenho e à entrega de produtos e serviços financeiros. Sob a óptica 
gerencial, a presente proposta serve de ponto de partida para a construção de ferramentas de análise mais adequadas, visto que aponta para elementos que tradicionalmente não são considerados pelos gestores, tais como mapeamento de inovações e consequente geração de valor e impacto dos relacionamentos com parceiros e clientes. $\mathrm{O}$ modelo proposto incorpora essas variáveis e as tornam insumos para a tomada de decisão, além de equacioná-las com o desempenho da organização.

Como sugestão para estudos futuros, sugere-se o debate mais aprofundado e a validação empírica de cada uma das proposições apresentadas e, para tal, propõem-se as seguintes diretrizes como agenda de pesquisa: (1) caracterizar e quantificar os efeitos de cada uma das variáveis do ambiente (regulação, fronteiras, dinamismo, competitividade, tecnologias e demandas) na inovação e, de forma similar, na coprodução; (2) explorar de forma mais detalhada a relação entre coprodução e inovação no setor financeiro; e (3) quantificar o impacto da inovação e da coprodução no desempenho de instituições financeiras. Além disso, o modelo proposto deve ser validado e confirmado empiricamente, com o propósito de complementar a literatura sobre o tema e promover um alicerce teórico-prático para a discussão. 


\section{ESTUDO I: INOVAÇÃO, DESEMPENHO E COPRODUÇÃO NO SETOR FINANCEIRO BRASILEIRO: UM ESTUDO EXPLORATÓRIO DE COMPANHIAS DE CAPITAL ABERTO}

A crise de 2008 gerou impacto significativo no setor financeiro visto que a desaceleração incisiva das atividades econômicas e a bancarrota generalizada demonstraram que as estruturas regulatórias e o paradigma neoliberal predominante mostraram-se incapazes de atuar de forma efetiva em termos de prevenção, gerenciamento e resolução de tumultos financeiros (Delimatsis, 2012; Hutton \& Lee, 2012; Ozbay, Dinçer \& Hacioglu, 2011). Neste cenário pós-crise, a regulação, a indefinição das fronteiras, a complexidade, competitividade, as inovações tecnológicas e as demandas por novos produtos e serviços caracterizam a dinâmica do setor (Caselli, 2010; Delimatsis, 2013; Hoffmann, Post \& Pennings, 2013; Rossignoli \& Arnaboldi, 2009; Shahrokhi, 2008). Contudo, mesmo em face do novo contexto, os modelos de análise apresentam dificuldades para explicar a dinâmica do mercado financeiro em situações extremas de desequilíbrio (Delimatsis, 2012).

Nesse contexto, instituições financeiras que melhor se adaptam à nova realidade $\mathrm{e}$ inovam constantemente retornam mais lucros no longo prazo (Blazevic \& Lievens, 2004; Delimatsis, 2013; Hutton \& Lee, 2012; Stevens \& Dimitriadis, 2005). Isso ocorre visto que a inovação no setor financeiro é o processo dinâmico e contínuo de criação e disseminação de instrumentos financeiros, tecnologias, instituições e mercados, e que tem como objetivo reduzir riscos e atender demandas específicas dos investidores por padrões particulares de fluxos de caixa (Bos, Kolari \& Lamoen, 2013; Delimatsis, 2012; Delimatsis, 2013; Frame \&White 2004; Mullineux, 2010; Rossignoli \& Arnaboldi, 2009). Entretanto, não há um consenso na literatura acerca de tais benefícios da inovação (Delimatsis, 2012). Diversos estudos apontam que a inovação no setor financeiro está também vinculada à fragilidade financeira, alienação e negligência de riscos e falta de liquidez (Gai, Kapadia, Millard \& Perez, 2008; Hutton \& Lee, 2012; Johnson \& Kwak, 2012). Nesse ponto, permanece o questionamento sobre o real impacto da inovação no desempenho do setor financeiro, posto que a literatura ainda traz poucas evidências empíricas de tal relação (Delimatsis, 2012; Gai, Kapadia, Millard \& Perez, 2008; Meng \& Guo, 2013; Mullineux, 2010; Stevens \& Dimitriadis, 2005).

Além disso, outro ponto relevante a ser explorado é a coprodução no setor financeiro, uma vez que a relação de investimento estrutura-se sobre o papel da confiança e os parceiros e clientes redefinem as regras do jogo a partir do momento em que se tornam mais interativos e aumentam as demandas por responsabilidade e transparência (Martovoy, Mention 
\& Torkkeli, 2015; Mende \& Doorn, 2014). Instituições financeiras organizam-se em diversos formatos e mecanismos de cooperação e interação com os demais atores do mercado no intuito de buscar sinergias, economizar esforços e gerar valor para as partes envolvidas. Contudo, de forma similar à inovação, coproduções recentes tiveram impactos negativos no desenrolar da crise, uma vez que acordos entre agências de rating e instituições financeiras de grande porte mascararam os riscos reais embutidos nos empréstimos subprimes (Delimatsis, 2012). A literatura pouco aponta para tais impactos negativos da coprodução, uma vez que os estudos focam nos benefícios e na geração de valor (Martovoy, Mention \& Torkkeli, 2015; Mende \& Doorn, 2014). Nesse âmbito, cabe destacar que há escassez de trabalhos que exploram a coprodução no setor financeiro, e menos ainda que a equacionem com inovação ou desempenho (Boor, Oliveira \& Veloso, 2014; Chen, Tsou \& Ching 2011; Zhaoquan, Chen \& Xiande, 2013). Portanto, tendo como base as lacunas teóricas apresentadas, o presente estudo tem como objetivo caracterizar a relação entre inovação, desempenho e coproducão no setor financeiro brasileiro. Para tal, realizou-se uma análise de conteúdo dos formulários de referência de instituições do setor financeiro brasileiro, listadas na bolsa de valores, no intuito de explorar de forma aprofundada tais relações. Essa análise ocorreu com base na constituição de evidências sobre o impacto da inovação e coprodução no desempenho, bem como na identificação de benefícios, riscos, moderadores e mediadores do processo.

\subsection{Marco Teórico}

O embasamento teórico da presente tese foi extensivamente abordado no capítulo anterior, de forma que aqui estão sumarizados os alicerces conceituais que concernem ao presente estudo. De forma específica, este trabalho visa a explorar de forma aprofundada as seguintes proposições: a coprodução tem relação positiva com a inovação (P3); a inovação tem relação positiva com o desempenho do setor financeiro (P4); e a coprodução tem relação positiva com o desempenho do setor financeiro (P5).

De forma geral, a crise de 2008 impactou significativamente a dinâmica do setor financeiro posto que modificou as estruturas regulatórias e os limites de atuação e aumentou a competitividade e a complexidade das transações financeiras (Caselli, 2010; Delimatsis, 2012; Delimatsis, 2013; Hoffmann, Post \& Pennings, 2013; Hutton \& Lee, 2012; Ozbay, Dinçer \& Hacioglu, 2011; Rossignoli \& Arnaboldi, 2009; Shahrokhi, 2008). Nesse contexto, a literatura divide-se sobre o papel da inovação posto esta ter sido considerada por diversos autores como a raiz da crise ao mesmo tempo em que outras vertentes a consideram o motor do 
desenvolvimento econômico (Bos, Kolari \& Lamoen, 2013; Delimatsis, 2012; Delimatsis, 2013; Frame \& White, 2004; Gai et al., 2008; Hutton \& Lee, 2012; Johnson \& Kwak, 2012; Lenzer \& Zhao, 2012; Mullineux, 2010; Rossignoli \& Arnaboldi, 2009; Tufano, 2003).

A fim de mitigar em parte tal lacuna, o presente trabalho utiliza a abordagem integradora da inovação, derivada da literatura de inovação em serviços, para caracterizar a inovação financeira, definida na literatura de economia como o processo dinâmico e contínuo de criação e disseminação de instrumentos financeiros, tecnologias, instituições e mercados, e que tem como objetivo reduzir riscos e atender demandas específicas dos investidores por padrões particulares de fluxos de caixa (Bos, Kolari \& Lamoen, 2013; Delimatsis, 2012; Delimatsis, 2013; Frame \& White 2004; Mullineux, 2010; Rossignoli \& Arnaboldi, 2009).

No que tange a esse assunto, a abordagem integradora da inovação ganhou destaque na literatura tendo em vista ser a mais promissora em termos de avanço teórico (Gallouj, 2002; Gallouj \& Weinstein, 1997; Gallouj \& Savona, 2009). De acordo com tal perspectiva, um produto ou serviço é caracterizado como um processo composto de vetores de competências, características técnicas, características processuais e entregas, e a inovação é estabelecida a partir do momento que um ou mais desses vetores sofrem modificação, ocorrendo em seis tipos: (1) radical, quando ocorre modificação em todos os vetores componentes; (2) melhoria, quando sucede modificação de elementos dentro de um determinado vetor; (3) incremental, no caso de adição ou eliminação de um determinado vetor; (4) ad hoc, específico para a resolução de um determinado problema baseado em uma interação prestador-cliente; (5) recombinação, quando se modifica a ordem e disposição de elementos e/ou vetores; e (6) formalização, quando há padronização do processo (Djellal \& Gallouj, 2010; Gallouj, 2002; Gallouj \& Weinstein, 1997; Gallouj \& Savona, 2010; Gallouj \& Toivonen, 2011). Ademais, Djellal e Gallouj (2005) estabelecem que a inovação ocorre com base em quatro lógicas: (1) extensiva, quando se tem a adição de vetores; (2) intensiva, quando se adicionam elementos aos vetores existentes; (3) regressiva, quando se eliminam vetores ou elementos; e (4) combinatória, quando se combinam vetores e/ou elementos existentes.

Ao se transpor tal óptica para o setor financeiro, verifica-se um produto ou serviço financeiro ( $\mathrm{Si}$ ) pode ser decomposto na forma de um processo de vetores constituintes $[\mathrm{C}][\mathrm{T}][\mathrm{Z}][\mathrm{Y}]$, onde $[\mathrm{C}]$ são competências, $[\mathrm{T}]$ características técnicas, $[\mathrm{Z}]$ características processuais e [Y] entregas (Djellal \& Gallouj, 2010; Gallouj \& Toivonen, 2011; Gallouj \& Weinstein, 1997).Tal óptica se mostra adequada para caracterização da inovação no setor financeiro uma vez que unifica produtos e serviços sob um modelo comum estruturado em uma lógica de processo, o que confere maior tangibilidade aos instrumentos financeiros e permite 
uma análise mais detalhada do desempenho (Djellal \& Gallouj, 2005; Gallouj \& Savona, 2009; Gallouj \& Weinstein, 1997).

Com base nesse pressuposto, é possível estabelecer um paralelo entre a concepção de desempenho e a abordagem integradora. Sob a perspectiva de desempenho, instituições financeiras entregam produtos e serviços e transferem recursos entre unidades superavitárias e deficitárias (Anthanassopoulos, 1998; Fethi \& Pasiouras, 2010; Sathye, 2001; Soteriou \& Zenios, 1997). Nesse âmbito, o desempenho de uma instituição financeira é normalmente definido como a medida de conversão das entradas em saídas (Charnes, Cooper \& Rhodes, 1978; Farrell, 1957; Kopp, 1981; Leibenstein, 1966), de forma que se argumenta que este pode ser representado como a medida de conversão de $[\mathrm{C}][\mathrm{T}][\mathrm{Z}]$ em [Y], que são as entradas e saídas, respectivamente, no processo de inovação da abordagem integradora.

Finalmente, no que se refere à coprodução, verifica-se que há possibilidade de ampliação do escopo de análise, pois esta permite que a instituição financeira seja caracterizada não apenas com base em fatores intrínsecos, mas também em consequência da interações com toda a rede de parceiros e clientes. Tal fato se justifica visto que a coprodução refere-se a todos os formatos de cooperação e interação entre a organização e seus stakeholders com o intuito de agregar valor (Chen, Tsou \& Ching 2011; Cheung \& To, 2011; Dunston, Lee, Boud, Brodie \& Chiarella, 2009; Ostrom, 1996; Vargo \& Lusch, 2004; Wu \& Lin, 2013) e no setor financeiro as transações são realizadas mediante relações de confiança entre as instituições e os investidores, que contribuem entre si a fim de gerar bem-estar financeiro (Martovoy, Mention \& Torkkeli, 2015; Mende \& Doorn, 2014). Ainda, a coprodução pode ocorrer em cinco tipos (Edvardsson et al., 2010): (1) comprador, quando o cliente ou parceiro é destinatário passivo e não atua sobre o processo de entrega do serviço; (2) objeto de interesse, caracterizado quando o prestador aguarda passivamente o compartilhamento de informações pelos clientes e parceiros; (3) fornecedor de informação, quando o prestador capta ativamente as informações com base em seus relacionamentos; (4) codesenvolvedor, representado no caso de o cliente ou parceiro envolver-se diretamente no processo; e (5) desenvolvedor, quando o cliente ou parceiro assume inteira responsabilidade pelo processo.

No modelo proposto, a coprodução é tradicionalmente representada na forma de interação entre as competências [C] e [C'] no processo de entrega do serviço, gerando inovação sempre que acarretar mudança nos vetores $[\mathrm{C}][\mathrm{T}][\mathrm{Z}]$ e melhoria de $[\mathrm{Y}]$ (Gallouj \& Weinstein, 1997; Gallouj \& Savona, 2009). Contudo, abre-se espaço não apenas para inclusão dos parceiros e demais envolvidos no processo coprodutivo, como também acréscimo de novos elementos e vetores. Portanto, de forma análoga aos vetores do cliente ([C'], [T'] e [Z']), 
sugere-se acrescentar os vetores $\left[\mathrm{C}^{\prime \prime}\right],\left[\mathrm{T}^{\prime \prime}\right]$ e $[\mathrm{Z}$ ''], para caracterizar as competências e características dos parceiros, de forma que no processo a coprodução passa a ser representada na forma da interação entre os vetores $[\mathrm{C}]\left[\mathrm{C}^{\prime}\right]\left[\mathrm{C}^{\prime}\right.$ ']. A Figura 3 sumariza as ideias apresentadas até aqui e propõe um modelo de pesquisa.

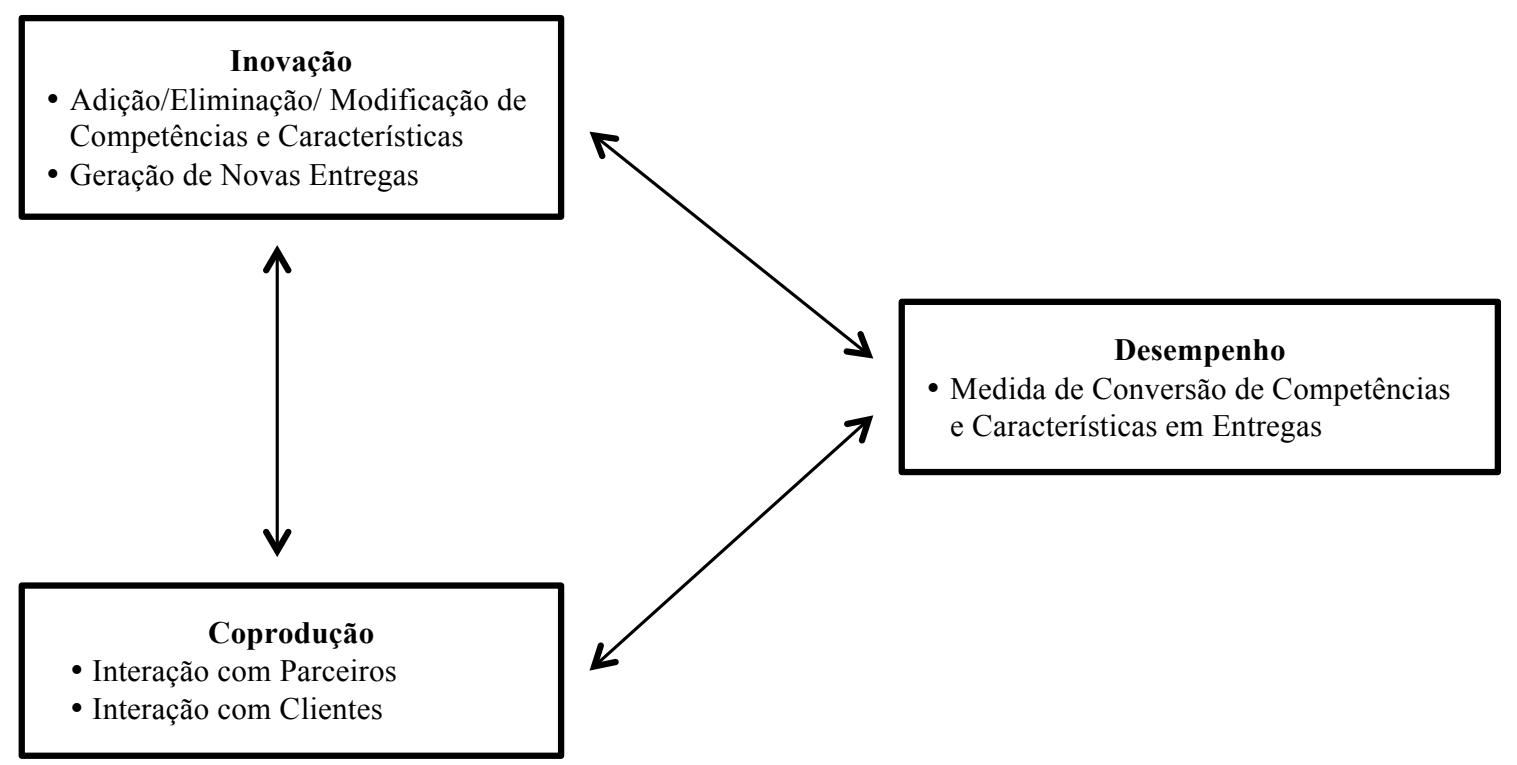

Figura 3. Modelo de pesquisa.

As discussões deste modelo foram debatidas no capítulo anterior, onde se argumentou que as relações estabelecidas entre os três constructos são positivas. De forma sucinta, posto que a inovação represente acréscimo de valor ao vetor [Y] e que o desempenho seja a medida de conversão de $[\mathrm{C}][\mathrm{T}][\mathrm{Z}]$ em $[\mathrm{Y}]$, defende-se que a inovação tem relação positiva com o desempenho, uma vez que a modificação de elementos e vetores para gerar novas entregas tende a otimizar a medida de conversão de entradas em saídas. Tal afirmação encontra respaldo na literatura (Bos, Kolari \& Lamoen, 2013; Delimatsis, 2012; Delimatsis, 2013; Frame \& White 2004; Mullineux, 2010; Rossignoli \& Arnaboldi, 2009). Paralelamente, posto que a coprodução vise também a gerar valor ao vetor [Y], sugere-se que a coprodução tem relação positiva com o desempenho, pois a organização produz mais ao aproveitar sinergias com parceiros e clientes (Edvardsson et al., 2010; Field, Xue \& Hitt, 2012; Lusch, Vargo \& O’Brien, 2007; Martovoy, Mention e Torkkeli, 2015; Mende \& Doorn, 2014).

Finalmente, argumenta-se que a coprodução tem relação positiva com a inovação, uma vez que a mobilização de competências $[\mathrm{C}]\left[\mathrm{C}^{\prime}\right]\left[\mathrm{C}^{\prime \prime}\right.$ '] entre prestadores, parceiros e clientes 
visa a agregar valor à entrega e proporcionar resultados finais (Y) ótimos. Tal fato fundamentase uma vez que a prática de colaboração produz sinergias que induzem à melhoria de processos a partir da introdução de novo conhecimento, além do que a coprodução é capaz de promover inovação (Chen, Tsou e Ching, 2011; Edvardsson et al., 2010; Martovoy, Mention \& Torkkeli, 2015; Ordanini et al., 2011; Wei, Wang, Tao \& Wang, 2006; Zhaoquan, Chen \& Xiande, 2013).

\subsection{Métodos}

O presente trabalho, qualitativo, transversal e de natureza explicativa, utilizou a análise de conteúdo a fim de caracterizar as relações entre inovação, desempenho e coprodução e explorar de forma aprofundada as proposições apresentadas pelo modelo. O nível de análise desta pesquisa é o organizacional, tendo como recorte dados das instituições financeiras listadas na Bolsa de Valores de São Paulo (BMF\&Bovespa). Justifica-se a escolha das companhias abertas visto que são as que apresentam maior impacto no setor e maior volume de atividades, além do que são obrigadas a apresentar informações relevantes de forma padronizada, o que permite análises comparativas mais robustas. Nesse âmbito, entre as 110 instituições elencadas, foram selecionadas aleatoriamente 29 empresas para compor a amostra (Quadro 3).

\begin{tabular}{|c|c|c|}
\hline Empresa & Subsetor & Segmento \\
\hline ABC Brasil & Intermediários Financeiros & Bancos \\
\hline Alfa Holdings & Intermediários Financeiros & Bancos \\
\hline Alfa Investimentos & Intermediários Financeiros & Bancos \\
\hline Banco Daycoval & Intermediários Financeiros & Bancos \\
\hline Banco do Brasil & Intermediários Financeiros & Bancos \\
\hline Banco Indusval & Intermediários Financeiros & Bancos \\
\hline Banco Itaú & Intermediários Financeiros & Bancos \\
\hline Banco PAN & Intermediários Financeiros & Bancos \\
\hline Banco Patagônia & Intermediários Financeiros & Bancos \\
\hline Banco PINE & Intermediários Financeiros & Bancos \\
\hline Banpará & Intermediários Financeiros & Bancos \\
\hline Bradesco & Intermediários Financeiros & Bancos \\
\hline Aliansce & Exploração de Imóveis & Exploração de Imóveis \\
\hline BR Properties & Exploração de Imóveis & Exploração de Imóveis \\
\hline Cyrela & Exploração de Imóveis & Exploração de Imóveis \\
\hline General Shopping & Exploração de Imóveis & Exploração de Imóveis \\
\hline Iguatemi & Exploração de Imóveis & Exploração de Imóveis \\
\hline Sonae Sierra Brasil & Exploração de Imóveis & Exploração de Imóveis \\
\hline
\end{tabular}




\begin{tabular}{|c|c|c|}
\hline BTG Pactual & Serviços Financeiros Diversos & Gestão de Recursos e Investimentos \\
\hline GP Investiments & Serviços Financeiros Diversos & Gestão de Recursos e Investimentos \\
\hline Bahema & Holdings Diversificadas & Holdings Diversificadas \\
\hline Bradespar & Holdings Diversificadas & Holdings Diversificadas \\
\hline Habitasul & Holdings Diversificadas & Holdings Diversificadas \\
\hline Monteiro Aranha & Holdings Diversificadas & Holdings Diversificadas \\
\hline Brasil Insurance & Previdência e Seguros & Seguradoras \\
\hline Sul America & Previdência e Seguros & Seguradoras \\
\hline BM\&FBovespa & Serviços Financeiros Diversos & Serviços Financeiros Diversos \\
\hline Cetip & Serviços Financeiros Diversos & Serviços Financeiros Diversos \\
\hline Cielo & Serviços Financeiros Diversos & Serviços Financeiros Diversos \\
\hline
\end{tabular}

Quadro 3. Amostra de Pesquisa.

O documento selecionado para compor a análise foi o Formulário de Referência, principal informe de comunicação e de prestação de contas da companhia a todos os públicos alvos, onde estão reunidas informações como atividades desenvolvidas, estrutura de controle, fatores de risco, dados econômico-financeiros, comentários dos administradores sobre o desempenho, políticas e práticas de governança corporativa e descrição da composição e da remuneração de sua administração. Para cada empresa foi levantado Formulário de Referência referente ao ano de 2015, que dispõe sobre as atividades realizadas no triênio anterior (20122014). Cabe ressaltar que este documento é publicado anualmente pelas empresas, de forma padronizada, de acordo com as normas da CVM.

O instrumento de coleta de dados foi o protocolo validado pelo Núcleo de Estudos em Inovação e Estratégia (NINE-UnB) para análise de dados secundários (Anexo 1). Tal instrumento foi construído para padronizar e validar a coleta de informações a partir de dados secundários, e propõe uma forma de categorização dos constructos de interesse por meio da especificação dos constructos, definições, referências, forma de detecção e identificação no texto e palavras-chave. Dessa forma, a inovação foi decomposta em duas dimensões: tipos radical, melhoria, incremental, adhoc, recombinação e formalização (Gallouj \& Weinstein, 1997); e lógicas - extensiva, intensiva, regressiva e de combinação (Djellal \& Gallouj, 2005). Paralelamente, a coprodução foi operacionalizada em função do coprodutor (coprodução com parceiros - B2B, com clientes - B2C e com parceiros e clientes - B2BC), bem como em função dos tipos desenvolvedor, codesenvolvedor e provedor de informação (Edvardsson et al., 2010). Os demais tipos (comprador e objeto de interesse) não foram considerados, uma vez que não implicam necessariamente em uma relação coprodutiva. Ainda, o desempenho de cada empresa foi classificado tendo como base os investimentos, lucros, prejuízos e impactos positivos e 
negativos no período, tendo como base as inovações e coproduções implantadas e a otimização da medida de conversão de insumos em produtos e serviços. A coleta de dados foi realizada no período de maio a junho de 2016.

A análise dos dados foi elaborada por meio da análise de conteúdo conforme (Bardin, 2011) veiculada por meio do software de análise qualitativa NVivo, e envolveu as seguintes fases: (1) pré-análise, (2) exploração do material e (3) tratamento dos resultados, inferência e interpretação. A análise de conteúdo é um conjunto de técnicas de análise das comunicações que utiliza procedimentos sistemáticos e objetivos de descrição do conteúdo das mensagens (Bardin, 2011). A pré-análise é a fase que tem como objetivo operacionalizar e sistematizar as ideias iniciais de maneira a conduzir a um esquema preciso do desenvolvimento das operações sucessivas em um plano de análise (Bardin, 2011). Essa fase é subdividida em cinco etapas: (a) leitura flutuante; (b) escolha dos documentos; (c) formulação de hipóteses; (d) referenciação dos índices e formulação de indicadores; e (e) preparação do material.

Dessa forma, a leitura flutuante iniciou-se após o levantamento de todos os documentos e informes publicados pelas companhias de capital aberto, bem como o mapeamento das informações e categorias de informações disponibilizadas em cada tipo de documento. A escolha dos documentos se deu posto que o Formulário de Referência consolidava de forma organizada e padronizada todos os demais informes textuais da companhia. Na sequência, a formulação de hipóteses ocorreu a partir da literatura e do modelo proposto no ensaio teórico com a respectiva identificação das porções dos Formulários de Referência que continham informações relacionadas aos constructos sob análise. Ademais, a referenciação dos índices e indicadores verificou-se com base nas palavras-chave do protocolo de análise, bem como nos sinônimos e outras palavras-chave identificadas. Finalmente, a etapa de preparação do material envolveu a compilação de todos os documentos relativos a cada empresa e levantamento no software NVivo.

A segunda fase da análise, a exploração do material, representa a administração sistemática das decisões tomadas e consiste essencialmente de operações de codificação, desconto e enumeração em função de regras previamente formuladas (Bardin, 2011). Nesse contexto, o software NVivo permitiu a importação dos documentos e codificação dos constructos de acordo com as palavras-chave listadas no protocolo, utilizando ferramentas de indexação e busca de palavras. Dessa forma, foi possível isolar as evidências e indícios de inovação e coproducão dos formulários de referência e fazer o refinamento. Com base em tais indícios, construiu-se uma base de dados que dispôs de forma ordenada cada evidência da seguinte forma: (1) inovação - empresa, evidência, finalidade, tipo, lógica, relação com 
coprodução, relação com desempenho e observações; e (2) coprodução - empresa, evidência, agrupador, coprodutor, tipo, relação com inovação, relação com desempenho e observações. Nesse contexto, os dados de entrada foram as evidências mapeadas com base nas palavraschave, enquanto os dados de saída foram as categorias de análise listadas no protocolo. A construção e organização de tais dados permitiu a realização de análises comparativas baseadas em evidências.

A última fase da análise de conteúdo é o tratamento dos resultados e intepretação, e se baseia na ideia de validação dos dados coletados (Bardin, 2011). Dessa maneira, os dados categorizados foram refinados e para cada evidência isolaram-se os elementos que compõem o processo, bem como destacaram-se as relações positivas e negativas e os fatores que impactam tais relações. Com base nisso, realizaram-se as interpretações e inferências, tendo em vista a totalidade dos dados e as comparações entre empresas e as categorias de análise. Finalmente, os resultados inferidos serviram de base para responder às proposições formuladas tendo como base o modelo teórico proposto.

\subsection{Resultados e Discussão}

Os resultados encontrados possibilitam a investigação das proposições derivadas do modelo (Fig. 3), tendo como suporte a evidenciação dos constructos de inovação, coprodução e desempenho. Nesse âmbito, primeiramente apresenta-se a descrição geral dos dados e, em seguida, são exploradas de forma aprofundada as relações entre inovaçãodesempenho, coprodução-desempenho e inovação-coprodução.

\subsubsection{Descrição Geral dos Dados}

A Tabela 1 consolida o número de indícios de inovação e coprodução mapeados para cada empresa da amostra. 


\begin{tabular}{|c|c|c|}
\hline Empresa & Inovações & Coproduções \\
\hline Banco Patagônia & 37 & 24 \\
\hline Banco Itaú & 31 & 25 \\
\hline BMF\&BOVESPA & 27 & 15 \\
\hline Cielo & 25 & 7 \\
\hline Sul América & 24 & 9 \\
\hline Aliansce & 23 & 17 \\
\hline BTG Pactual & 20 & 12 \\
\hline Banpará & 19 & 13 \\
\hline Bradesco & 19 & 23 \\
\hline Cetip & 18 & 6 \\
\hline Banco Daycoval & 17 & 9 \\
\hline Banco do Brasil & 16 & 31 \\
\hline Banco Indusval & 15 & 12 \\
\hline Banco PAN & 13 & 9 \\
\hline Cyrela & 13 & 14 \\
\hline BR Properties & 11 & 7 \\
\hline General Shopping & 11 & 5 \\
\hline Bradespar & 10 & 4 \\
\hline Sonae Sierra Brasil & 10 & 13 \\
\hline Brasil Insurance & 7 & 7 \\
\hline Habitasul & 7 & 9 \\
\hline ABC Brasil & 6 & 7 \\
\hline Banco PINE & 5 & 8 \\
\hline Iguatemi & 5 & 1 \\
\hline Alfa Holdings & 3 & 5 \\
\hline Alfa Investimentos & 3 & 3 \\
\hline GP Investiments & 3 & 4 \\
\hline Bahema & 1 & 2 \\
\hline Monteiro Aranha & 1 & 2 \\
\hline Total & 400 & 303 \\
\hline
\end{tabular}

Tabela 1.Quantidade de indícios de inovações e coproduções de cada empresa da amostra.

De forma específica, no que se refere aos tipos e lógicas de inovação (Tabela 2), verifica-se que na amostra há predominância de indícios de inovações do tipo radical, incremental e melhoria sobre as demais. Isso se justifica tendo em vista que inovações do tipo adhoc, recombinação e formalização envolvem a criação de vetores e o acréscimo de elementos, de modo que são primeiramente classificadas nos três primeiros tipos, o que sugere que tais tipos seriam na verdade um subtipo das demais. Tal fato é pouco explorado no âmbito da literatura, que considera os três últimos tipos como formatos especializados, enquanto os primeiros seriam mais abrangentes (Gallouj \& Savona, 2009; Gallouj \& Weinstein, 1997). De forma semelhante, a maior parte das inovações segue uma lógica extensiva, que vai ao encontro 
dos tipos mapeados (Djellal \& Gallouj, 2005), posto que inovações radicais e incrementais tendem a seguir a lógica extensiva (acréscimo de elementos), inovações de melhoria são reflexos da lógica incremental (melhoria de elementos) e as lógicas regressivas e combinatórias, nesse contexto, são apenas residuais.

\begin{tabular}{|c|c|}
\hline Tipos & Porcentagem \\
\hline Radical & $30 \%$ \\
\hline Incremental & $37 \%$ \\
\hline Melhoria & $22 \%$ \\
\hline Adhoc & $3 \%$ \\
\hline Recombinação & $3 \%$ \\
\hline Formalização & $5 \%$ \\
\hline Lógicas & Porcentagem \\
\hline Extensiva & $70 \%$ \\
\hline Intensiva & $25 \%$ \\
\hline Regressiva & $4 \%$ \\
\hline Combinatória & $1 \%$ \\
\hline
\end{tabular}

Tabela 2. Porcentagem de tipos e lógicas de inovação mapeadas.

De forma paralela, buscou-se acessar o panorama geral dos indícios de coprodução na amostra (Tabela 3), tendo como base o coprodutor e os tipos de coproducão, conforme Edvardsson et al. (2010). No geral, observa-se que há prevalência de indícios de coproduções do tipo codesenvolvedor, onde os atores estabelecem uma relação de troca e atuam em igualdade de papéis. Na sequência, a quantidade de coproduções do tipo provedor de informação é, em grande parte, reflexo das normas e regulamentos que dispõem sobre a obrigatoriedade de transparência e divulgação de informações das sociedades de capital aberto. Por fim, o tipo desenvolvedor é resultante das diversas contratações e delegações de atividades a terceiros e coligadas. Adicionalmente, a dimensão B2B foi predominante, o que indica que, no âmbito do setor financeiro, as organizações têm tendência a estabelecer relacionamentos com parceiros mais que com clientes, o que está de acordo com a literatura, que afirma que, em grande maioria, as relações coprodutivas do setor financeiro ocorrem entre parceiros de negócio (Martovoy, Mention \& Torkkeli, 2015; Mende \& Doorn, 2014). 


\begin{tabular}{|c|c|}
\hline Tipos & Porcentagem \\
\hline Provedor de Informação & $14 \%$ \\
\hline Codesenvolvedor & $77 \%$ \\
\hline Desenvolvedor & $9 \%$ \\
\hline Dimensão & Porcentagem \\
\hline B2B & $63 \%$ \\
\hline B2C & $32 \%$ \\
\hline B2BC & $5 \%$ \\
\hline
\end{tabular}

Tabela 3.Tipos e dimensões de coproduções mapeadas.

Os dados elencados nas tabelas acima não possuem rigor estatístico ou validade quantitativa tendo em vista este não ser o foco do presente estudo, mas, sim, servem para ilustrar o panorama geral dos indícios levantados na análise. Nos próximos subtópicos tais dados são explorados de forma aprofundada tendo como base os relatos das empresas e as evidências mapeadas.

\subsubsection{Inovação e Desempenho}

No que tange à relação entre inovação e desempenho, cabe destacar que para as empresas do setor financeiro o conceito de inovação está relacionado apenas a inovações radicais estruturadas, que acarretam grandes mudanças para a organização. Tal fato se distancia da literatura, posto que os estudos sobre o tema considerem a inovação de forma mais ampla (Gallouj \& Savona, 2009). Entretanto, tendo como base a abordagem integradora da inovação, foi possível mapear os indícios de forma abrangente, tendo como base palavras-chave como novo, novidade, implantação, melhoria, combinação, solução de problema, padronização e especialização, dentre outras.

Inicialmente, as evidências de inovações foram categorizadas de acordo com suas finalidades e respectivos exemplos (Quadro 4), o que fornece insumos sobre os motivadores da inovação no âmbito do setor financeiro brasileiro. Os dados estão dispostos de acordo com a ordem decrescente de aparição nos relatos da empresa.

\section{Finalidades da Inovação}

Desenvolvimento de Novos Produtos e Serviços

\section{Exemplos}

Novos instrumentos financeiros, novos mecanismos de captação, novas modalidades de crédito, novas tecnologias de pagamento e atendimento 


\begin{tabular}{|c|c|}
\hline Melhoria de Processos & $\begin{array}{l}\text { Novos sistemas de gerenciamento, reestruturação da } \\
\text { companhia, melhoria de controles, revisão de políticas } \\
\text { e procedimentos, formalização de processos, melhoria } \\
\text { contínua e auditoria, adesão a acordos e normas }\end{array}$ \\
\hline Melhoria de Produtos e Serviços & $\begin{array}{c}\text { Expansão do portfólio, incremento dos instrumentos } \\
\text { financeiros, melhoria em pagamentos e cobranças, } \\
\text { melhoria no atendimento, customização e } \\
\text { especialização }\end{array}$ \\
\hline $\begin{array}{c}\text { Relacionamentos (Acordos, Convênios, Aquisições, } \\
\text { Parcerias) }\end{array}$ & $\begin{array}{l}\text { Fortalecimento de relacionamentos, estreitamento da } \\
\text { relação com o cliente, melhoria no atendimento, } \\
\text { fusões, aquisições, joint ventures }\end{array}$ \\
\hline Projetos e Empreendimentos Imobiliários & $\begin{array}{c}\text { Novos empreendimentos mobiliários, novas agências, } \\
\text { expansão da infraestrutura, revitalização das } \\
\text { instalações }\end{array}$ \\
\hline Práticas de Sustentabilidade Empresarial & $\begin{array}{l}\text { Projetos sociais, melhoria da eficiência energética, } \\
\text { incentivo ao esporte e à cultura, acordos de proteção } \\
\text { ambiental, crédito sustentável, }\end{array}$ \\
\hline Melhoria da Força de Trabalho & $\begin{array}{c}\text { Pesquisas salariais e de melhores práticas, capacitação } \\
\text { e treinamento, programa de qualidade de vida no } \\
\text { trabalho, bolsas de estudo }\end{array}$ \\
\hline Investimentos em TI & $\begin{array}{l}\text { Desenvolvimento e atualização de softwares, agências } \\
\text { digitais, atualização das bases de dados }\end{array}$ \\
\hline Planos, Políticas e Estratégias & $\begin{array}{c}\text { Práticas de governança corporativa, planos de } \\
\text { contingência e continuidade, política de divulgação, } \\
\text { adesão a acordos internacionais }\end{array}$ \\
\hline
\end{tabular}

Quadro 4. Finalidades da inovação no setor financeiro brasileiro.

Dessa forma, observa-se que as instituições financeiras brasileiras inovam principalmente para desenvolver novos produtos e serviços e incrementar e melhorar produtos, serviços e processos existentes. Adicionalmente, as empresas inovam para estabelecer e/ou estreitar relacionamentos com parceiros e clientes, expandir a infraestrutura, investir em práticas socioambientais e melhorar a força de trabalho. Ainda, as empresas citaram que investem no desenvolvimento de tecnologias da informação e comunicação e no estabelecimento de planos, políticas e estratégias. Com base em tais dados observa-se que no geral as instituições financeiras investem em iniciativas inovadoras a fim de se obter a melhoria de desempenho planejada, o que vai ao encontro do proposto pela literatura, uma vez que diversos trabalhos destacam que as inovações possuem impacto positivo no desempenho (Bos, Kolari \& Lamoen, 2013; Delimatsis, 2012; Delimatsis, 2013; Frame \& White 2004; Mullineux, 2010; Rossignoli \& Arnaboldi, 2009).

Entretanto, o sucesso da inovação depende de uma série de fatores, tal como destacado pelo relato abaixo da BM\&FBovespa:

Pretendemos continuar a explorar e buscar oportunidades estratégicas para fortalecer nosso negócio e expandir nossa companhia, o que pode nos ajudar a penetrar em novos mercados, oferecer novos produtos e serviços, e desenvolver nossos sistemas de negociação e tecnologias. Podemos fazer 
aquisições ou investimentos ou estabelecer parcerias estratégicas, joint ventures ou alianças, sendo que não há qualquer garantia de que nossos esforços terão sucesso. Nós podemos não ter sucesso na identificação de oportunidades de crescimento e outros benefícios de iniciativas ou alianças estratégicas de crescimento que tivermos feito ou faremos no futuro, assim como na identificação de ameaças à nossa posição ou projeção de posição nos mercados em que atuamos, nos âmbitos nacional ou internacional. Podemos incorrer em gastos significativos para endereçar as eventuais necessidades operacionais adicionais do nosso crescimento, as quais podem vir a ter um impacto adverso na nossa condição financeira e em nossos resultados operacionais. Internamente, podemos não responder adequadamente à implementação dos objetivos e projetos estratégicos, devido às falhas no processo de tomada de decisão, dificuldades operacionais e contratação de terceiros inadequados para a prestação do serviço.

Observa-se, portanto, que a inovação parte de um investimento inicial que objetiva gerar um retorno positivo na forma de resultado para a companhia. Tais esforços demandam capital intensivo e estão programados para períodos de tempo em desenvolvimento antes que possam começar a gerar receita. Dessa forma, a habilidade de financiar tais inovações, arcar com dispêndios de capital e outras despesas operacionais e administrar o endividamento depende da capacidade de geração de caixa futuro e da obtenção de capital a custos e termos razoáveis. As inovações exigem processos de integração de redes, sistemas, planejamento financeiro, elaboração de relatórios, produtos, serviços e clientes, o que acarreta custos operacionais e demandas adicionais para a administração. Tais informações são pouco exploradas na literatura posto que poucos estudos têm como foco caracterizar o processo de inovação no setor financeiro (Meng \& Guo, 2013), de forma que maior atenção a tais elementos determinantes, facilitadores e barreiras à inovação poderiam ser melhor elucidados.

Ainda, as companhias destacaram que a inovação as coloca em contato, direta ou indiretamente, com indivíduos e instituições que não estão entre seus tradicionais clientes e contrapartes, expondo-os a novas classes de ativos e a novos mercados. Tais atividades podem expor a companhia a novos riscos, incluindo aqueles associados à negociação junto a órgãos governamentais, preocupação em relação à reputação, maior sujeição regulatória sobre as atividades e aumento dos riscos de crédito, soberano e operacional. Estas afirmações estão alinhadas com os estudos que ressaltam que a inovação está relacionada à fragilidade financeira (Delimatsis, 2012; Gai, Kapadia, Millard \& Perez, 2008; Johnson \& Kwak, 2012). Contudo, mesmo em face dos riscos e custos, as companhias continuam a explorar e buscar oportunidades estratégicas de fortalecimento do negócio e expansão, com o objetivo de penetrar em novos mercados, oferecer novos produtos e serviços, e desenvolver tecnologias e sistemas. 
Ressalta-se que, nesse âmbito, o desempenho futuro dependerá da capacidade de gerenciar tais mudanças, visto que o sucesso da companhia depende da administração bemsucedida da expansão, manutenção e projeção das posições de mercado, identificação de oportunidades de crescimento, benefícios de iniciativas, alianças estratégicas, tempo exigido para o desenvolvimento de novos projetos, melhorias e retorno sobre o capital investido. Desse modo, as empresas destacam que é necessária agilidade e eficiência no gerenciamento da inovação, visto que solidez, flexibilidade e experiência da administração permitem tirar proveito de oportunidades de mercado de forma ágil e com eficiência de custos, sempre observando rígidos critérios de retorno e exposição a risco. Tais informações resgatam insumos do debate sobre o impacto da inovação no desempenho (Delimatsis, 2012) e demonstram em parte como as empresas lidam com os impactos positivos e negativos da inovação.

O Quadro 5 abaixo consolida os principais fatores destacados que atuam como mediadores e moderadores da relação entre inovação e desempenho e fornece insumos para discussão.

\begin{tabular}{|l|l|}
\hline \multicolumn{1}{|c|}{ Internos } & \multicolumn{1}{c|}{ Externos } \\
\hline Experiência da administração & Crescimento econômico do país \\
\hline Solidez e flexibilidade da estrutura organizacional & Liquidez dos mercados e nível de inadimplência \\
\hline Monitoramento contínuo do mercado & Inflação, taxa de juros e Preços dos ativos \\
\hline Análise de viabilidade prévia & Alterações da regulamentação \\
\hline Adaptação tempestiva ao mercado de atuação & Concorrentes e fatores competitivos \\
\hline Tomada de decisão & Preferências do consumidor \\
\hline Acompanhamento e Controle dos Processos & Novos modelos de negócio e novas tecnologias \\
\hline
\end{tabular}

Quadro 5. Fatores que Impactam o Sucesso da Inovação.

Verifica-se que os fatores internos possuem efeito mediador na relação posto que sejam capazes de modificar a magnitude da relação e são determinantes do processo. Tais elementos são pouco explorados pela literatura uma vez que há escassez de estudos que caracterizam o processo de inovação no setor financeiro (Delimatsis, 2012; Gai, Kapadia, Millard\& Perez, 2008; Meng \& Guo, 2013; Mullineux, 2010; Stevens \& Dimitriadis, 2005). De forma geral, o que se observou nas evidências é que tais elementos são essenciais para o sucesso da inovação, de forma que as companhias devem considerá-los em quaisquer etapas de planejamento a fim de maximizar os benefícios da inovação. Por outro lado, no que tange aos fatores externos, observa-se que estes vão ao encontro da literatura, uma vez que as variáveis destacadas nos relatos estão alinhadas com os elementos que ditam a dinâmica do setor, a saber: 
regulação, indefinição e redesenho das fronteiras, dinamismo e complexidade, competitividade, inovações tecnológicas e demandas de mercado (Blazevic \& Lievens 2004; Caselli, 2010; Delimatsis, 2013; Hoffmann, Post \& Pennings, 2013; Rossignoli \& Arnaboldi, 2009; Shahrokhi, 2008; Stevens \& Dimitriadis, 2005). Tais fatores são apontados pelas empresas como moderadores do processo uma vez que podem modificar a direção e a força da relação. Tais informações servem para elucidar em parte o debate da literatura acerca do real impacto da inovação sobre o desempenho (Delimatsis, 2012), uma vez que traz novos elementos para discussão. Eles reforçam a ideia de que a relação entre inovação e desempenho é mediada por fatores internos e moderada por fatores externos à organização.

De forma geral, os relatos das empresas permitiram inferir que no contexto considerado a inovação tende a apresentar impacto positivo no desempenho, posto que as companhias de capital aberto apresentem maturidade administrativa ao mesmo tempo que possuem grandes volumes de capital, o que confere a elas maior flexibilidade para assumir riscos e inovar. De forma específica, as empresas relataram que a inovação é resultado de esforços constantes na identificação de novos ramos de negócios que possam maximizar e otimizar o uso da rede e dos ativos existentes, e busca a criação de valor para o acionista por meio do crescimento, da diversificação de receita em negócios e de maior eficiência operacional, o que está de acordo com trabalhos da área (Delimatsis, 2012; Mullineux, 2010; Rossignoli \& Arnaboldi, 2009). Nesse âmbito, o Quadro 6 consolida os principais benefícios da inovação destacados pelas empresas.

\begin{tabular}{|l|}
\hline Inovações são investimentos estratégicos que impactam o resultado operacional da companhia \\
\hline Investimentos em novos projetos, expansões e aquisições são parte da estratégia de crescimento da empresa \\
\hline A capacidade de reestruturação e remodelação da companhia impacta diretamente a capacidade de gerar lucros \\
\hline Inovações geram melhoria de eficiência, otimizam as operações e diversificam as receitas \\
\hline Inovações têm como objetivo manter a agilidade, qualidade, controle de riscos e segurança das operações \\
\hline Inovações expandem o escopo de atuação da companhia \\
\hline Inovações promovem praticidade, melhoria no atendimento e rentabilização da base de clientes \\
\hline O uso intensivo de tecnologias contribui para o aumento das vendas de produtos e serviços \\
\hline Novos instrumentos financeiros contribuem para o aumento da captação \\
\hline Desenvolvimento contínuo, expansão e implementação de projetos gera crescimento sólido e sustentável \\
\hline Melhoria contínua gera mais estabilidade, melhor alocação do capital e otimização da relação risco-retorno \\
\hline Reavaliação periódica visa aderência dos instrumentos aos requisitos regulatórios e melhores práticas \\
\hline Melhoria de instrumentos financeiros está diretamente relacionado a um aumento proporcional das receitas \\
\hline Quadro 6. Benefícios da inovação no setor financeiro.
\end{tabular}


As evidências mapeadas não indicaram os impactos negativos da relação, mas sim apenas apontaram para os riscos inerentes ao processo. Tal fato pode se dar em virtude do fato de que as empresas evitarem externalizar desempenhos negativos no intuito de não afastar investidores e gerar perda de valor. De qualquer sorte, as companhias enfatizaram os benefícios da inovação, e, em sua maioria, ressaltaram que, vencidos os riscos e por meio de planejamentos estruturados, a inovação gera impacto positivo no desempenho. Tal afirmação explica o grande número de estudos que defendem que a inovação está atrelada ao desenvolvimento econômico (Bos, Kolari \& Lamoen, 2013; Delimatsis, 2012; Delimatsis, 2013; Frame \& White, 2004; Johnson \& Kwak, 2012; Lenzer \& Zhao, 2012; Rossignoli \& Arnaboldi, 2009; Tufano, 2003), uma vez que as grandes empresas tendem a apresentar resultados positivos derivados da inovação, pois, caso contrário, não teriam sobrevivido no mercado. O relato do Banco Daycoval abaixo exemplifica esse fenômeno:

\footnotetext{
A companhia acredita que a solidez e flexibilidade de sua estrutura operacional, aliada à experiência de sua administração, têm permitido desenvolver novos produtos e tirar proveito de oportunidades de mercado de forma ágil e com eficiência de custos, sempre observando rígidos critérios de retorno e exposição a risco.
}

Depreende-se das evidências levantadas que no setor financeiro a inovação é um investimento planejado, de forma similar a qualquer outro investimento realizado pela companhia. Trata-se de uma mudança que objetiva gerar retorno a partir de um capital inicial, e tal fato é corroborado em diversos relatos extraídos dos formulários de referência das empresas. Com base nisso, argumenta-se que, mesmo face aos riscos, capital e demandas de planejamento, a inovação no setor financeiro tem relação positiva com o desempenho, o que está de acordo com o proposto por diversos autores na literatura (Bos, Kolari \& Lamoen, 2013; Delimatsis, 2012; Delimatsis, 2013; Djellal \& Gallouj, 2010; Frame \& White 2004; Gallouj \& Toivonen, 2011; Gallouj \& Weinstein, 1997; Mullineux, 2010; Rossignoli \& Arnaboldi, 2009).

\subsubsection{Coprodução e Desempenho}

O Quadro 7 consolida os principais formatos de coprodução mapeados combase nas evidências, dispostos em ordem decrescente de aparição nos relatos das empresas, ou seja, alianças e parcerias estratégicas foram os mais citados, enquanto terceirização de atividades e eventos foram os menos citados. Tal classificação representa a categorização ex post realizada e fornece insumos relevantes para discussão. 


\begin{tabular}{|l|}
\hline Alianças e Parcerias Estratégicas/ joint Ventures \\
\hline Atendimento ao Cliente e Investidores \\
\hline Práticas de Sustentabilidade Empresarial \\
\hline Divulgação de Informações \\
\hline Acordos e Convênios Imobiliários \\
\hline Relacionamento com Sindicatos \\
\hline Participações Societárias em Empresas \\
\hline Fusões e Aquisições \\
\hline Relacionamento com Correspondentes \\
\hline Relacionamento com Governo \\
\hline Acordos de Investimento/ Acordos de Acionistas \\
\hline Consultoria \\
\hline Terceirização de Atividades \\
\hline Eventos \\
\hline
\end{tabular}

Quadro 7. Formatos de Coprodução no Setor Financeiro.

Percebe-se que a maioria dos relacionamentos coprodutivos do setor financeiro se dá entre instituições e parceiros de negócio, sendo que alguma atenção é dada ao estreitamento da relação com o cliente, bem como com governo e sociedade de forma geral. Tais evidências ilustram o grau de interatividade no setor, uma vez que transações financeiras se baseiam na questão do relacionamento e confiança entre instituições e investidores com o intuito de promover desenvolvimento econômico (Martovoy, Mention \& Torkkeli, 2015; Mende \& Doorn, 2014). Contudo, de forma similar à inovação, verifica-se que o sucesso da coprodução está atrelado a uma série de fatores, tal como destacado abaixo no relato do Banco Itaú:

Como parte da nossa estratégia de crescimento no setor financeiro do Brasil e da América Latina, temos realizado uma série de fusões, aquisições e parcerias com outras empresas e instituições financeiras no passado e podemos procurar por novas operações dessa natureza no futuro. No entanto, qualquer um desses negócios envolve certos riscos, como por exemplo, a possibilidade de incorrermos em custos não esperados dada a dificuldade de integrarmos as plataformas de sistemas, finanças, contabilidade e pessoas ou a ocorrência de contingências não previstas. Ademais, as sinergias operacionais e financeiras e outros benefícios decorrentes das operações podem não ser alcançados.

No que tange a esse aspecto, há evidências de que diversos fatores impactam diretamente o processo de coprodução (Quadro 8). 


\begin{tabular}{|l|}
\hline Internos \\
\hline Proposta de valor agregado \\
\hline Estratégias consistentes e complementares \\
\hline Análise de viabilidade com pesquisas de mercado \\
\hline Identificação de oportunidades de crescimento, benefícios e ameaças da coprodução \\
\hline Alinhamento na execução \\
\hline Envolvimento dos Parceiros \\
\hline Externos \\
\hline Demandas dos clientes \\
\hline Movimentos de mercado \\
\hline Mudanças regulatórias \\
\hline Restrições ao Crédito \\
\hline Fatores Macroeconômicos \\
\hline
\end{tabular}

Quadro 8. Principais fatores que impactam a coprodução no setor financeiro.

Com base nestes dados, o que se observa no setor financeiro é que diversas variáveis possuem impacto sobre a relação entre coprodução e desempenho. A grande maioria das empresas destacou que quaisquer iniciativas de coprodução demandam um planejamento estruturado e detalhado e que fatores como proposta de valor, análise de viabilidade, sinergia e alinhamento na execução e envolvimento dos parceiros são elementos essenciais para o sucesso do empreendimento. Estes dados fornecem indícios de que os fatores internos são variáveis explicativas da inovação, posto que a mesma não possa ocorrer na ausência deles, e dessa forma devem ser considerados quando do planejamento da coprodução. Tais elementos são pouco considerados na literatura visto que há escassez de estudos que caracterizam o processo de coprodução no setor financeiro (Akamavi, 2005; Boor, Oliveira \& Veloso, 2014; Chen, Tsou \& Ching 2011; Edvardsson et al.; 2010; Martovoy, Mention \& Torkkeli, 2015; Mende \& Doorn, 2014; Zhaoquan, Chen \& Xiande, 2013). Ainda, de forma semelhante à inovação, os fatores externos estão alinhados com as variáveis que impactam a dinâmica do setor (Blazevic \& Lievens 2004; Caselli, 2010; Delimatsis, 2013; Hoffmann, Post \& Pennings, 2013; Rossignoli \& Arnaboldi, 2009; Shahrokhi, 2008; Stevens \& Dimitriadis, 2005), com maior destaque para os fatores macroeconômicos, regulação e demandas de mercado e menos enfoque para as novas tecnologias. Tais dados reforçam a ideia de que a coprodução é explicada com base em outras variáveis, e que sua relação com o desempenho é moderada por fatores externos.

Ademais, as evidências destacaram diversos riscos inerentes ao processo, bem como os impactos negativos da coprodução. Tal fato está exemplificado no relato abaixo do Banco Pan: 
A Companhia pode ficar exposta ao risco de contrapartes no setor de serviços financeiros no curso normal das atividades. Essa exposição ao risco pode se originar de negociação, concessão de crédito, captação de depósitos, compensação e liquidação, entre outras atividades e relacionamentos. Entre tais contrapartes estão corretoras e operadores, bancos comerciais, bancos de investimento, fundos mútuos e outros clientes institucionais. Esses relacionamentos expõem a Companhia ao risco de crédito em caso de inadimplemento de uma contraparte. Ademais, o risco de crédito da Companhia poderá ser intensificado quando a garantia detida não puder ser efetivada ou for liquidada a preços não suficientes para recuperar o montante integral do crédito ou derivativo devido à Companhia. Muitas das operações de hedging e outras estratégias de gestão de risco utilizadas pela Companhia envolvem operações com contrapartes de serviços financeiros. Qualquer deficiência ou insolvência dessas contrapartes poderá prejudicar a eficácia das operações de hedging e outras estratégias de gestão de risco.

No que tange a esse aspecto, há evidências de diversos riscos atrelados ao processo de coprodução, e que estes podem causar danos à reputação e gerar uma percepção negativa da instituição por parte de clientes, contrapartes, acionistas, investidores, supervisores, parceiros comerciais e outros públicos, como o não cumprimento de obrigações legais, vendas irregulares para clientes, envolvimento com fornecedores externos com postura ética questionável, vazamento de informações de clientes, má conduta de colaboradores e falhas na gestão de riscos. Além disso, algumas ações significativas, tomadas por terceiros, como concorrentes ou outros participantes do mercado, podem, indiretamente, abalar a reputação perante clientes, investidores e o mercado em geral. Finalmente, as companhias destacam que danos à reputação podem afetar, adversamente e de maneira relevante, os negócios e clientes em potencial. $\mathrm{O}$ Quadro 9 abaixo consolida os principais riscos atrelados ao processo de coprodução citados pelas companhias.

\begin{tabular}{l}
\hline Coproduções envolvem exposição a novos riscos e responsabilidades relativas a contingências \\
\hline Resultados negativos de parceiros e coligadas podem impactar negativamente os resultados da companhia \\
\hline Coproduções com parceiros podem restringir a capacidade de celebrar acordos com outros parceiros \\
\hline Interesses divergentes no relacionamento podem comprometer a implantação das estratégias e o sucesso \\
\hline Problemas no relacionamento coprodutivo podem comprometer a imagem e a relação com o cliente \\
\hline Dependência e perda de parceiros-chave podem afetar adversamente os resultados da companhia \\
Quadro 9. Riscos associados ao processo de coprodução.
\end{tabular}

De forma geral, relações de coprodução colocam as organizações em contato com novos parceiros e clientes que podem deixá-las expostas a novos riscos. Ainda, o número de 
relacionamentos pode implicar na queda do nível de qualidade, o que gera perda de oportunidades de novos negócios e distanciamento dos clientes. Tais elementos citados pelas empresas servem de barreira à coprodução e, especificamente no setor financeiro, são pouco explorados pela literatura, (Chen, Tsou \& Ching, 2011; Cheung \& To, 2011; Dunston et al., 2009; Martovoy, Mention \& Torkkeli, 2015; Mende \& Doorn, 2014; Vargo \& Lusch, 2004; Wu \& Lin, 2013).

Entretanto, mesmo em face dos riscos envolvidos, as empresas argumentam que o relacionamento próximo com parceiros e clientes é fator essencial para o desempenho comercial, e que, a depender das estratégias definidas, a organização pode realizar novas incorporações, alienações, aquisições e parcerias estratégicas e, desta forma, aproveitar-se das vantagens relativas a essas transações, o que vai ao encontro do proposto por Martovoy, Mention e Torkkeli (2015). Tais indícios são relevantes para a discussão, posto que, se os benefícios da coprodução não superassem os riscos envolvidos, as instituições financeiras não investiriam em novos relacionamentos. O Quadro 10 fornece um panorama geral acerca dos benefícios da coprodução no âmbito do setor financeiro.

\begin{tabular}{|l|}
\hline Relações de respeito e confiança de forma geral são essenciais para o sucesso dos negócios \\
\hline Coproduções compõem a estratégia de expansão da empresa e agregam conhecimento \\
\hline Coproduções diversificam a oferta de serviços e melhoram a utilização de recursos \\
\hline Relacionamentos coprodutivos otimizam a entrega dos produtos e serviços \\
\hline Coproduções geram resposta rápida às necessidades dos clientes, o que representa vantagem competitiva \\
\hline Relacionamento e melhoria do atendimento promovem rentabilização da base de clientes \\
\hline Coprodução contribui para o fortalecimento dos vínculos com parceiros e clientes \\
\hline Troca de experiência entre parceiros fortalece as melhores práticas \\
\hline Projetos socioculturais são investimentos que fortalecem a marca \\
\hline
\end{tabular}

Quadro 10. Benefícios da coprodução no setor financeiro.

Cabe ressaltar que os indícios sobre os benefícios foram mais frequentes nos relatos das empresas do que a ênfase nos riscos associados, o que reforça a ideia de que os benefícios que podem resultar da coprodução tendem a superar os riscos envolvidos. De forma geral, as companhias relataram que o setor financeiro é altamente interativo, e que relacionamentos com parceiros-chave e clientes são essenciais para a sobrevivência no mercado. Nesse âmbito, o sucesso é resultado da identificação dos benefícios de tais relacionamentos, bem como da análise de viabilidade destes empreendimentos. Posto isso, o que se observa é que, de forma similar à inovação, a coprodução segue uma lógica de investimento estruturado, onde se parte de um capital inicial e uma análise de custos, riscos e retorno a fim de se alcançar resultados 
positivos, que podem ser tangíveis ou intangíveis. As empresas relatam que mantêm relacionamento com inúmeras instituições financeiras e não financeiras, correspondentes, acionistas e investidores, fundos de investimento, clientes e sociedade, com o intuito de intensificar os resultados da companhia e expandir o negócio. Dessa forma, as companhias utilizam de tal artefato como parte de suas estratégias de crescimento e ganhos de sinergia nos mercados nacional e internacional.

Portanto, o que se observa no setor financeiro é que as companhias investem em relacionamentos coprodutivos sob diversos formatos com o intuito de alcançar resultados que aproveitem a sinergia dos parceiros e clientes e maximizem os retornos. Tais fatos corroboram a ideia de que a coprodução tem relação positiva com o desempenho (Edvardsson et al., 2010; Field, Xue \& Hitt, 2012; Lusch, Vargo \& O’Brien, 2007; Martovoy, Mention e Torkkeli, 2015; Mende \& Doorn, 2014), principalmente no âmbito do setor financeiro, onde a relação entre investidor e instituição e a reputação impactam diretamente os resultados da companhia. Contudo, cabe a ressalva de que o sucesso das relações coprodutivas está atrelado a diversos fatores, tais como análise de viabilidade, quantidade de relacionamentos e riscos atrelados ao processo.

Adicionalmente, verifica-se que há espaço para refinamento e melhorias no que se refere à tipologia de coprodução proposta por Edvardsson et al. (2010); primeiramente porque esta foca apenas na dimensão B2C; em seguida, nos dois primeiros tipos (comprador e objeto de interesse) não há necessariamente uma relação de coprodução; terceiro, pois o foco da tipologia está apenas nos benefícios para a organização, negligenciando os benefícios mútuos e geração de valor para ambas as partes; e, finalmente, a tipologia não comporta alguns atores com papéis mais abrangentes, tais como acionistas, investidores, governo e sociedade. Nesse sentido, o Quadro 5 sugere uma nova tipologia tendo como base as considerações levantadas e o modelo teórico proposto (Fig. 3). Nesse contexto, parte-se do pressuposto que a relação pode ser representada na forma de um processo $[\mathrm{C}]\left[\mathrm{C}^{\prime}\right]\left[\mathrm{C}^{\prime}\right.$ '] e que, de forma similar à tipologia de inovação da abordagem integradora, a coprodução ocorre quando um ou mais atores assumem um papel ativo para gerar valor para ambas as partes (o símbolo * representa o papel ativo) 


\begin{tabular}{|c|c|c|c|}
\hline Tipo de Coprodução & \multicolumn{2}{c|}{ Descrição } \\
\hline Desenvolvimento & $\begin{array}{c}\text { Cliente ativo e assume responsabilidade pelo } \\
\text { processo }\end{array}$ & B2C & Simbologia \\
\hline Participação & $\begin{array}{c}\text { Parceiro ativo e assume responsabilidade pelo } \\
\text { processo }\end{array}$ & B2B & {$[\mathrm{C}]\left[\mathrm{C}^{\prime \prime}\right]^{*}$} \\
\hline Interação & Organização e cliente interagem ativamente & B2C & {$[\mathrm{C}]^{*}\left[\mathrm{C}^{\prime}\right]^{*}$} \\
\hline Cooperação & Organização e parceiro interagem ativamente & $\mathrm{B} 2 \mathrm{~B}$ & {$[\mathrm{C}]^{*}\left[\mathrm{C}^{\prime \prime}\right]^{*}$} \\
\hline Codesenvolvimento & $\begin{array}{c}\text { Organização, cliente e parceiro interagem } \\
\text { ativamente }\end{array}$ & $\mathrm{B} 2 \mathrm{BC}$ & {$[\mathrm{C}]^{*}\left[\mathrm{C}^{\prime}\right]^{*}\left[\mathrm{C}^{\prime \prime}\right]^{*}$} \\
\hline
\end{tabular}

Quadro 11. Proposta de tipologia de coprodução.

\subsubsection{Coprodução e Inovação}

No que tange à relação entre inovação e coprodução, o Quadro 12 sumariza as principais características de tal relação tendo como base os relatos das companhias.

\begin{tabular}{|l|}
\hline Inovação, pioneirismo e conhecimento do negócio transformam a empresa em parceiro preferencial \\
\hline Coprodução explora sinergias de negócio e identifica oportunidades de inovação \\
\hline Parcerias incrementam o modelo de negócio e ampliam o portfólio de produtos e serviços \\
\hline Coprodução com o governo contribui para o desenvolvimento do país \\
\hline Acordo para substituição dos terminais de autoatendimento \\
\hline Inovações melhoram o atendimento das necessidades específicas dos clientes e estreitam os relacionamentos \\
\hline Novos instrumentos financeiros contribuem para a fidelização dos clientes \\
\hline Produtos e serviços de maior valor agregado geram maior vínculo com o cliente \\
\hline Parcerias contribuem para o lançamento de novos produtos e serviços e diversificação da carteira \\
\hline Demandas específicas dos clientes estimulam o desenvolvimento de novos produtos e serviços \\
\hline
\end{tabular}
Quadro 12. Características da relação entre inovação e coprodução.

Nesse contexto, os relatos indicam que o crescimento da companhia depende dos relacionamentos e investimentos estratégicos, onde e a negociação de novos acordos e a integração de esforços permite alcançar novos produtos e serviços e diversificar suas receitas, sempre levando em consideração os riscos envolvidos e a análise do custo-benefício. No que tange a esse aspecto, as empresas destacam que devem promover aquisições e alianças ou parcerias para aproveitar oportunidades estratégicas para inovar, o que está de acordo com a literatura (Chen, Tsou \& Ching, 2011; Martovoy, Mention \& Torkkeli, 2015; Mende \& Doorn, 
2014). Estes elementos estão exemplificados no relato da Seguradora SulAmérica, delineado a seguir:

Como parte de sua estratégia, a Companhia pode buscar seu crescimento por meio de aquisições e/ou investimentos estratégicos em novas carteiras. A negociação de aquisições potenciais ou investimentos estratégicos, bem como a integração de um negócio adquirido ou do novo pessoal incorporado, pode resultar na diversificação dos recursos de gestão.

Bem como no relato do Banco Pine, no que tange ao estreitamento do relacionamento com o cliente:

Desde a sua fundação, a companhia tem focado sua estratégia em estabelecer relacionamentos de longo prazo com seus clientes e investidores. Sua estratégia baseia-se em conhecer cada cliente profundamente, entendendo seu negócio e seu potencial, de modo a construir soluções e alternativas personalizadas. Esta estratégia requer diversidade de produtos, capital humano qualificado, administração de riscos eficiente e agilidade, características consistentemente desenvolvidas pelo Banco. O processo de prospecção de clientes e concessão de crédito e outros produtos e serviços financeiros para empresas envolve a proximidade e entendimento das necessidades de seus clientes. Isso possibilita atendê-los de forma completa e otimizando os recursos do Banco.

As afirmações das empresas e dados levantados estão de acordo com a literatura, posto que relacionamentos colaborativos visem a aproveitar-se das sinergias de negócios entre parceiros e clientes no intuito de agregar valor e incorporar novo conhecimento, o que, por sua vez, acarreta em inovação (Chen, Tsou e Ching, 2011; Edvardsson et al., 2010; Ordanini, Miceli, Pizzetti \& Parasuraman, 2011; Wei, Wang, Tao \& Wang, 2006; Zhaoquan, Chen \& Xiande, 2013). Além disso, observa-se que no setor financeiro a interatividade é essencial para o desenvolvimento de novos serviços e melhoria de produtos, serviços e processos, uma vez que a rede interorganizacional e o estreitamento da relação com o cliente permitem à instituição financeira atender melhor às necessidades de mercado e se adaptar (Martovoy, Mention \& Torkkeli, 2015).

Deste modo, argumenta-se que a coprodução tem relação direta e positiva com a inovação, o que vai ao encontro da teoria (Chen, Tsou e Ching, 2011; Edvardsson et al., 2010; Martovoy, Mention \& Torkkeli, 2015; Ordanini, Miceli, Pizzetti e Parasuraman, 2011; Wei, Wang, Tao \& Wang, 2006; Zhaoquan, Chen \& Xiande, 2013). As evidências levantadas demonstram que as empresas estabelecem relações coprodutivas a fim de agregar valor à companhia, e que acordos e parceiras sempre objetivam promover novos produtos, entregas e 
fortalecer a marca e imagem dos atores envolvidos. Em síntese, as empresas investem em relacionamentos coprodutivos para gerarem novos resultados que sozinhas não poderiam alcançar, o que caracteriza uma inovação.

Outrossim, a maioria dos investimentos em inovação exigem que as empresas busquem conhecimento e recursos de fontes externas, seja através de consultorias, parceiros, clientes e demais atores do mercado, o que acarreta um novo relacionamento coprodutivo. No setor financeiro é comum as empresas realizarem novos investimentos na forma de participações, joint-ventures, fusões e aquisições, sempre visando ao lucro, de forma que em um mercado onde o investimento é a atividade principal e todas as empresas estão à venda (sociedades de capital aberto), as inovações estão em sua grande maioria atreladas a relacionamentos interativos.

\subsection{Conclusões e Recomendações}

Os resultados do presente estudo demonstraram que no âmbito do setor financeiro a inovação tem relação positiva com o desempenho, posto que novas iniciativas e melhorias são caracterizadas na forma de um investimento planejado que tem como objetivo a geração de valor, diluição de riscos e diversificação de receitas. Entretanto, tal relação é mediada por fatores internos tais como experiência da administração, flexibilidade organizacional, monitoramento contínuo do mercado, análise de viabilidade, adaptação tempestiva e tomada de decisão. Ainda, observou-se também que a relação é moderada por fatores externos tais como inflação, taxa de juros e inadimplência, liquidez do mercado, regulamentação, demandas de mercado e novas tecnologias. De qualquer sorte, no contexto do setor financeiro brasileiro, as companhias apresentem maturidade administrativa e volumes de capital suficientes para assumir riscos e inovar, o que na maioria das vezes acarreta resultados positivos para a organização. Tal fato vai ao encontro da "vertente otimista" da literatura de inovação no setor financeiro (Bos, Kolari \& Lamoen, 2013; Delimatsis, 2012; Delimatsis, 2013; Frame \& White 2004; Mullineux, 2010; Rossignoli \& Arnaboldi, 2009) ao mesmo tempo em que fornece insumos para explicar os insucessos de algumas inovações (Gai, Kapadia, Millard \& Perez, 2008; Hutton \& Lee, 2012; Lenzer \& Zhao, 2012).

De forma similar, coprodução e desempenho também apresentam uma relação positiva uma vez que as empresas do setor financeiro optam por construir novos relacionamentos sempre visando ao lucro, seja na forma de retornos tangíveis, seja na forma de retornos intangíveis. Contudo, a coprodução é explicada com base em variáveis como proposta 
de valor agregado, alinhamento na execução e envolvimento dos parceiros. A falha em considerar tais elementos pode acarretar em insucessos derivados do processo colaborativo. Além disso, a relação com desempenho é moderada por fatores externos, principalmente no que concerne a fatores macroeconômicos, mudanças regulatórias e movimentos de mercado. Ainda, as companhias destacaram diversos riscos associados à coprodução tais como exposição a novos riscos e contingências, resultados negativos de parceiros, desalinhamento, risco reputacional, dependência e interesses divergentes. Contudo, mesmo em face de tais elementos, as companhias do setor financeiro brasileiro assumem diversos formatos cooperativos para aproveitar as sinergias com parceiros e clientes e obter benefícios apoiados em seus relacionamentos, o que é evidenciado também por estudos da área (Edvardsson et al., 2010; Field, Xue \& Hitt, 2012; Lusch, Vargo \& O’Brien, 2007; Martovoy, Mention e Torkkeli, 2015; Mende \& Doorn, 2014).

Finalmente, observou-se que inovação e coprodução apresentam relação positiva, não apenas porque ambas são caracterizadas como investimentos estratégicos da companhia, mas principalmente porque, por um lado, parcerias e acordos planejados proporcionam novas entregas e, por outro lado, novas iniciativas geram nova interações e acesso a diferentes atores do mercado. Nesse ponto destacou-se que a interatividade é essencial para a incorporação de novo conhecimento, o que por sua vez está diretamente relacionado à capacidade de inovar. Tais evidências possuem respaldo na literatura, posto que diversos estudos ressaltem a relação positiva entre inovação e coproducão (Chen, Tsou e Ching, 2011; Edvardsson et al., 2010; Ordanini, Miceli, Pizzetti \& Parasuraman, 2011; Wei, Wang, Tao \& Wang, 2006; Zhaoquan, Chen \& Xiande, 2013).

Tais fatos podem estar restritos ao contexto das companhias de grande porte, visto que a amostra foi composta apenas de empresas listadas na bolsa de valores. Estas empresas movem maiores volumes de recursos e possuem, portanto, capital para investimentos vultosos em inovação e coprodução, além do que tendem a apresentar bom desempenho. Outra limitação do estudo é que tais relações não foram quantificadas, mas exploradas de forma aprofundada tendo como base dados qualitativos. De todo modo, do ponto de vista acadêmico, este trabalho contribui para mitigar em parte algumas lacunas da literatura, principalmente no que se refere ao debate sobre o impacto da inovação e coprodução no desempenho e na caracterização do processo de inovação e coprodução no setor financeiro. Sob uma óptica gerencial, os resultados apresentados indicam que o desenvolvimento e a melhoria de produtos e serviços, investimentos e novos acordos, parcerias e relacionamentos geram resultados positivos para a organização. 
Como sugestão para estudos futuros, são propostas as seguintes diretrizes como agenda de pesquisa: (1) investigar o impacto do ambiente (regulação, limites, competitividade, dinamismo, tecnologias e demandas) em cada um dos constructos trabalhados (inovação, desempenho e coprodução); (2) validar quantitativamente o modelo proposto e os resultados deste trabalho; (3) replicar o trabalho para pequenas e médias empresas do setor financeiro a fim de averiguar se as relações se mantêm; e (4) ampliar o escopo de análise do modelo proposto para outros setores e países. Além disso, há espaço para se aprofundar o estudo dos resultados aqui apresentados, no intuito de explorar de forma detalhada os efeitos mediadores e moderadores delineados e identificar os elementos e vetores que caracterizam o processo. 


\section{ESTUDO II: APLICAÇÃO DE DEA BASEADA NO ÍNDICE DE PRODUTIVIDADE DE MALMQUIST: MENSURAÇÃO DO DESEMPENHO DE BANCOS BRASILEIROS COM BASE NA INOVAÇÃO E NA COPRODUÇÃO}

\subsection{Introdução}

Em 2008 a economia sofreu sua maior crise desde a grande depressão de 1929, em virtude da super oferta de empréstimos subprimes sem lastro aos clientes do setor imobiliário norte-americano (Delimatsis, 2012; Hutton \& Lee, 2012; Ozbay, Dinçer \& Hacioglu, 2011). A crise levou a umarecessão global, perda geral de confiançae redução considerável de liquidez que passou dos bancos para as empresas, mercado imobiliário e consumidores,o que expôs a fraqueza das estruturas regulatórias vigentes e de uma economia endividada (Caselli, 2010; Delimatsis, 2012; Hutton \& Lee, 2012; Ozbay, Dinçer \& Hacioglu, 2011; Rossignoli \& Arnaboldi, 2009). Tal conjuntura resultou em uma reformulação de toda a dinâmica do setor financeiro a partir de um aumento significativo da competitividade e a entrada de novos modelos de negócio, estruturas regulatórias e tecnologias (Caselli, 2010; Delimatsis, 2013; Hoffmann, Post \& Pennings, 2013; Rossignoli \& Arnaboldi, 2009; Shahrokhi, 2008).

Nesse contexto, a inovação foi considerada por muitos autores como a raiz e principal causa da crise, visto que os empréstimos hipotecários foram criados segundo a combinação de instrumentos financeiros com demandas por fluxos de rentabilidade elevadas (Delimatsis, 2012; Delimatsis, 2013). Sobre esse aspecto, a literatura se divide visto que por um lado os autores argumentam que a inovação está diretamente relacionada à fragilidade financeira, uma vez que a negligência de riscos acarreta a supervalorização das seguranças e o otimismo dos investidores fomenta a habilidade dos intermediários de inovar (Gai et al., 2008; Hutton \& Lee, 2012; Lenzer \& Zhao, 2012). Por outro lado, diversos pesquisadores defendem que a inovação é essencial para o desenvolvimento econômico, posto que tenha como objetivo a redução de custos, desenvolvimento de novos produtos e serviços, diversificação de receitas, gerenciamento de riscos e atendimento de demandas específicas do mercado (Bos, Kolari \& Lamoen, 2013; Delimatsis, 2012; Frame \&White 2004; Rossignoli \& Arnaboldi, 2009).

Entretanto, apesar dessa dicotomia, há evidências na literatura de que a inovação no setor financeiro tem relação positiva com o desempenho e bem-estar social (Bos, Kolari \& Lamoen, 2013; Blazevic \& Lievens, 2004; Delimatsis, 2013; Frame \& White, 2004; Hutton \& Lee, 2012; Mullineux, 2010; Rossignoli \& Arnaboldi, 2009; Stevens \& Dimitriadis, 2005; Tufano, 2003). Contudo, em meio a tais debates, cabe destacar que pouco foi realizado no 
sentido de elucidar e validar empiricamente essas relações (Delimatsis, 2012; Delimatsis, 2013; Gai et al., 2008; Meng \& Guo, 2013; Mullineux, 2010; Stevens \& Dimitriadis, 2005).

A esse respeito, vale ressaltar que o sucesso da inovação depende dos investimentos da organização nos relacionamentos com parceiros e clientes, fenômeno chamado de coprodução pela literatura (Chen, Tsou \& Ching, 2011). No setor financeiro, a inovação impacta positivamente o número de trocas e interações entre atores de mercado, visto que estes se constituem importantes fontes de ideias para inovar (Chen, Tsou \& Ching, 2011; Delimatsis, 2012; Martovoy, Mention \& Torkelli, 2015; Rossignoli \& Arnaboldi, 2009; Tsou \& Chen, 2012). Ainda, a literatura apresenta diversos estudos que afirmam que a coprodução tem relação positiva com a inovação (Chen, Tsou e Ching, 2011; Cheung \& To, 2011; Edvardsson et al., 2010; Martovoy, Mention \& Torkkeli, 2015; Ordanini, Miceli, Pizzetti e Parasuraman, 2011; Tsou \& Chen, 2012; Wei et al., 2006; Zhaoquan, Chen \& Xiande, 2013). Nesse ponto cabe destacar que, apesar de o discurso e a prática da coprodução terem se tornado o paradigma emergente, ainda há poucas evidências empíricas da relação entre inovação e coproducão e até mesmo do impacto desta no desempenho (Akamavi, 2005; Boor, Oliveira \& Veloso, 2014; Dunston, Lee, Boud, Brodie \& Chiarella, 2009; Martovoy, Mention \& Torkkeli, 2015; Mende \& Doorn, 2014).

No que concerne ao desempenho, cabe salientar que numerosos estudos discutem que a eficiência da intermediação financeira afeta o crescimento econômico, enquanto outros indicam que as insolvências bancárias podem resultar em crises sistêmicas que têm consequências adversas para a economia como um todo (Fethi \& Pasiouras, 2010). Nesse âmbito, o desempenho e a eficiência do setor bancário recebem um fluxo contínuo de investigação que atrai considerável atenção tanto dos acadêmicos quanto dos formuladores de políticas públicas (Berger \& Humphrey, 1997; Fethi \& Pasiouras, 2010; Luo, 2003; Resti, 1997; Soteriou \& Zenios, 1997). Verifica-se, portanto, que há espaço para estudos que contribuam para mitigar as lacunas apresentadas e que sirvam de base para a construção de análises e ferramentas de prevenção de crises e mensuração de desempenho mais precisas. Segundo essas afirmações, o presente trabalho tem como objetivo mensurar a mudança de produtividade de bancos brasileiros tendo como base os investimentos em inovação e coprodução. Para tal foram analisados demonstrativos contábeis-financeiros dos últimos oito anos de bancos brasileiros de capital aberto e, em seguida, utilizou-se a análise por envoltória de dados (DEA), baseada no índice de Produtividade de Malmquist (MPI) para analisar o desempenho de tais instituições,e verificar a melhoria de produtividade, eficiência e tecnologia. 
As contribuições do presente trabalho referentes à aplicação de DEA e ao desempenho bancário incluem: a inclusão da inovação e coproducão como insumos para o modelos DEA, posto que não foram encontradas na literatura evidências de tal inserção; a utilização de bancos brasileiros como objeto de estudo, já que são escassos os trabalhos sobre inovação no setor financeiro brasileiro; e a mensuração da relação entre inovação, coproducão e desempenho. A escolha pelo mercado nacional se deve uma vez que os bancos brasileiros fazem frente aos padrões europeus e americanos de operações de concessão de crédito, tecnologia, estrutura, regulamentação e saúde financeira, de forma que estudos sobre desempenho bancário e inadimplência podem contribuir para a análise do risco de crédito e estabilidade financeira (Costa \& Blum, 2008; Dantas, Medeiros \& Capelletto, 2011).

\subsection{Marco Teórico}

\subsubsection{Inovação e Coprodução no Setor Financeiro}

No cenário pós-crise, há um debate na literatura acerca do papel da inovação no setor financeiro (Delimatsis, 2012). Por um lado, alguns autores argumentam que na última década, como resultado de um ambiente regulatório combinado à formação de uma crescente bolha imobiliária especulativa, a globalização e a inovação financeira aceleraram a tal ponto que a regulação se tornou incapaz de acompanhar o ritmo. Dessa forma, a exposição de tais lacunas regulatórias possibilitou o ressurgimento de assimetrias de informação e riscos de reputação no processo hipotecário, o que, combinado com outros fatores, acarretou uma crise financeira global (Lenzer \& Zhao, 2012). Nessa vertente, a inovação foi considerada como a raiz e principal causa do tumulto e, inclusive, argumenta-se que a inovação no setor financeiro tem pouco ou nenhum valor social (Delimatsis, 2013; Lenzer \& Zhao, 2012). Por outro lado, alguns estudos argumentam que a inovação no setor financeiro é um mecanismo de redução de custos, riscos e/ou criação de instrumentos, produtos e serviços financeiros (Rossignoli \& Arnaboldi, 2009). Tais autores argumentam que a inovação é parte essencial de quaisquer atividades do sistema financeiro, à medida que contribui para mitigar conflitos de agência e reduzir custos de transação, facilita a redistribuição de atividades e representa o motor do crescimento econômico, principalmente em virtude de seu papel crucial no financiamento de investimentos ou projetos (Delimatsis, 2012).

Tal debate acadêmico ocorre em virtude, principalmente, da recente crise de 2008, em que num contexto onde intermediários similares a bancos, não sujeitos à regulação, 
tornaram-se fonte de alavancagem elevada e risco sistêmico, de forma que as inovações tiveram efeitos dramáticos. Tal fato demonstrou o papel da inovação na geração de risco sistêmico em um sistema financeiro altamente interligado (Delimatsis, 2013). Nesse âmbito, argumenta-se que todos os atores de mercado podem sofrer perdas no caso de negligenciarem os riscos associados à inovação, de forma que se a instituição financeira provê os instrumentos, então a estrutura regulatória deve requerer que os atores detenham capital suficiente para honrar tais garantias ou absorver aumentos inesperados de demandas (Delimatsis, 2012).

De qualquer sorte, no contexto pós-crise, instituições financeiras que melhor se adaptam à nova realidade e inovam constantemente retornam mais lucros no longo prazo (Blazevic \& Lievens, 2004; Delimatsis, 2013; Hutton \& Lee, 2012; Stevens \& Dimitriadis, 2005). Nesse ponto, a literatura reconhece os benefícios da inovação no setor financeiro, principalmente no que concerne à redução de riscos, diversificação de receitas,geração de vantagem competitiva, atendimento das demandas de mercado, combinação e reorganização de instrumentos financeiros, melhoria de processos, liquidez e intermediação financeira, geração de crédito, redução da volatilidade macroeconômica e crescimento econômico(Bos, Kolari \& Lamoen, 2013; Delimatsis, 2012; Delimatsis, 2013; Frame \&White 2004; Mullineux, 2010; Rossignoli \& Arnaboldi, 2009). Nesse contexto, enquanto o sistema financeiro é responsável principalmente pela transferência de fundos e gerenciamento de risco, a inovação no setor é definida como o conjunto de atividades que reduzem os custos e riscos internos ou externamente atendem as conveniências e necessidades dos clientes. Tais mecanismos têm como funções o atendimento das demandas de mercado, resolução de problemas de agência, minimização dos custos de transação, atendimento a demandas regulatórias; resposta a inovações tecnológicas e gerenciamento de riscos (Bos, Kolari \& Lamoen, 2013; Rossignoli \& Arnaboldi, 2009; Tufano, 2003).

Cabe ressaltar que a inovação no setor financeiro alterou a perfil de risco das instituições financeiras e contribuiu substancialmente para o aumento da interconectividade entre instituições financeiras e não financeiras (Delimatsis, 2012; Rossignoli \& Arnaboldi, 2009). Isso se deve ao fato de que o setor financeiro tradicionalmente foi classificado como dependente de tecnologias externas e outros tipos de conhecimentos (Barras, 1990), onde as instituições financeiras recorrem a diversas fontes de informação a fim de inovar, tais como instituições do mesmo grupo, profissionais e associados, fornecedores, clientes e competidores (Martovoy, Mention \& Torkelli, 2015). Dessa forma, clientes e parceiros constituem-se nos mais importantes depósitos de conhecimento e fontes externas de ideias para a inovação, a tal ponto que aproximadamente metade das inovações no setor financeiro são desenvolvidas 
conjuntamente com parceiros e clientes (Chen, Tsou \& Ching, 2011; Martovoy, Mention \& Torkelli, 2015; Tsou \& Chen, 2012).

Nesse contexto, a coprodução, definida como a participação construtiva no processo de criação e entrega dos serviços, que engloba todos os formatos de cooperação entre o cliente, parceiros e prestador, desempenha um papel cada vez mais central na inovação, visto que tem como finalidade um entendimento mútuo com o propósito de agregar valor para as partes envolvidas (Chen, Tsou \& Ching 2011; Cheung \& To, 2011; Wu \& Lin, 2013). Além disso, o desempenho das instituições é influenciado diretamente pelo grau de confiança dos atores e investidores e pelos formatos e mecanismos de cooperação entre instituições financeiras, parceiros e clientes. Portanto, o papel crescente dos parceiros e clientes como participantes ativos e mandatórios da dinâmica é evidente em um contexto onde os atores estão cada vez mais interconectados (Dunston et al., 2009; Martovoy, Mention \& Torkkeli, 2015; Mende \& Doorn, 2014).

\subsubsection{Desempenho Bancário e Inadimplência}

Quando se discute o desempenho de uma firma, deve-se mencionar o sucesso na eficência na produção de todas as saídas dado um determinado conjunto de entradas(Charnes, Cooper \& Rhodes, 1978; Farrell, 1957; Fethi \& Pasiouras, 2010; Kopp, 1981; Leibenstein, 1966; Paradi \& Zhu, 2013; Varian, 1990; Zaher, Zeineldin \& Abdelshafy, 2015). Tal eficiência pode ser dicotomizada emdois subcomponentes que refletem a eficiência física da transformação de insumos (entradas) em produtos ou serviços (saídas), chamada de componente técnica, e a eficiência econômica do fator de alocação ideal dos elementos e função dos preços, caracterizada como eficiência de preço ou eficiência alocativa.(Farrell, 1957; Kopp, 1981; Leibenstein, 1966; Varian, 1990). Diversos estudos trouxeram tal conceito de eficiência para o setor bancário, já que os bancos desempenham papel central na economia e, no nível macroeconômico, a eficiência bancária representa um alvo social ótimo (Berger \&Humphrey, 1997; Fethi \& Pasiouras, 2010; Luo, 2003; Resti, 1997; Soteriou \& Zenios, 1997).

Nesse âmbito, a análise por envoltória de dados (DEA) tem sido bastante utilizada na literatura para a mensuração do desempenho de bancos, pois tem como objetivo comparar a eficência de unidades em relação a fronteiras teóricas de efiência determinadas combase em um determinado conjunto de dados (Berger \& Humphrey, 1997; Kopp, 1981; Paradi \& Zhu, 2013; Resti, 1997). A ideia principal da técnica é avaliar a eficiência relativa de um conjunto de unidades tomadoras de decisão (DMUs) homogêneas utilizando a razão entre a soma ponderada 
das saídas e a soma ponderada de entradas (Charnes, Cooper \& Rhodes, 1978; Zaher, Zeineldin \& Abdelshafy, 2015), e a fronteira eficiente é formada a partir da combinação linear que conecta o conjunto de melhores práticas observadas, resultando em um conjunto de possibilidades de produção convexas que não requer a especificação explícita da forma da relação de produção subjacente (Berger \& Humphrey, 1997; Sathye, 2001; Varian, 1990). Cabe destacar que a literatura mostrou que estimadores DEA têm boas propriedades estatísticas e podem ser usados para fornecer estimadores consistentes do desempenho de empresas (Banker, 1993; Banker e Natarajan, 2008; Luo, 2003; Fethi \& Pasiouras, 2010; Seiford \& Thrall, 1990).

A validade da técnica está diretamente relacionada à seleção das entradas e saídas que compôem o modelo e, para o setor financeiro, a definição e a mensuração de entregas bancárias têm sido um assunto central de debate entre os pesquisadores (Fethi \& Pasiouras, 2010; Paradi \& Zhu, 2013). No geral, adota-se a abordagem de produção, onde a instituição financeira é caracterizada como prestadora de serviços para seus clientes, ou a de intermediação, onde as instituições são consideradas intermediárias que convertem e transferem ativos entre unidades superavitárias e deficitárias (Anthanassopoulos, 1998; Fethi \& Pasiouras, 2009; Sathye, 2001; Soteriou \& Zenios, 1997). Mais recentemente, alguns estudos têm adotado uma outra variação da abordagem de intermediação, a chamada abordagem orientada para o lucro (ou operacional), que define os componentes de receita como saídas e componentes de custos como entradas (Fethi \& Pasiouras, 2010). Ainda, há a questão sobre a correta definição das entradas e saídas a compor o modelo, visto que houve quase tantas hipóteses de entradas e saídas quanto o número de aplicações da DEA (Fethi \& Pasiouras, 2010; Varian, 1990). No que se refere a esse ponto, destaca-se que não há nenhuma escolha definitiva, comumente acordada na literatura (Kopp, 1981; Luo, 2003; Sathye, 2001).

No que aborda esse aspecto, diversos estudos vêm destacando que a análise de desempenho bancário deve levar em consideração, além dos fatores intrínsecos, os riscos associados, principalmente o de crédito, pois a capacidade dos bancos de honrar seus compromissos está diretamente relacionada não apenas à sobrevivência no mercado, mas também à estabilidade do sistema financeiro como um todo (Annibal, 2009; Dantas, Medeiros \& Capelletto, 2011; Niyama, 2001; Takami \& Tabak, 2007). Nesse ponto abre-se espaço para a discussão do conceito de inadimplência (default), definida como o fracasso em pagar determinada quantia nos termos do contrato original da operação de crédito (Annibal, 2009). Tal fenômeno prejudica tanto credores quanto devedores e ainda afeta a avaliação sistêmica, posto que os bancos incorporam na taxa de juros o risco de inadimplência, o que representa um 
aumento do spread bancário e impacta de forma significativa o desempenho da instituição (Dantas, Medeiros \& Capelletto, 2011).

Quando se fala em crédito bancário, é natural que algumas perdas ocorram ao longo do tempo e, embora as instituições financeiras não conheçam de antemão as perdas que incorrerão em determinado período, ela pode, dada a sua experiência no ramo, estimar um nível de perda para este período tendo como base o risco de crédito, caracterizado como a probabilidade de um cliente tomador de crédito não honrar o compromisso assumido (Niyama, 2001). Nesse contexto, o índice de inadimplência pode ser acessado a partir da razão entre as provisões constituídas em um período e o saldo total médio de operações de crédito, o que a literatura chama de abordagem por provisão (Annibal, 2009; Costa \& Blum, 2008).

\subsubsection{Articulação e Hipóteses de Pesquisa}

O presente trabalho explora quantitativamente duas proposições de pesquisa delineadas no ensaio teórico, a saber: a inovação tem relação positiva com o desempenho do setor financeiro (P4); e a coprodução tem relação positiva com o desempenho do setor financeiro (P5). O embasamento teórico que sustenta tais proposições está descrito no segundo capítulo desta tese.

Apesar do recente avanço na literatura sobre inovação, o que se observa é que no âmbito do mercado financeiro ainda não houve a adoção de um modelo de análise focado no processo, uma vez que produtos e serviços financeiros são intangíveis, arriscados e complexos, o que os torna difíceis de serem analisados e caracterizados (Hoffmann, Post \& Pennings, 2013; Rossignoli \& Arnaboldi, 2009). Sobre esse aspecto, a abordagem integradora da inovação ganhou destaque na literatura tendo em vista ser a mais promissora em termos de avanço teórico e permitir analisar produtos e serviços financeiros sob a óptica de um modelo comum, fornecendo mais tangibilidade à análise (Djellal \& Gallouj, 2005; Djellal \& Gallouj, 2010; Gallouj \& Savona, 2009; Gallouj \& Savona, 2010; Gallouj \& Toivonen, 2011; Hoffmann, Post \& Pennings, 2013; Hsieh, Chiu, Wei, Yen \& Cheng, 2013). Tal perspectiva considera um produto ou serviço como um processo composto de vetores de competências (C), características técnicas $(\mathrm{T})$, características processuais $(\mathrm{Z})$ que, conjuntamente, geram entregas $(\mathrm{Y})$, de forma que a inovação ocorre quando há modificação, eliminação ou adição de vetores ou elementos ao processo (Djellal \& Gallouj, 2005; Djellal \& Gallouj, 2010; Gallouj, 2002; Gallouj \& Weinstein, 1997; Gallouj \& Savona, 2010; Gallouj \& Toivonen, 2011). Ao se transpor tal abordagem para o setor financeiro, um produto ou serviço financeiro ( $\mathrm{Si}$ ) passa a ser 
decomposto na forma de um processo de vetores constituintes [C][T][Z][Y] (Djellal \& Gallouj, 2010; Gallouj \& Toivonen, 2011; Gallouj \& Weinstein, 1997).

Esse modelo pode ser transposto também para o constructo de coprodução visto que no âmbito da abordagem integradora a coprodução é representada como a mobilização de competências [C] entre a organização, parceiros e clientes (Edvardsson et al., 2010; Gallouj \& Savona, 2009; Gallouj \& Weinstein, 1997). Tal ideia surgiu do trabalho de Peter Hill (1977), que foi quem primeiramente afirmou que um serviço é representado como uma mudança na condição de certas realidades resultante da interação de agentes econômicos. Nesse contexto, a prestação do serviço envolve duas unidades econômicas onde uma serve a outra, gerando mudança de condição (Hill, 1977). Tal conceito foi extrapolado por Gadrey (2000) no chamado "triângulo da prestação de serviços", onde um serviço é considerado um conjunto de operações fornecido por um fornecedor (B) para um cliente (A) em um meio (C), com o intuito de gerar mudança de estado no meio (C). Essa ideia está embutida na abordagem integradora, que além de considerar produtos e serviços sob uma mesma óptica, argumenta que a inovação apenas pode ocorrer como resultado de uma parceria e não pode ser criada com base unicamente nos méritos individuais da organização (Chen, Tsou \& Ching, 2011).

Finalmente, no que se refere à terceira lacuna, argumenta-se, uma vez que a medida de desempenho bancário seja obtida a partir da maximização da transformação de entradas em saídas (Charnes, Cooper \& Rhodes, 1978; Farrell, 1957; Fethi \& Pasiouras, 2010; Kopp, 1981; Leibenstein, 1966; Paradi \& Zhu, 2013; Varian, 1990; Zaher, Zeineldin \& Abdelshafy, 2015), o desempenho pode ser representado como a medida de conversão de $[\mathrm{C}][\mathrm{T}][\mathrm{Z}]$ em $[\mathrm{Y}]$, onde os componentes de entrada são elementos dos vetores $[\mathrm{C}][\mathrm{T}][\mathrm{Z}]$ e as saídas são as entregas $[\mathrm{Y}]$. Tal ideia está consonante com a lógica de processo que permeia tanto a abordagem integradora quanto a literatura de coprodução e desempenho (Charnes, Cooper \& Rhodes, 1978; Farrell, 1957; Gallouj \& Savona, 2009; Gallouj \& Weinstein, 1997). Adicionalmente, no que concerne à inadimplência, a mesma está embutida no processo, visto que as operações de crédito e provisões, bem como as receitas advindas de tais operações, são entradas e saídas do processo.

Com base nas ideias levantadas é possível delinear as hipóteses de pesquisa do presente trabalho. Primeiramente, uma vez que a inovação representa acréscimo de valor ao vetor [Y] e que o desempenho está caracterizado como a medida de conversão de $[\mathrm{C}][\mathrm{T}][\mathrm{Z}] \mathrm{em}$ [Y], argumenta-se que a inovação tem relação positiva com o desempenho bancário. Tal fato será verdade sempre que o valor gerado ao vetor [Y] superar o valor investido para modificar os vetores do processo. Corrobore-se a isso o fato de que a inovação no setor financeiro contribui para a redução de volatilidade macroeconômica, promove redução de custos de 
transações financeiras e melhoria no gerenciamento de riscos, otimiza trocas e meios de pagamento, desenvolve instrumentos e mercados, promove o crescimento econômico e desenvolvimento de mercados e transforma ativos em oportunidades de diversificação (Bos, Kolari \& Lamoen, 2013; Delimatsis, 2012; Delimatsis, 2013; Frame \&White, 2004; Mullineux, 2010; Rossignoli \& Arnaboldi, 2009). Adicionalmente, posto que entre os benefícios da inovação encontram-se a redução de riscos e a melhoria no gerenciamento de riscos (Bos, Kolari \& Lamoen, 2013; Delimatsis, 2012; Delimatsis, 2013; Frame \&White, 2004; Mullineux, 2010; Rossignoli \& Arnaboldi, 2009; Tufano, 2003), argumenta-se que a inovação no setor financeiro contribui para a diminuição da taxa de inadimplência bancária uma vez que menores riscos e volatilidade aumentam a capacidade dos bancos de cumprirem seus compromissos de crédito (Annibal, 2009; Dantas, Medeiros \& Capelletto, 2011; Niyama, 2001; Takami \& Tabak, 2007). Dessa forma, delineia-se a primeira hipótese de pesquisa:

\section{H1:a inovação tem relação positiva com o desempenho bancário}

De forma análoga, tendo em vista que a coprodução visa também a gerar valor ao vetor [Y], sugere-se que a coprodução tem relação positiva com o desempenho bancário. De forma similar à inovação, isso ocorrerá sempre que o valor agregado superar o capital investido na constituição de tais relacionamentos. Tal argumentação fundamenta-se na ideia de que em um contexto onde o sucesso das transações financeiras depende do comportamento colaborativo entre as partes relacionadas (governo, consultores, clientes, fornecedores, associações profissionais, competidores e investidores) a mobilização de competências caracteriza transferência de conhecimentos e consequente vantagem competitiva, o que impacta positivamente o desempenho da organização (Dunston et al., 2009; Edvardsson et al., 2010; Field, Xue \& Hitt, 2012; Lusch, Vargo \& O’Brien, 2007; Martovoy, Mention e Torkkeli, 2015; Mende \& Doorn, 2014). Além disso, defende-se que a coprodução também contribui para a redução da inadimplência uma vez que o aumento da interconectividade e das interações entre instituições financeiras, parceiros e clientes acarreta uma diluição do risco através da rede de relacionamentos, bem como estabelecimento de acordos e atendimento a demandas específicas de mercado, o que contribui para que os compromissos de créditos sejam honrados (Delimatsis, 2012; Martovoy, Mentio\& Torkelli, 2015; Mende \&Doorn, 2014;Rossignoli \& Arnaboldi, 2009). Portanto, é possível estabelecer a segunda hipótese de pesquisa: 
A utilização do método Malmquist-DEA permitiu responder às hipóteses de pesquisa, já que a técnicase fundamenta na aplicaçãodo algoritmo DEA para cada período ao mesmo tempo em que compara os resultados entre dois períodos subsequentes. Dessa forma, ele permite acessar a mudança de produtividade, mudança de eficiência e mudança de tecnologia de cada DMU. Maiores detalhes sobre o método são explorados no tópico seguinte.

\subsection{Métodos}

O presente trabalho é um estudo quantitativo, longitudinal e de natureza explicativa que utiliza a DEA para testar as hipóteses apresentadas. A DEA é um modelo de programação linear que define relações não paramétricas entre múltiplas entradas e saídas e basicamente identifica a fronteira de produção eficiente tendo como base os dados de um conjunto préestabelecido de DMUs (Charnes, Cooper \& Rhodes, 1978). Dessa forma, os bancos eficientes serão aqueles que melhor otimizem a proporção de saídas dado determinado conjunto de entradas (Paradi \& Zhu, 2013; Resti, 1997).

Trata-se de uma técnica não paramétrica posto que o modelo proposto não apresente distribuição de probabilidade. Nesse caso, a justificativa de escolha do método fundamenta-se em virtude da flexibilidade, aplicabilidade e robustez da DEA para medição de desempenho e consistência de seus estimadores estatísticos (Banker, 1993; Banker e Natarajan, 2008; Fethi \& Pasiouras, 2010; Seiford \& Thrall, 1990; Zaher, Zeineldin \&Abdelshafy, 2015). Além disso, a literatura destaca o papel crescente da DEA como ferramenta de aferição de desempenho bancário (Paradi \& Zhu, 2013).

\subsubsection{Limitações e Vantagens da DEA}

Apesar das facilidades do método, faz-se necessário destacar que se trata de uma abordagem não paramétrica. A DEA assume que: não há erro aleatório na fronteira; não há elementos temporais que possibilitam alguma DMU a ter um melhor desempenho; e não há erros de mensuração criados a partir de regras que direcionam as entradas e saídas a elementos não econômicos. Quaisquer erros desses podem resultar em modificações nos escores de desempenho, o que pode comprometer toda a formulação da fronteira em virtude das combinações lineares que envolvem tal unidade (Berger \& Humphrey, 1997). Além disso, a DEA apresenta alta sensibilidade para os dados, uma vez que a metodologia foca em fronteiras 
ou limites, e, portanto, erros de medição de dados podem causar problemas significativos. Nesse sentido argumenta-se que a técnica requer uma medição exata das entradas e saídas (Zaher, Zeineldin \& Abdelshafy, 2015).

Entretanto, mesmo em face de suas limitações, a pesquisa teórica mostrou que estimadores DEA têm boas propriedades estatísticas e podem ser usado para fornecer medidas consistentes acerca do desempenho de empresas (Banker, 1993; Banker e Natarajan, 2008). Além de não requerer a especificação prévia da forma funcional, a técnica permite focar nas organizações que se destacam, normalmente considerados outliers e eliminados da amostra em testes paramétricos em virtude da orbigatoriedade da normalidade. Com base nisso, é possível estabelecer fronteiras de eficiência considerando as empresas de melhor desempenho e a partir disso determinar as eficiências relativas de cada empresa, bem como fornecer benchmarks de referência, subsidiar estratégias de produção e fornecer insumos para a tomada de decisão (Fethi \& Pasiouras, 2010; Paradi \& Zhu, 2013).

\subsubsection{Modelo DEA baseado no Índice de Produtividade de Malmquist}

O presente trabalho compara os resultados dos modelos CCR (Charnes, Cooper \& Rhodes 1978), que assume retornos constantes de escala (CRS) e do modelo BCC (Banker, Charnes \& Cooper, 1984), que decompõe a eficiência do modelo CCR em dois componentes: eficiência técnica e eficiência de escala e permite ajustar os escores em virtude dos retornos variáveis de escala (VRS). Adicionalmente, a orientação do modelo é para a maximização dos outputs, posto que a inovação e coprodução têm como objetivo maximizar a geração de valor.

Dessa forma, o presente trabalho utiliza a construção do modelo Malmquist-DEA (Wang \& Lan, 2011), que busca estabelecer índices para aferir a mudança de produtividade entre períodos. Portanto, suponha que existam nDMUs a serem avaliadas em termo de m inputs e s outputs. Considere então $x_{i j}^{t}$ e $y_{r j}^{t}$, bem como $x_{i j}^{t+1}$ e $y_{r j}^{t+1}$ os inputs e outputs da $\mathrm{DMU}_{\mathrm{j}}$ nos períodos de $\mathrm{t}$ e $\mathrm{t}+1$, respectivamente, onde $i=1, \ldots, m ; \mathrm{r}=1, \ldots, \mathrm{s} ; \mathrm{e} \mathrm{j}=1, \ldots, \mathrm{n}$. Portanto, a solução do Modelo DEA baseado no índice de produtividade de Malmquist requer a solução dos modelos CCR (1) e (2), BCC (5)e modelos de programação linear (3) e (4).

$$
D_{o}^{t}\left(x_{o}^{t}, y_{o}^{t}\right)=\text { Maximizar } \theta
$$

Sujeito a: 
$\sum_{j=1}^{n} \lambda_{j} x_{i j}^{t} \leq x_{i o}^{t}, \quad i=1,2, \ldots, m$

$\sum_{j=1}^{n} \lambda_{j} y_{r j}^{t} \geq \theta y_{r o}^{t}, \quad r=1,2, \ldots, s$,

$\lambda_{j} \geq 0, \quad j-1,2, \ldots, n$

$$
D_{o}^{t}\left(x_{o}^{t+1}, y_{o}^{t+1}\right)=\text { Maximizar } \theta
$$

Sujeito a:

$\sum_{j=1}^{n} \lambda_{j} x_{i j}^{t} \leq x_{i o}^{t+1}, \quad i=1,2, \ldots, m$,

$\sum_{j=1}^{n} \lambda_{j} y_{r j}^{t} \geq \theta y_{r o}^{t+1}, \quad r=1,2, \ldots, s$,

$\lambda_{j} \geq 0, \quad j-1,2, \ldots, n$

$$
D_{o}^{t+1}\left(x_{o}^{t+1}, y_{o}^{t+1}\right)=\text { Maximizar } \theta
$$

Sujeito a:

$\sum_{j=1}^{n} \lambda_{j} x_{i j}^{t+1} \leq x_{i o}^{t+1}, \quad i=1,2, \ldots, m$

$\sum_{j=1}^{n} \lambda_{j} y_{r j}^{t+1} \geq \theta y_{r o}^{t+1}, \quad r=1,2, \ldots, s$, 
$\lambda_{j} \geq 0, \quad j=1,2, \ldots, n$

$$
D_{o}^{t+1}\left(x_{o}^{t}, y_{o}^{t}\right)=\text { Maximizar } \theta
$$

Sujeito a:

$\sum_{j=1}^{n} \lambda_{j} x_{i j}^{t+1} \leq x_{i o}^{t}, \quad i=1,2, \ldots, m$

$\sum_{j=1}^{n} \lambda_{j} y_{r j}^{t+1} \geq \theta y_{r o}^{t}, \quad r=1,2, \ldots, s$,

$\lambda_{j} \geq 0, \quad j=1,2, \ldots, n$

Matematicamente, o modelo BCC traz consigo apenas a seguinte restrição adicional para todas as fórmulas acima:

$\sum_{j=1}^{n} \lambda_{j}=1$

Dessa forma, $\mathrm{o} D_{o}^{t}\left(x_{o}^{t}, y_{o}^{t}\right)$ e o $D_{o}^{t+1}\left(x_{o}^{t+1}, y_{o}^{t+1}\right)$ mensuram as eficiências da $\mathrm{DMU}_{\mathrm{o}}$ $(o \in\{1,2, \ldots, n\})$ nos períodos de tempo t e $\mathrm{t}+1$, respectivamente, $D_{o}^{t}\left(x_{o}^{t+1}, y_{o}^{t+1}\right)$ mensura a eficiência do período $t+1$ utilizando a produção tecnológica do período $t$, o que é chamado de índice de crescimento da $\mathrm{DMU}_{\mathrm{o}}$, e $D_{o}^{t+1}\left(x_{o}^{t}, y_{o}^{t}\right)$ mensura a eficiência da $\mathrm{DMU}_{\mathrm{o}}$ no período $\mathrm{t}$ utilizando a produção tecnológica do período $\mathrm{t}+1$.

Com base nisso, propõe-se o seguinte Índice de Produtividade de Malmquist para DEA:

$M P I_{o}=\left[\frac{D_{o}^{t}\left(x_{o}^{t+1}, y_{o}^{t+1}\right)}{D_{o}^{t}\left(x_{o}^{t}, y_{o}^{t}\right)} \cdot \frac{D_{o}^{t+1}\left(x_{o}^{t+1}, y_{o}^{t+1}\right)}{D_{o}^{t+1}\left(x_{o}^{t}, y_{o}^{t}\right)}\right]^{1 / 2}$ 
Que mensura a mudança de produtividade de um período $t$ para um período $t+1$, com $\mathrm{MPI}_{\mathrm{o}}>0$ indicando progressão da produtividade, $\mathrm{MPI}_{\mathrm{o}}=1$ representando manutenção da produtividade e $\mathrm{MPI}_{\mathrm{o}}<1$ caracterizando declínio.

A fim de eliminar o pressuposto de que $D_{o}^{t}\left(x_{o}^{t}, y_{o}^{t}\right)$ e $D_{o}^{t+1}\left(x_{o}^{t+1}, y_{o}^{t+1}\right)$ deveriam ser igual a uma unidade para permitir a ineficiência técnica, o MPI é decomposto em dois subcomponentes:

$$
\begin{gathered}
M P I_{o}=\left[\frac{D_{o}^{t}\left(x_{o}^{t+1}, y_{o}^{t+1}\right)}{D_{o}^{t}\left(x_{o}^{t}, y_{o}^{t}\right)} \cdot \frac{D_{o}^{t+1}\left(x_{o}^{t+1}, y_{o}^{t+1}\right)}{D_{o}^{t+1}\left(x_{o}^{t}, y_{o}^{t}\right)}\right]^{1 / 2} \\
=\frac{D_{o}^{t+1}\left(x_{o}^{t+1}, y_{o}^{t+1}\right)}{D_{o}^{t}\left(x_{o}^{t}, y_{o}^{t}\right)}\left[\frac{D_{o}^{t}\left(x_{o}^{t}, y_{o}^{t}\right)}{D_{o}^{t+1}\left(x_{o}^{t}, y_{o}^{t}\right)} \cdot \frac{D_{o}^{t}\left(x_{o}^{t+1}, y_{o}^{t+1}\right)}{D_{o}^{t+1}\left(x_{o}^{t+1}, y_{o}^{t+1}\right)}\right]^{1 / 2} \\
\text { OEC }=\frac{D_{o}^{t+1}\left(x_{o}^{t+1}, y_{o}^{t+1}\right)}{D_{o}^{t}\left(x_{o}^{t}, y_{o}^{t}\right)} \\
\text { OTC } C_{o}=\left[\frac{D_{o}^{t}\left(x_{o}^{t}, y_{o}^{t}\right)}{D_{o}^{t+1}\left(x_{o}^{t}, y_{o}^{t}\right)} \cdot \frac{D_{o}^{t}\left(x_{o}^{t+1}, y_{o}^{t+1}\right)}{D_{o}^{t+1}\left(x_{o}^{t+1}, y_{o}^{t+1}\right)}\right]^{1 / 2}
\end{gathered}
$$

O primeiro subcomponente representa a mensuração da mudança de eficiência (OEC) da $\mathrm{DMU}_{\mathrm{o}}$, com $\mathrm{OEC}_{\mathrm{o}}>0$ indicando melhoria da eficiência e $\mathrm{OEC}_{\mathrm{o}}<1$ indicando declínio. Já o segundo componente mensura a mudança tecnológica (OTC) da $\mathrm{DMU}_{\mathrm{o}}$ no período $\mathrm{t}$ para $\mathrm{t}+1$.

\subsubsection{Coleta de Dados}

A amostra foi constituída por todos os bancos brasileiros de capital aberto, listados na Bolsa de Valores de São Paulo (BM\&FBovespa) e o horizonte de tempo para a pesquisa abrangeu o período de 2008-2015, com o intuito de melhor explorar o cenário do sistema financeiro pós-crise. Os dados foram extraídos das Demonstrações Financeiras Padronizadas (DFPs) anuais de cada banco e da Relação de Agências, Postos e Filiais disponibilizada mensalmente pelo Banco Central do Brasil, e a análise dos dados foi veiculada por meio do software MaxDEA. 
O formulário DFP é um documento eletrônico de encaminhamento periódico à CVM preenchido com dados das demonstrações financeiras elaboradas de acordo com as regras definidas para cada tipo de instituição. A norma exige que as empresas brasileiras encaminhem tal documento, em até três meses após o encerramento do exercício social ou na mesma data do envio das demonstrações financeiras, se este ocorrer em data anterior. Os valores dispõem sobre o balanço patrimonial, demonstração de resultado, fluxo de caixa e demontração de valor adicionado.

\subsubsection{Especificação dos Inputs e Outputs}

Em relação à definição das entradas e saídas, o presente trabalho adota a abordagem de produção, que considera bancos como unidades prestadoras de serviços para os clientes (Sathye, 2001). Essa ideia está alinhada com a abordagem integradora da inovação, visto essa focar originalmente no processo de inovação em serviços (Gallouj \& Savona, 2009), além de ser condizente com a ideia de geração de valor e posicionamento do cliente de forma central no processo. Ainda, cabe ressaltar que não foram encontradas na literatura evidências da utilização de inovação ou coprodução como insumos para DEA. Portanto, o presente modelo considera três entradas (inovação, coprodução e rede de atendimento) que conjuntamente produzem duas saídas (geração de valor e adimplência).

Cabe ressaltar que a seleção das variáveis se deu com o objetivo de verificar o impacto da inovação e coprodução no desempenho bancário, tendo em vista o papel destas na geração de valor e redução de riscos, tal qual destacado pela literatura da área. Dessa forma, optou-se por não utilizar as variáveis tradicionais de mensuração de desempenho (despesas de pessoal, receitas de intermediação financeira, empréstimos, depósitos etc.) uma vez que o foco não era unicamente determinar o desempenho de cada banco, mas sim discutir como a inovação e coprodução podem também ser considerados estimadores consistentes de desempenho.

De forma específica, a variavel inovação foi construída com base no somatório dos ativos diferidos e ativos intangíveis, desconsideradas as amortizações. As Normas Internacionais de Contabilidade (IFRS) dispõem em seu normativo IAS38 que os ativos intangíveis compreendem todo ativo não monetário identificável sem substância física, mantido para uso na produção ou suprimento de bens ou serviços, para arrendamento a terceiros ou para propósitos administrativos, e reforçam que se tratam de recursos do qual se esperam que sejam gerados benefícios econômicos futuros para a entidade (IFRS, 2014). 
De acordo com a norma, incluem-se nesse rol, desde que obedecidos os critérios estabelecidos, as despesas de reorganização, custo de estudos e projetos, despesas préoperacionais, despesas com investigação científica e tecnológica para desenvolvimento de produtos, processos de produção e encargos incorridos com a reorganização ou reestruturação da entidade, construção e testes de protótipos, modelos, materiais aprimorados, dispositivos, produtos, processos, sistemas ou serviços. Ademais, o Comitê de Pronunciamentos Contábeis (CPC) em seu Pronunciamento Técnico CPC $\mathrm{n}^{\circ} 4$ proveu maior detalhamento ao afirmar que estão incluídos no ativo intangível todos os custos relativos a salários, encargos e outros custos de pessoal alocados a tais atividades; materiais e serviços consumidos; depreciação de equipamentos e instalações utilizadas nas pesquisas; e gastos gerais, apropriados a essas atividades, como, por exemplo, a amortização de patentes e licenças.

Adicionalmente o normativo estabeleceu que os gastos feitos com pesquisas e desenvolvimento de produtos devem observar o regime de competência e de prudência devendo ser reconhecidos como despesa quando incorridos. Entretanto, no Brasil a Lei n ${ }^{\circ} 6.404$ de 1976 estabeleceu que os ativos intangíveis, incluídas as despesas com pesquisa e desenvolvimento de novos produtos, deveriam ser considerados como ativos diferidos, o que ocorreu até o advento da Lei $\mathrm{n}^{\mathrm{o}} 11.941$ de 2009, que, por sua vez, extinguiu o ativo diferido do sistema contábil brasileiro. Após esse ano as empresas passaram a contabilizar tais gastos no ativo intangível ou como despesas, de forma que para as companhias de capital aberto no período considerado é plausível considerar a totalidade dos investimentos em inovação como o somatório dos ativos intangies e diferidos.

No que se refere à variável coprodução, a mesma foi operacionalizada com base nas relações interfinanceiras (RI), visto que de acordo com o Plano Contábil das Instituições do Sistema Financeiro (COSIF) esta conta compila todos os valores transacionados relativos a transações com parceiros, a saber: serviço de compensação de cheques e outros papéis com parceiros dos sistemas de liquidação; créditos vinculados, normalmente relacionados ao governo e Banco Central; repasses interfinanceiros; relações com correspondentes; e recursos em trânsito de terceiros (Banco Central do Brasil (BC), 1987). Cabe ressaltar que a mesma conta ocorre tanto no ativo, representando a totalidade de valores financeiros gerados com base nos relacionamentos com parceiros, quanto no passivo, caracterizando as perdas resultantes de tais relacionamentos, de forma que para a construção da variável será utilizado o valor líquido, ou seja, a diferença entre RI ativo e passivo. Adicionalmente, a última entrada, rede de atendimento, será contabilizada a partir do somatório do número de agências com o número de Postos de Atendimento (PA), que inclui os Postos de Atendimento Bancário (PAB), Postos 
Avançados de Atendimento (PAA), Postos de Atendimento Transitório (PAT), Postos de Compra de Ouro (PCO), Postos de Atendimento Cooperativo (PAC), Postos de Atendimento de Microcrédito (PAM), Postos Bancários de Arrecadação e Pagamento (PAP) e os Postos de Câmbio (BC, 2012). Tal variável representa a medida de relacionamento com o cliente, que além de ser dimensão da coprodução é elemento essencial para a inovação no contexto da abordagem integradora.

Do lado das saídas, a geração de valor foi representada com base no Valor Adicionado Bruto (VAB), que na contabilidade é caracterizado como a evidência dos valores correspondentes à formação da riqueza gerada pela empresa em determinado período resultante do processo produtivo. De acordo com a Lei $\mathrm{n}^{\mathrm{0}} 11.638$ de 2007, tal medida, componente da Demonstração de Valor Adicionado (DVA), é um indicador da eficiência da empresa na utilização dos fatores de produção, comparando o valor das saídas com o valor das entradas. Tal ideia vai ao encontro do modelo proposto, visto que tanto a inovação quanto a coprodução têm como objetivo a geração de valor, e para as companhias de capital aberto este valor é contabilizado na forma de VAB.

Finalmente, a última saída, adimplência, foi caracterizada sob a óptica da abordagem de provisão, ou seja, foi representada como a razão entre as Perdas Estimadas em Créditos de Liquidação Duvidosa (PECLD) e o saldo total das Operações de Crédito (Annibal, 2009; Costa \& Blum, 2008). Argumenta-se que tal medida representa um indicador robusto para a taxa de adimplência bancária uma vez que com o advento da Resolução nº 2.682 de 1999, do Conselho Monetário Nacional (CMN), as instituições financeiras se adequaram aos novos critérios de constituição da provisão para créditos de liquidação duvidosa sobre suas operações, de forma que passaram a considerar elementos-chave da operação (número de operações; valor das operações; prazo das operações; valor das prestações; probabilidade de inadimplência; natureza e finalidade da transação; características das garantias, particularmente quanto à suficiência e liquidez) bem como características dos devedores (situação econômico-financeira; grau de endividamento; capacidade de geração de resultados; fluxo de caixa; administração e qualidade dos controles; pontualidade e atraso nos pagamentos; contingências; setor de atividade econômica; e limite de crédito). Dessa forma, a PECLD mostra-se como um bom estimador da capacidade de gerenciamento de risco e cumprimento de obrigações de instituicoes bancárias brasileiras(Costa \& Blum, 2008; Dantas, Medeiros \& Capelletto, 2011; Niyama, 2001).

Cabe ressaltar que as variáveis inovação, coprodução e rede de atendimento foram consideradas inputs para a DEA visto que no modelo teórico apresentado tanto a inovação 
quanto a coprodução são representadas na forma de modificações das características e competências, que na óptica da abordagem integradora são os insumos do processo (Gallouj \& Weinstein, 1997). Da mesma forma, a geração de valor é representada na forma de entregas, que são as saídas do processo do produto/serviço, o que justifica o posicionamento da variável como output. Finalmente, a adimplência foi considerada também um output do modelo, uma vez que de acordo com a literatura a inovação e coprodução trazem como benefícios a redução do risco, de forma que a adimplência é resultado. O Quadro 7 abaixo sumariza as informações levantadas e a operacionalização das variáveis de pesquisa que compôem o modelo DEA.

\begin{tabular}{|c|c|c|c|c|}
\hline Variável & Tipo & Operacionalização & Fonte & Referências Operacionais \\
\hline Inovação & Input & $\begin{array}{c}\text { Ativo Intangível + Ativo } \\
\text { Diferido - Amortizações }\end{array}$ & DFP & $\begin{array}{c}\text { IAS38 (IFRS, 2014); CPC; Lei } \\
6.404 / 76 ; \text { e Lei 11.941/09 }\end{array}$ \\
\hline Coprodução & Input & $\begin{array}{c}\text { Relações Interfinanceiras } \\
\text { (Ativo) - Relações } \\
\text { Interfinanceiras (Passivo) }\end{array}$ & DFP & COSIF \\
\hline $\begin{array}{c}\text { Rede de } \\
\text { Atendimento }\end{array}$ & Input & $\begin{array}{c}\text { Agências + Postos de } \\
\text { Atendimento (PA) }\end{array}$ & $\begin{array}{c}\text { Banco Central } \\
\text { Central }\end{array}$ \\
\hline $\begin{array}{c}\text { Geração de } \\
\text { Valor }\end{array}$ & Output & $\begin{array}{c}\text { Valor Adicionado Bruto } \\
\text { (VAB) }\end{array}$ & DFP & Lei 11.638/07 \\
\hline $\begin{array}{c}\text { Adimplência } \\
\text { Output }\end{array}$ & PECLD/Operações de Crédito & DFP & $\begin{array}{c}\text { Annibal, 2009; Costa \& Blum, 2008; } \\
\text { Resolução CMN 2.682/99 }\end{array}$ \\
\hline
\end{tabular}

Quadro 13. Operacionalização das variáveis de pesquisa.

\subsubsection{Tratamento dos Dados}

A aplicação da Análise por Envoltória de Dados em demonstrações contábeis requer primeiramente o tratamento dos valores negativos e iguais a zero, visto que a grande maioria dos softwares utilizados, o MaxDEA incluído, não permite a execução das análises na existência de tais valores. A literatura sugere a transformação dos valores negativos em positivos a partir do somatório de uma constante, equivalente ao valor mais negativo da variável, de forma que todos os elementos passem a ter valores positivos (Ali \& Seiford, 1990; Pastor, 1997). Portanto, aplicou-se esta transformação de escala às seguintes variáveis: coprodução, geração de valor e adimplência. Ainda, todas as variáveis iguais a zero foram transformadas em 0,001 a fim de manter os resultados sem gerar modificações significativas nos valores. Finalmente, realizou-se a transformação das variáveis em percentuais para mitigar as dissonâncias entre valores muito grandes e pequenos de diferentes variáveis que podem interferir na análise. 


\subsubsection{Parâmetros para Análise dos Dados}

Os dados foram analisados conforme interpretação do índice de Malmquist e seus componentes (Wang \& Lan, 2011), e estão descritos no Quadro 8 abaixo. Dessa forma, para cada banco da amostra foi mensurado o índice de eficiência global, bem como o índice Malmquist de produtividade (MPI), mudança na eficiência técnica (OEC) e mudança na tecnologia (OTC), para cada um dos anos no período de 2008 a 2015. Tais indicadores baseiamse no cálculo das taxas marginais de substituição, e portanto fornecem dados estatisticamente significativos acerca da variação de produtividade, tecnologia e eficiência de um determinado período.

\begin{tabular}{|c|c|c|}
\hline Índice & Período crescente ( $t$ para $t+1)$ & Interpretação \\
\hline \multirow{3}{*}{$\begin{array}{l}\text { Índice Malmquist de } \\
\text { Produtividade (MPI) }\end{array}$} & MPI $>1$ & Progressão da produtividade \\
\hline & $\mathrm{MPI}=1$ & Manutenção da produtividade \\
\hline & $\mathrm{MPI}<1$ & Declínioda produtividade \\
\hline \multirow{3}{*}{ Mudança na Eficiência Técnica } & $\mathrm{OEC}>1$ & Melhoria da eficiência \\
\hline & $\mathrm{OEC}=1$ & Manutenção da efíciência \\
\hline & $\mathrm{OEC}<1$ & Declínio da eficiência \\
\hline \multirow{3}{*}{ Mudança na Tecnologia (OTC) } & $\mathrm{OTC}>1$ & Melhoria da tecnologia \\
\hline & $\mathrm{OTC}=1$ & Manutenção da tecnologia \\
\hline & $\mathrm{OTC}<1$ & Declínio da tecnologia \\
\hline
\end{tabular}

Quadro 14. Parâmetros para análise dos resultados DEA. Fonte: Wang \& Lan (2011).

\subsection{Resultados e Discussão}

\subsubsection{Panorama Geral do Setor Bancário Brasileirono Período 2008-2015}

Na tabela 4 abaixo estão detalhados o somatório total década uma das variáveis de pesquisa no período de 2008 a 2015. 


\begin{tabular}{|c|c|c|c|c|c|c|c|c|}
\hline & $\mathbf{2 0 0 8}$ & $\mathbf{2 0 0 9}$ & $\mathbf{2 0 1 0}$ & $\mathbf{2 0 1 1}$ & $\mathbf{2 0 1 2}$ & $\mathbf{2 0 1 3}$ & $\mathbf{2 0 1 4}$ & $\mathbf{2 0 1 5}$ \\
\hline Inovação (bilhões de R\$) & 17 & 22 & 26 & 34 & 36 & 41 & 42 & 44 \\
\hline Coprodução (bilhões de R\$) & 40 & 55 & 194 & 215 & 170 & 190 & 156 & 185 \\
\hline $\begin{array}{c}\text { Rede de Atendimento (milhares } \\
\text { de unidades) }\end{array}$ & 45 & 53 & 57 & 60 & 62 & 61 & 58 & 53 \\
\hline Valor Adicionado (bilhões de R\$) & 34 & 58 & 71 & 70 & 80 & 84 & 74 & 41 \\
\hline Adimplência Média (\%) & 13 & 28 & 15 & 16 & 19 & 21 & 16 & 22 \\
\hline
\end{tabular}

Tabela 4. Inovação, coprodução e desempenho do setor bancário brasileiro.

De forma geral, observa-se que ao longo do período estudado os investimentos em inovação foram crescentes, enquanto a coprodução teve um salto no ano de 2010 e manteve-se em patamares elevados desde então. Na sequência, verifica-se que a rede de atendimento se manteve crescente até 2013, quando passou a assumir valores decrescentes. Do lado das saídas, verifica-se um aumento do valor adicionado até 2013, quando então houve uma queda repentina, enquanto a adimplência média se manteve por volta dos $20 \%$, com alguns destaques positivos e negativos. Estes dados gerais serão mais bem aprofundados abaixo.

No que se refere ao comparativo entre inovação e geração de valor (Gráfico 1), verifica-se que no âmbito do setor bancário os investimentos em inovação mantiveram-se crescentes. Tais dados justificam-se em virtude não apenas do crescimento do setor bancário como um todo, mas também em função do aumento dos ativos bancários, receitas de intermediação financeira, receitas de prestação de serviços e operações de crédito, o que vai ao encontro da literatura, posto que a inovação normalmente está relacionada ao crescimento econômico (Bos, Kolari \& Lamoen, 2013; Delimatsis, 2012; Delimatsis, 2013; Frame \&White 2004; Mullineux, 2010; Rossignoli \& Arnaboldi, 2009). Paralelamente, os dados demonstram que os bancos brasileiros vêm cada vez mais investindo em inovação.

Do lado da geração de valor observa-se um aumento gradual até o ano de 2013, o que está de acordo com a recuperação da economia e do setor financeiro no período pós-crise. Contudo, a partir de 2014 verifica-se uma redução significativa, chegando inclusive a ser menor que o total investido em inovação no ano de 2015. Tais dados coincidem com a crise econômica no qual o país vem passando desde 2014, período marcado pela retração do PIB, crise política, desequilíbrio econômico e queda na lucratividade das empresas. 


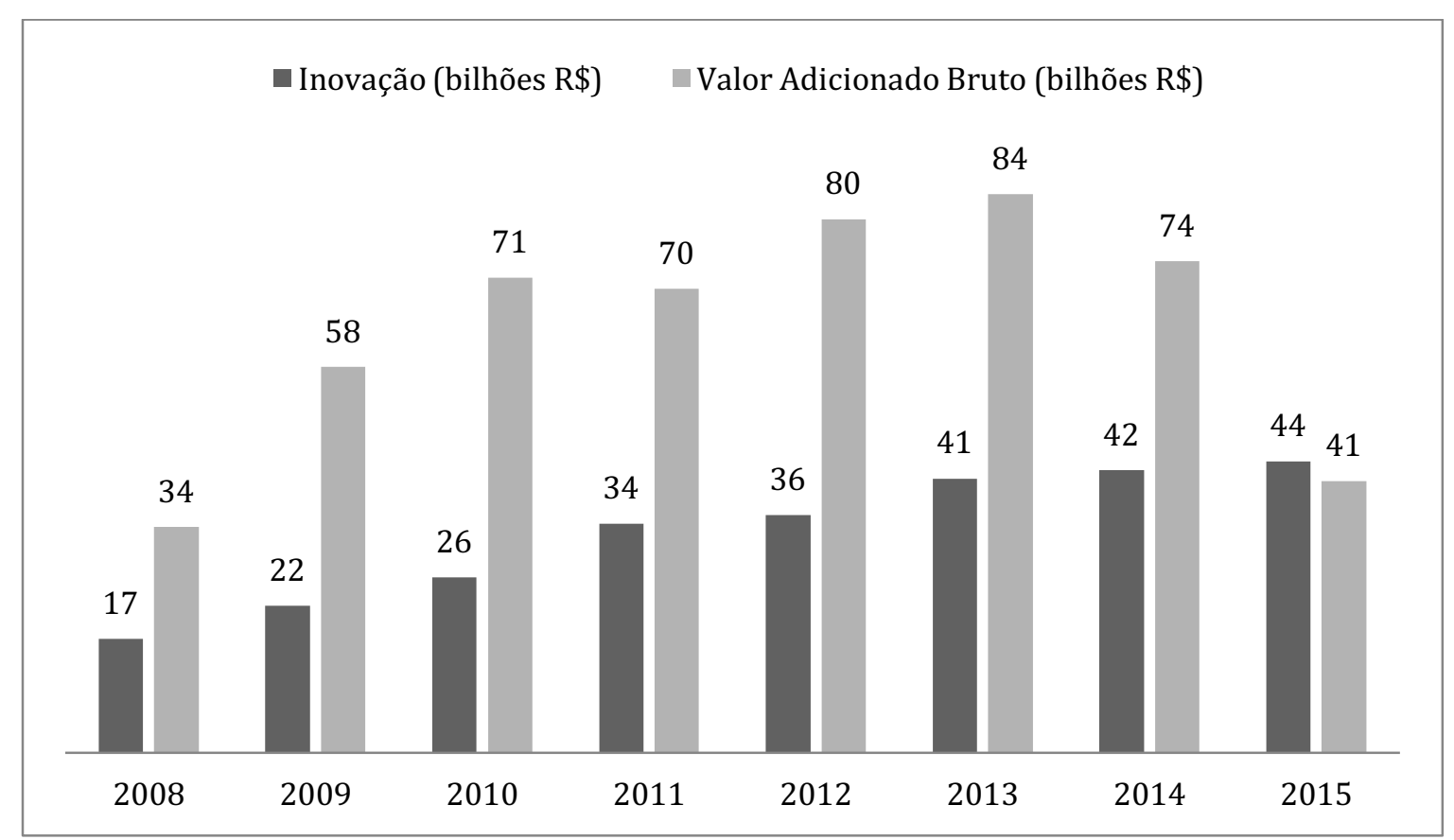

Gráfico 1. Inovação e geração de valor no setor bancário brasileiro

Estes dados fornecem indícios de uma relação positiva entre inovação e geração de valor, mas destaca que o desempenho dos bancos de forma geral pode ser afetado adversamente por fatores externos, de forma que a inovação sozinha não é capaz de sustentar a geração de riqueza. Este fato é corroborado pela literatura, que afirma que apesar da inovação no setor financeiro estar relacionada diretamente à redução de riscos, diversificação de receitas e redução da volatilidade macroeconômica (Bos, Kolari \& Lamoen, 2013; Delimatsis, 2012; Delimatsis, 2013; Rossignoli \& Arnaboldi, 2009), o desempenho do setor financeiro como um todo é ditado conjuntamente por variáveis como regulação, indefinição e redesenho das fronteiras, dinamismo e complexidade, competitividade, inovações tecnológicas e demandas por novos produtos e serviços(Blazevic \& Lievens 2004; Caselli, 2010; Delimatsis, 2013; Hoffmann, Post \& Pennings, 2013; Rossignoli \& Arnaboldi, 2009; Shahrokhi, 2008; Stevens $\&$ Dimitriadis, 2005). Cabe destacar que a análise DEA apresentada no próximo tópico fornece maior aprofundamento sobre estes dados tendo como base os resultados detalhados de cada banco.

Na sequência, no que se refere à coprodução (Gráfico 2), o que se observa é que no ano de 2010 houve um aumento significativo no quantitativo total transacionado entre bancos e parceiros, o que pode ser explicado pela retomada de fôlego no período imediatamente seguinte à crise, bem como à implantação dos Acordos de Basileia III. Tais normativos representam o conjunto de propostas de regulamentação bancária, que exigiu dos bancos o aumento das reservas bancárias e que impactou diretamente no montante de valores 
transacionados com parceiros e Banco Central para adequação aos novos limites de capital, principalmente no que se refere aos grandes bancos.

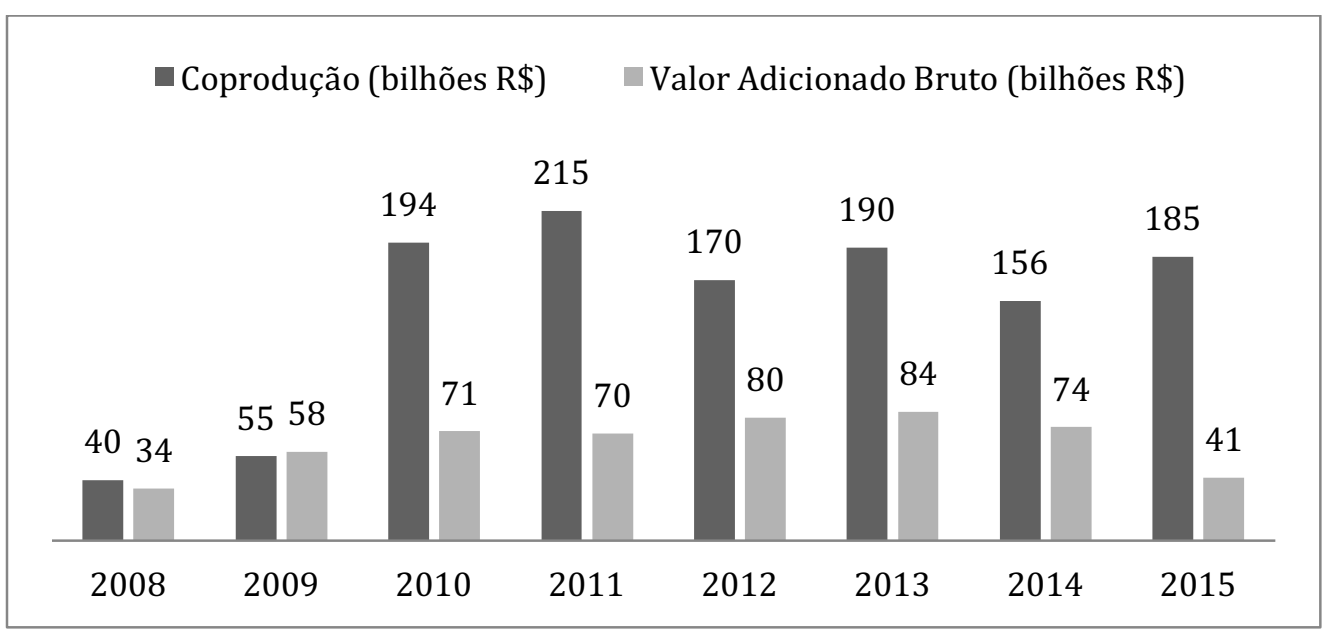

Gráfico 2.Coprodução e geração de valor no setor bancário brasileiro.

Ao comparar tais montantes com a geração de valor o que se observa é que a relação desta com a coprodução não é linear e é fortemente impactada por fatores externos. Tal fato não é explicitado na literatura, visto que os estudos sobre coprodução apontam uma relação direta entre coprodução e geração de valor (Chen, Tsou \& Ching 2011; Cheung \& To, 2011; Dunston et al., 2009; Martovoy, Mention \& Torkkeli, 2015; Mende \& Doorn, 2014; Wu \& Lin, 2013). Nesse caso, tal qual descrito anteriormente, fatores como a crise política e econômica comprometeram a geração de valor no período após 2014.

Por outro lado, ao se comparar a rede de atendimento com a geração de valor (Gráfico 3), o que se observa é que há uma certa relação positiva entre as duas variáveis. A rede de atendimento assumiu valores crescentes até meados de 2012, quando passou a diminuir em virtude da concentração bancária. De forma semelhante, o valor adicionado começou a declinar a partir de meados de 2013. Estes dados fornecem indícios de que o fortalecimento do relacionamento com o cliente favorece a geração de valor das instituições bancárias, o que vai ao encontro do proposto pela literatura (Martovoy, Mention \& Torkkeli, 2015; Mende \& Doorn, 2014). 


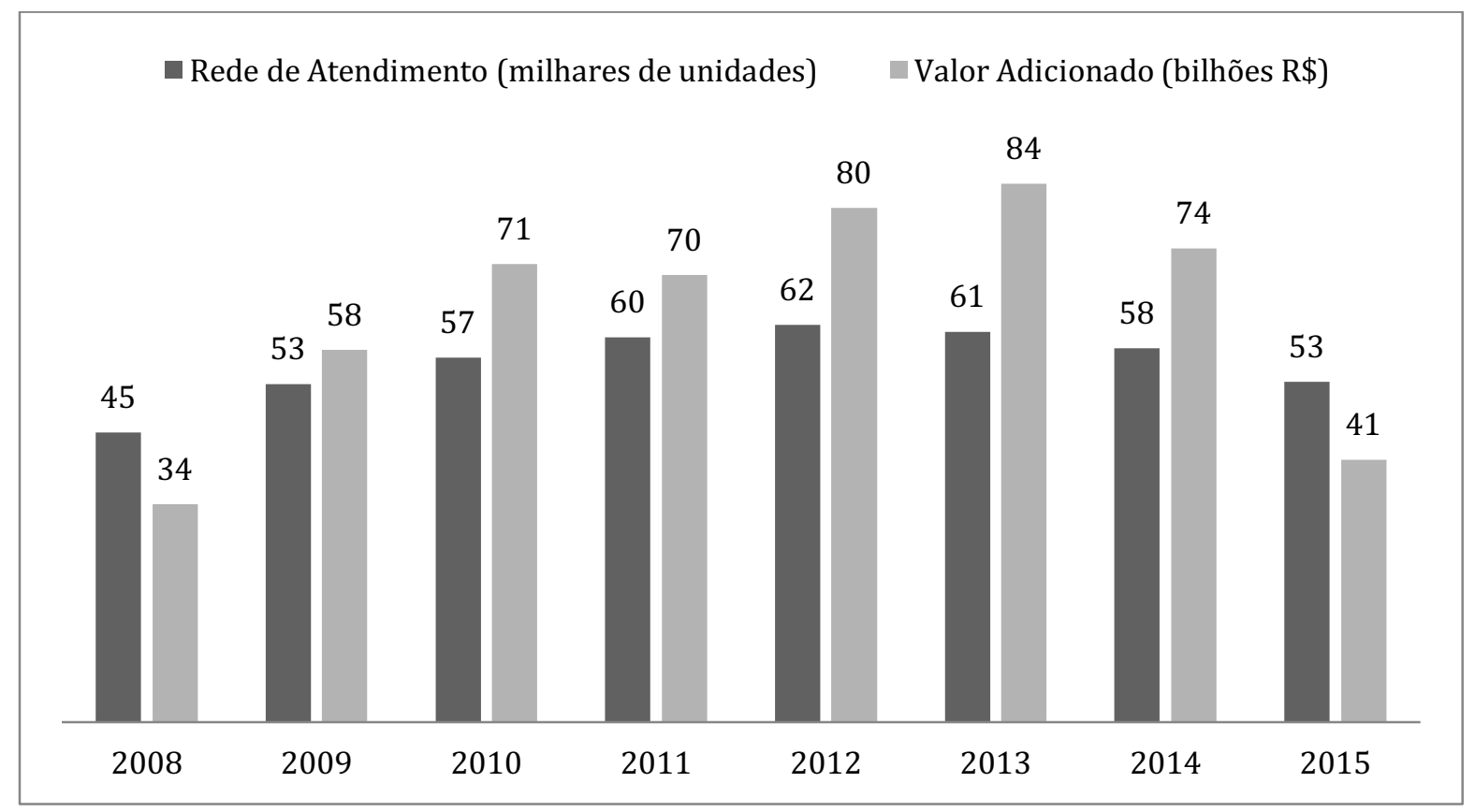

Gráfico 3.Rede de atendimento e geração de valor no setor bancário brasileiro.

Finalmente, no que e refere à adimplência (Gráfico 4), o que se observa é que esta se manteve próxima do valor de $20 \%$, mesmo com o aumento dos investimentos em inovação e coprodução, devido às instituições bancárias tenderem a manter suas reservas de capital próximas aos limites de capital estabelecidos pela regulamentação. Dessa forma, os dados fornecem sinais de que não há relação entre inovação e adimplência ou coprodução e adimplência, quanto à composição de reservas, fornecendo indícios de que o impacto positivo da inovação e coprodução na redução de riscos e otimização do gerenciamento de riscos explicitado na literatura (Bos, Kolari \& Lamoen, 2013; Delimatsis, 2012; Delimatsis, 2013; Frame \&White 2004; Mullineux, 2010;Rossignoli \& Arnaboldi, 2009; Tufano, 2003) não impacta diretamente o montante de reservas de capital. 


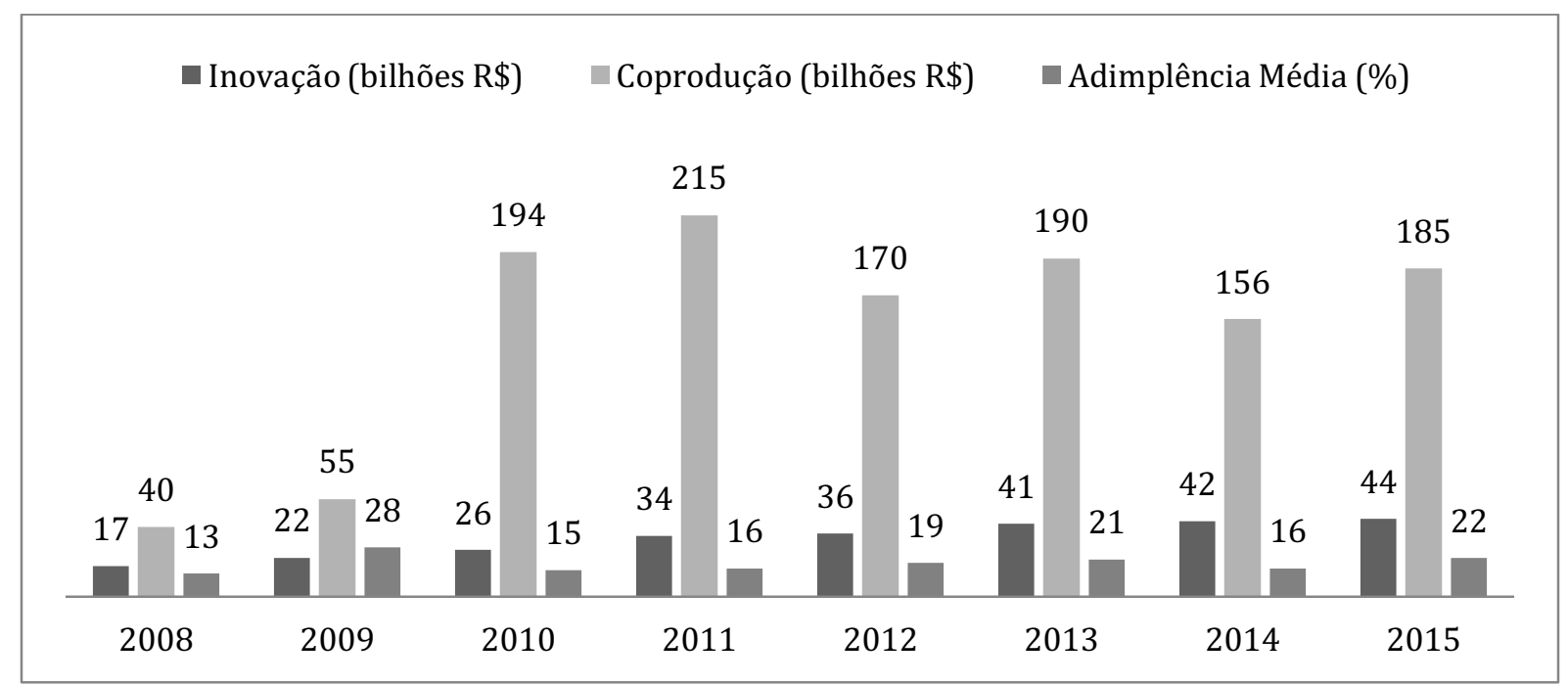

Gráfico 4.Inovação, coprodução e adimplência média no setor bancário brasileiro.

Os dados levantados anteriormente representam o panorama geral do setor bancário brasileiro tendo como base os bancos de capital aberto, e em virtude disso são fortemente impactados pelos resultados dos grandes bancos. Por esse motivo, a análise DEA contribui para elucidar tais relações de forma aprofundada e fornecer medidas de desempenho bancário individuais, o que permite a realização de análises comparativas mais robustas.

\subsubsection{Análise dos Resultados da DEA}

Inicialmente, cabe destacar que todos os dados que serviram de base para a presente análise constam no Anexo II desta tese (Tabelas 14 a 20). Os dados serviram para compor os índices de eficiência, eficiência global, produtividade, mudança de eficiência e mudança de tecnologia, que serão discutidos a seguir.

A Tabela 5 consolida os escores médios de eficiência aferidos pelos modelos CCR e BCC de cada DMU considerando o período de 2008 a 2015. Além disso, as DMUs estão dispostas em ordem decrescente de desempenho. 


\begin{tabular}{|c|c|c|c|c|c|}
\hline DMU & $\begin{array}{c}\text { Eficiência } \\
\text { (CCR) }\end{array}$ & Desempenho & DMU & $\begin{array}{c}\text { Eficiência } \\
\text { (BCC) }\end{array}$ & Desempenho \\
\hline Pan & 1 & Eficiente & Brasil & 1 & Eficiente \\
\hline Mercantil (Inv.) & 0,999501 & Acima da Média & Daycoval & 1 & Eficiente \\
\hline Daycoval & 0,998443 & Acima da Média & Mercantil (Inv.) & 1 & Eficiente \\
\hline Indusval & 0,99645 & Acima da Média & BCO Nordeste & 1 & Eficiente \\
\hline Paraná & 0,989568 & Acima da Média & Pan & 1 & Eficiente \\
\hline Alfa & 0,943981 & Acima da Média & Paraná & 0,999906 & Acima da Média \\
\hline BCO Nordeste & 0,92252 & Acima da Média & Santander & 0,999787 & Acima da Média \\
\hline Pine & 0,896489 & Acima da Média & Indusval & 0,997131 & Acima da Média \\
\hline Banpará & 0,862212 & Acima da Média & Pine & 0,996175 & Acima da Média \\
\hline ABC Brasil & 0,821213 & Acima da Média & ABC Brasil & 0,995716 & Acima da Média \\
\hline Amazônia & 0,689713 & Acima da Média & Alfa & 0,986036 & Acima da Média \\
\hline Mercantil & 0,669215 & Acima da Média & Banrisul & 0,97597 & Acima da Média \\
\hline BTG Pactual & 0,668369 & Acima da Média & Itaú & 0,963382 & Acima da Média \\
\hline Banestes & 0,64368 & Acima da Média & Amazônia & 0,940738 & Abaixo da Média \\
\hline Banese & 0,619476 & Acima da Média & BTG Pactual & 0,936303 & Abaixo da Média \\
\hline $\mathrm{BRB}$ & 0,589082 & Acima da Média & Mercantil & 0,925513 & Abaixo da Média \\
\hline Itaú & 0,461785 & Abaixo da Média & Banpará & 0,92027 & Abaixo da Média \\
\hline Banrisul & 0,256747 & Abaixo da Média & Banese & 0,906917 & Abaixo da Média \\
\hline Santander & 0,082576 & Abaixo da Média & Banestes & 0,902038 & Abaixo da Média \\
\hline Brasil & 0,058533 & Abaixo da Média & $\mathrm{BRB}$ & 0,890641 & Abaixo da Média \\
\hline Bradesco & 0,039312 & Abaixo da Média & Bradesco & 0,79878 & Abaixo da Média \\
\hline Média & 0,515026 & & Média & 0,957333 & \\
\hline
\end{tabular}

Tabela 5. Escores médios de eficiência das DMUs de acordo com os modelos CCR e BCC, considerando o período 2008-2015.

Com base nestes resultados, observa-se que os modelos apresentaram algumas divergências entre si. De acordo com o modelo CCR, o único banco eficiente no período foi o Banco Pan, seguido de perto pelo Mercantil de Investimentos, Daycoval, Indusval e Banco do Paraná. Por outro lado, o modelo BCC considerou como eficientes os bancos do Brasil, Mercantil de Investimentos, Daycoval, Banco do Nordeste e Pan, seguidos de perto pelos bancos Paraná, Santander, Indusval, Pine e ABC Brasil. Cabe ressaltar que o Banco do Brasil e Santander, considerados eficientes pelo BCC, estão entre aqueles de piores desempenho pelo CCR. Além disso, enquanto a média geral de desempenho pelo modelo CCR foi de 0,51 , no BCC foi de 0,95, o que está mais próximo da realidade posto que, apesar das recentes crises, não há indícios de que o setor bancário brasileiro tenha sofrido uma queda de eficiência de aproximadamente $50 \%$. Dessa forma, argumenta-se que o modelo BCC está mais fidedigno à realidade. 
Na sequência, a Tabela 6 fornece os resultados dos escores de eficiência global, ou seja, comparam-se as DMUs não apenas com base no ano, mas sim com base nos resultados de todas as DMUs em todos os anos do período 2008-2015.

\begin{tabular}{|c|c|c|c|c|c|}
\hline DMU & $\begin{array}{c}\text { Eficiência } \\
\text { Global (CCR) } \\
\end{array}$ & Desempenho & DMU & $\begin{array}{c}\text { Eficiência } \\
\text { Global (BCC) } \\
\end{array}$ & Desempenho \\
\hline Mercantil (Inv.) & 0,995215 & Acima da Média & Mercantil (Inv.) & 0,999817 & Acima da Média \\
\hline Daycoval & 0,982545 & Acima da Média & Daycoval & 0,996829 & Acima da Média \\
\hline Paraná & 0,9356 & Acima da Média & BCO Nordeste & 0,989909 & Acima da Média \\
\hline Alfa & 0,900387 & Acima da Média & Paraná & 0,9827 & Acima da Média \\
\hline Indusval & 0,787316 & Acima da Média & Alfa & 0,970575 & Acima da Média \\
\hline BCO Nordeste & 0,657496 & Acima da Média & Pine & 0,968079 & Acima da Média \\
\hline Pine & 0,637884 & Acima da Média & ABC Brasil & 0,96579 & Acima da Média \\
\hline Pan & 0,601268 & Acima da Média & Indusval & 0,960091 & Acima da Média \\
\hline Banpará & 0,557382 & Acima da Média & Santander & 0,947811 & Acima da Média \\
\hline ABC Brasil & 0,455026 & Acima da Média & Brasil & 0,94754 & Acima da Média \\
\hline Banestes & 0,399083 & Acima da Média & Pan & 0,927142 & Acima da Média \\
\hline BTG Pactual & 0,236973 & Acima da Média & Banrisul & 0,919466 & Acima da Média \\
\hline BRB & 0,202937 & Acima da Média & BTG Pactual & 0,885366 & Abaixo da Média \\
\hline Banese & 0,192335 & Acima da Média & Banpará & 0,878282 & Abaixo da Média \\
\hline Mercantil & 0,192149 & Acima da Média & Amazônia & 0,86128 & Abaixo da Média \\
\hline Amazônia & 0,110832 & Abaixo da Média & Itaú & 0,852425 & Abaixo da Média \\
\hline Banrisul & 0,062076 & Abaixo da Média & Banese & 0,849207 & Abaixo da Média \\
\hline Santander & 0,005704 & Abaixo da Média & Mercantil & 0,837451 & Abaixo da Média \\
\hline Bradesco & 0,00429 & Abaixo da Média & Banestes & 0,837212 & Abaixo da Média \\
\hline Brasil & 0,003951 & Abaixo da Média & $\mathrm{BRB}$ & 0,834378 & Abaixo da Média \\
\hline Itaú & 0,003888 & Abaixo da Média & Bradesco & 0,625268 & Abaixo da Média \\
\hline Média & 0,170784 & & & 0,902015 & \\
\hline
\end{tabular}

Tabela 6.Escores médios de eficiência das DMUs de acordo com os modelos CCR e BCC, considerando o período 2008-2015.

Nesse âmbito, verifica-se que pelo modelo CCR os bancos Mercantil de Investimentos e Daycoval se destacam como os mais eficientes, com escores próximos de uma unidade. Pelo BCC estes mesmos bancos apontaram como os mais eficientes, juntamente com o Banco do Nordeste e Banco Paraná. Na ponta negativa, os Bancos do Brasil, Itaú, Bradesco e Santander apontam como aqueles de pior desempenho pelo CCR, inclusive com escores menores que 0.01 , fato que não se replica no BCC. Uma vez que tais bancos são os maiores do setor e nos últimos anos atingiram resultados positivos de crescimento, tais dados fornecem uma evidência adicional de que o modelo BCC é o mais adequado para a análise. Além disso, a média de desempenho no período aponta uma redução de eficiência global de aproximadamente $83 \%$ pelo CCR, enquanto pelo BCC tal redução foi de apenas $10 \%$, o que 
reforça ainda mais a fidedignidade do modelo BCC. Com base em tais dados, a análise que se segue considerou apenas os resultados do BCC.

A fim de se comparar as mudanças de produtividade aferidas no período, a Tabela 7 apresenta os valores do índice de Malmquist e sua decomposição (Wang \& Lan, 2011), e constituem a síntese do crescimento da produtividade dos bancos brasileiros no período de 2008 a 2015.

\begin{tabular}{|c|c|c|c|}
\hline Período & $\begin{array}{c}\text { Índice de Malmquist } \\
\text { (MPI) }\end{array}$ & $\begin{array}{c}\text { Mudança de Eficiência } \\
\text { (OEC) }\end{array}$ & $\begin{array}{c}\text { Mudança Tecnológica } \\
\text { (OTC) }\end{array}$ \\
\hline $2008-2009$ & 1,032611 & 0,993218 & 1,039662 \\
\hline $2009-2010$ & 0,993598 & 1,00878 & 0,98495 \\
\hline $2010-2011$ & 0,973244 & 0,993278 & 0,979831 \\
\hline $2011-2012$ & 1,012187 & 0,991308 & 1,021062 \\
\hline $2012-2013$ & 1,002027 & 0,994931 & 1,007131 \\
\hline $2013-2014$ & 0,981218 & 1,013516 & 0,968132 \\
\hline $2014-2015$ & 0,943553 & 0,957457 & 0,985478 \\
\hline Média Geométrica & 0,990845 & 0,993071 & 0,997758 \\
\hline Média Aritmética & 0,991205 & 0,993213 & 0,998035 \\
\hline Máximo & $1,032611(2008-2009)$ & $1,013516(2013-2014)$ & $1,039662(2008-2009)$ \\
\hline Mínimo & $0,943553(2014-2015)$ & $0,957457(2014-2015)$ & $0,968132(2013-2014)$ \\
\hline Períodos $>1$ & 3 & 2 & 3 \\
\hline Períodos $<1$ & 4 & 5 & 4 \\
\hline
\end{tabular}

Tabela 7. Índices de produtividade no setor bancário brasileiro no período de 2008 a 2015.

De forma específica, verifica-se que no período de 2008 a 2009 houve um crescimento de produtividade de $3,26 \%$, o maior do período considerado, caracterizado principalmente em virtude da melhoria tecnológica de aproximadamente $4 \%$, também a maior do período. O ano de 2008 foi marcado pela evolução da crise financeira global, a maior desde a década de 1930, que teve origem com a quebra do mercado imobiliário americano e se alastrou por diversos países. Tal conjuntura refletiu-se desfavoravelmente na forma de redução das condições de crédito do mercado internacional, falta de liquidez, maior aversão ao risco e forte deterioração das perspectivas de crescimento da economia mundial. No Brasil, os efeitos adversos se manifestaram na forma de restrição ao fluxo de recursos externos e ao crédito, bem como na redução do ritmo da atividade econômica e um processo de forte desvalorização do real frente ao dólar. A escassez das linhas externas de financiamento levou as empresas brasileiras a buscarem crédito, o que acarretou no mercado bancário novas demandas e aumento da inadimplência. Todavia, o Brasil se mostrou mais resiliente em virtude de uma forte política macroeconômica, o que mitigou os potenciais impactos das turbulências externas. 
Em 2009, houve a retomada da economia mundial em virtude principalmente da forte recuperação logo após a crise e no aumento do PIB dos EUA e da Área do Euro, após um longo período de recessão. A retomada do crescimento dos países desenvolvidos promoveu a recuperação do comércio internacional e da atividade econômica em outras regiões do mundo. Os efeitos de estímulos monetários e fiscais anticíclicos em escala global se manifestaram por meio do fim da recessão das economias centrais e principais emergentes, com esse último bloco econômico apresentando melhor desempenho que o primeiro. No Brasil, a solidez dos fundamentos macroeconômicos e do sistema financeiro permitiu que fossem implantadas medidas tempestivas contracíclicas na área creditícia e na esfera fiscal. Dessa forma, a atividade econômica brasileira mostrou forte retomada em um ambiente inflacionário favorável. Cabe destacar que no setor bancário houve uma rápida recuperação do crédito. Portanto, o forte aumento de produtividade no período se justifica em um contexto imediatamente a crise, onde após um declínio considerável, os bancos passaram por uma rápida recuperação.

O período seguinte, 2009-2010, foi caracterizado por uma leve queda de produtividade de $0,64 \%$. Apesar da ligeira melhoria de eficiência a tecnologia apresentou um declínio de aproximadamente $1,5 \%$. Tal fato se justifica porque o ano de 2010 foi caracterizado pelo baixo ritmo de crescimento nos países desenvolvidos frente a uma recuperação mais significativa dos mercados emergentes. No cenário internacional houve desaquecimento da atividade econômica doméstica, o que levou os governos a adotarem pacotes de expansão da liquidez. Paralelamente, a estabilidade financeira global passou a ser negativamente afetada pelas dívidas fiscais de países europeus, em especial, Grécia, Irlanda,Portugal e Espanha, enquanto os países emergentes mantiveram sua trajetória de recuperação econômica. De forma específica, o Brasil apresentou crescimento devido à combinação da elevação da inflação internacional pressionada pela elevação dos preços das commodities, o que gerou a valorização do real. O dinamismo da economia brasileira refletiu-se no bom desempenho dos mercados de trabalho e de crédito, principais vetores de impulso à demanda doméstica, impulsionado pelo crescimento das despesas públicas e pela maior disponibilidade de crédito oferecida pelos bancos. Entretanto, o período foi caracterizado pelo aumento da inflação e elevação da taxa de juros, bem como implantação de medidas macroprudenciais por parte do governo, tais como elevação dos depósitos compulsórios e a majoração do fator de ponderação de risco para operações de crédito. Tais fatores conjuntamente contribuíram para a leve queda de produtividade.

Em 2011, o ambiente internacional apresentou deterioração na percepção de risco acerca da sustentabilidade fiscal de países europeus em uma conjuntura de forte revisão das 
perspectivas de crescimento econômico, aumento do risco soberano, rebaixamento de rating e declínio das condições de financiamento. Portanto, o período foi marcado pela elevada volatilidade no cenário internacional, deterioração das perspectivas de crescimento das economias desenvolvidas, demandas por ajustes fiscais e contenção do crédito privado. Em meio a essas adversidades, a economia brasileira mostrou-se resiliente, ancorada em fundamentos macroeconômicos e sustentada pelo dinamismo da demanda doméstica. $\mathrm{O}$ ano foi caracterizado por taxas de desemprego em patamares mínimos, elevada geração líquida de empregos formais, ganhos reais de renda e dinamismo do mercado de crédito. Contudo, mesmo assim consolidou-se a tendência de desaceleração da atividade econômica em virtude do aperto fiscal e monetário, aumento da inflação e inadimplência e redução no crescimento do mercado de crédito. Tal conjuntura justifica a queda na produtividade aferida de aproximadamente $2,7 \%$ no período, gerada a partir da combinação de uma queda de $0,7 \%$ na eficiência e $2,1 \%$ na tecnologia.

Na sequência, o ano de 2012 foi marcado pelo aumento da aversão global ao risco aliado a um arrefecimento das economias emergentes e queda nos preços das commodities. Dessa forma, houve baixo crescimento global com elevada volatilidade decorrente de temores de crise no cenário internacional. A economia brasileira, respondeu negativamente à desaceleração do crescimento mundial, requerendo do Governo a implantação de medidas fiscais, monetárias e creditícias de estímulo à economia. Nesse contexto, o crescimento foi menor que a expectativa, em particular em virtude da queda da produção industrial e do investimento. Nessa conjuntura, a inflação desacelerou e a taxa Selic declinou para seu patamar histórico. No setor bancário as concessões de crédito apresentaram alta e o estoque de crédito como proporção do PIB aumentou ao mesmo tempo em que a taxa de inadimplência também aumentou. Enfim, os juros e spreads bancários apresentaram trajetória de queda durante todo o ano de 2012. Dessa forma, o setor bancário apresentou um aumento de 1,2\% de produtividade, veiculada principalmente pela melhoria tecnológica da ordem de $2,1 \%$.

A recuperação da economia mundial caracterizou o ano de 2013. O período foi marcado pela recuperação modesta da economia americana e da zona do euro. Essa conjuntura propiciou a valorização do dólar, o que trouxe impactos adversos diretos na cotação das moedas e na avaliação do prêmio de risco associado às economias emergentes. A economia brasileira foi afetada pelas incertezas do ambiente externo e o crescimento do PIB ficou abaixo do esperado. Paralelamente, iniciou-se um novo ciclo de elevação da Selic para conter a alta da inflação. No mercado bancário as concessões de crédito apresentaram altas significativas e o estoque de crédito como proporção do PIB também aumentou. Com relação à inadimplência, 
as taxas apresentaram tendência de queda ao longo do ano. Ainda, as taxas de juros bancários interromperam o processo de queda e os spreads permaneceram estáveis. Nesse contexto, a produtividade se mostrou praticamente constante (aumento de $0,2 \%$ ), gerada a partir de uma leve queda de eficiência de $0,5 \%$ aliada a uma ligeira melhoria da tecnologia de $0,7 \%$.

No período de 2013-2014 houve uma queda de produtividade de 1,9\%, resultado de uma melhoria de aproximadamente $1,3 \%$ de eficiência, a maior do período estudado, com um declínio de 3,2\% da tecnologia, a menor do período. Tal fato se justifica, uma vez que no ano de 2014 a conjuntura internacional manteve-se complexa com dinâmicas distintas entre as principais economias. A recuperação da economia americana se solidificou e na zona do euro a atividade econômica apresentou recuperação modesta. Na América Latina, de maneira geral, as economias mostraram taxas de crescimento mais baixas em 2014 do que no ano anterior. Nesse contexto, o Brasil retomou a trajetória de crescimento suportada por condições favoráveis do mercado de trabalho e evolução do mercado de crédito, mesmo em face de uma elevação da inflação. A atividade econômica apresentou-se abaixo do esperado, com redução da confiança de consumidores e empresários. No setor bancário, houve a desaceleração do crescimento do estoque de crédito e a inadimplência do sistema permaneceu estável. Além disso, o início da crise política impactou negativamente o resultado do período.

Em 2015, o ritmo de crescimento da economia global foi menor que o esperado. Enquanto os Estados elevaram a taxa básica de juros, na Europa, a atividade econômica respondeu positivamente aos estímulos monetários. Na América Latina, os preços mais baixos das commodities influenciaram negativamente o investimento, confiança e renda nacional. Especificamente no Brasil, o ano de 2015 foi caracterizado por ajustes nos planos fiscal e monetário, com efeitos adversos sobre a atividade econômica. O período foi marcado pela contração do PIB, aumento da taxa de desemprego, forte elevação da inflação e aumento da taxa de juros. O Brasil enfrentou um aumento do déficit primário e uma forte desvalorização do real frente ao dólar. Além disso, a crise política e econômica se intensificou no período, o que impactou negativamente os resultados das empresas. Tal conjuntura justifica a maior queda de produtividade no período considerado (5,7\%), resultado do declínio de 4,3\% na eficiência, o maior do período, atrelado a uma queda de $1,5 \%$ da tecnologia.

Com base nos fatos apresentados, o Gráfico 5 apresenta os resultados da produtividade no setor bancário de forma consolidada, segundo as variações percentuais acumuladas. Verifica-se de forma mais clara que de 2008 para 2009 o setor bancário teve um forte aumento de produtividade, seguido de uma leve queda em 2010 para uma queda maior em 2011. Após 2011 a produtividade assumiu uma tendência de crescimento que se estendeu até 
2013, seguida de uma queda que se estendeu até 2015. Nesse âmbito, e a partir dos dados da Tabela 10, verifica-se que a produtividade sofreu um declínio médio de um ponto percentual, caracterizados principalmente por uma média de queda de $0,7 \%$ de eficiência e $0,3 \%$ de tecnologia ao ano.

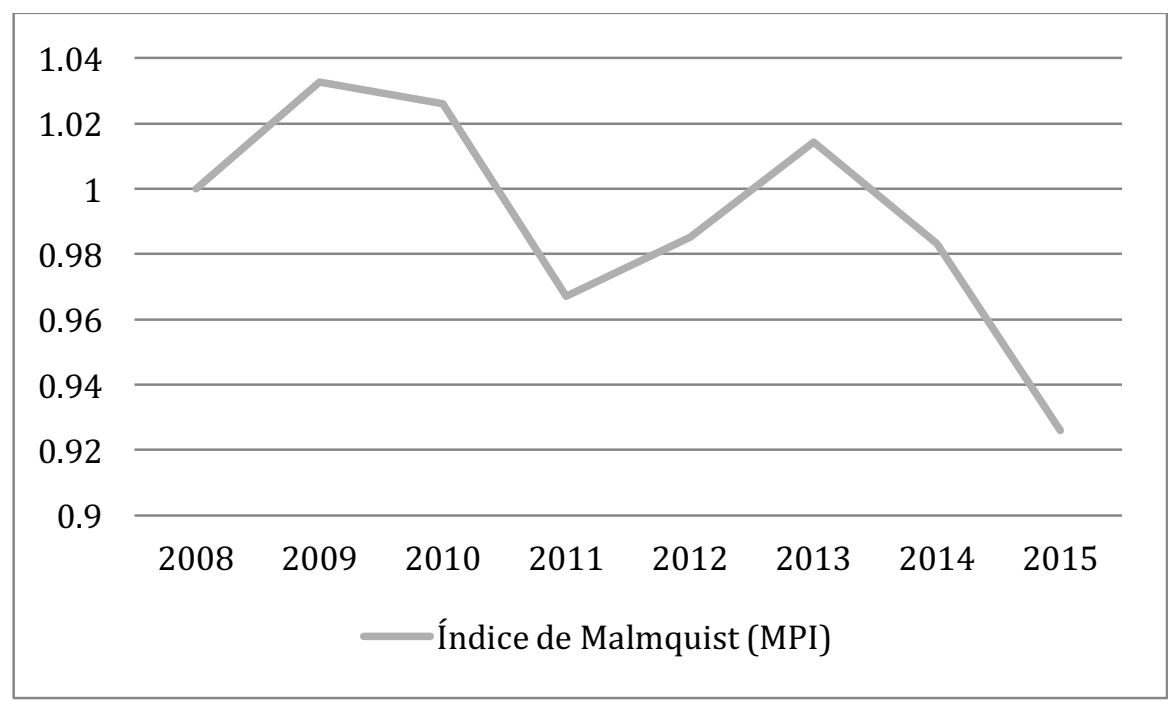

Gráfico 5. Produtividade do setor bancário brasileiro no período de 2008 a 2015.

A Tabela 8 consolida os índices médios de produtividade de cada DMU no período considerado a fim de aprofundar os resultados apresentados acima e considerar as especificidades de cada banco.

\begin{tabular}{|c|c|c|c|}
\hline DMU & $\begin{array}{c}\text { Índice de Malmquist } \\
\text { (MPI) }\end{array}$ & $\begin{array}{c}\text { Mudança de Eficiência } \\
\text { (OEC) }\end{array}$ & $\begin{array}{c}\text { Mudança Tecnológica } \\
\text { (OTC) }\end{array}$ \\
\hline Itaú & 1,049336 & 1,016412 & 1,032392 \\
\hline Banrisul & 1,018337 & 1,007782 & 1,010473 \\
\hline Santander & 1,009663 & 1 & 1,009663 \\
\hline Amazônia & 1,006224 & 0,996956 & 1,009297 \\
\hline BCO Nordeste & 1,004146 & 1 & 1,004146 \\
\hline BRB & 1,003352 & 0,998422 & 1,004938 \\
\hline Mercantil & 1,002336 & 0,990723 & 1,011722 \\
\hline Daycoval & 1,000405 & 1 & 1,000405 \\
\hline Alfa & 1,000296 & 1,001112 & 0,999185 \\
\hline Mercantil (Inv.) & 1,000052 & 1 & 1,000052 \\
\hline Banestes & 1,000039 & 0,994779 & 1,005288 \\
\hline Paraná & 0,997779 & 1 & 0,997779 \\
\hline Banese & 0,996194 & 1,000095 & 0,9961 \\
\hline ABC Brasil & 0,995397 & 1,000428 & 0,994972 \\
\hline Pine & 0,993435 & 0,99762 & 0,995805 \\
\hline
\end{tabular}




\begin{tabular}{|c|c|c|c|}
\hline Indusval & 0,989392 & 1 & 0,989392 \\
\hline Banpará & 0,988072 & 0,994107 & 0,99393 \\
\hline Pan & 0,98784 & 1 & 0,98784 \\
\hline Brasil & 0,956751 & 1 & 0,956751 \\
\hline Bradesco & 0,915297 & 0,933348 & 0,98066 \\
\hline BTG Pactual & 0,903895 & 0,927541 & 0,974507 \\
\hline
\end{tabular}

Tabela 8. Média de produtividade dos bancos brasileiros no período de 2008 a 2015.

Verifica-se, portanto, que no período o banco que teve melhor desempenho foi o Banco Itaú, com um aumento de aproximadamente 5\% na produtividade, produto de uma melhoria de 1,6\% de eficiência aliada a uma melhoria tecnológica de 3,2\%. Na sequência seguem o Banrisul e Santander, com aumento de produtividade de 1,8\% e 0,9\%, respectivamente. Estes três bancos constituem benchmarks de referência no setor.

Em síntese, os resultados apresentados demonstraram que de forma geral a produtividade no período de 2008 a 2015 sofreu uma queda em virtude de fatores macroeconômicos externos relacionados principalmente à aversão ao risco, desaceleração do crescimento e crise política e econômica. A produtividade do setor bancário declinou em aproximadamente $7,4 \%$ no período, com um declínio de 3\% na eficiência e $4,6 \%$ na tecnologia. Entretanto, mesmo diante de tais condições adversas, alguns bancos se destacaram no período. No que tange à eficiência, 12 dos 21 bancos ficaram acima da média, além do que a média de eficiência global no período foi de 0.902 , o que demonstra que, mesmo frente a condições adversas, os bancos de maneira geral se mostraram eficientes. Quanto à produtividade, 11 dos 21 bancos demonstraram melhoria, sendo que outros cinco não apresentaram declínio menor que $1 \%$, o que indica que o setor bancário no Brasil é de forma geral resiliente a fatores externos.

Além disso, os resultados demonstraram que inovação e coproducão são indicadores estatísticos robustos para explicar eficiência e produtividade no setor bancário, de maneira que ficam comprovadas as hipóteses de pesquisa. Uma vez que a utilização da inovação e coproducão como inputs para DEA, gerando valor e adimplência como outputs, se mostrou uma construção válida para explicar o desempenho bancário, bem como a melhoria de produtividade e suas componentes, verifica-se que ambas as variáveis representam bons estimadores de desempenho.

De forma específica, a inovação apresentou relação positiva com o desempenho uma vez que a técnica demonstrou ser viável a utilização de inputs de inovação para mensurar a performance bancária, além do que os resultados foram condizentes com os fatos macroeconômicos ocorridos no período. Portanto, o estudo demonstrou que a inovação pode 
ser utilizada como variável explicativa de desempenho, o que encontra respaldo na literatura (Bos, Kolari \& Lamoen, 2013; Delimatsis, 2012; Delimatsis, 2013; Frame \&White 2004; Mullineux, 2010; Rossignoli \& Arnaboldi, 2009). Paralelamente, verificou-se que a coproducão é capaz de explicar desempenho bancário uma vez que a medida de interação e relacionamento com parceiros e clientes demonstrou ser um bom estimador da geração de valor e produtividade, o que vai ao encontro da literatura (Edvardsson et al., 2010; Field, Xue\&Hitt, 2012; Lusch, Vargo \& O’Brien, 2007; Martovoy, Mention e Torkkeli, 2015; Mende \& Doorn, 2014).

\subsection{Conclusões}

O presente estudo teve como objetivo mensurar a mudança de produtividade de bancos brasileiros nos últimos anos tendo como base os investimentos em inovação e coprodução. Com base no levantamento bibliográfico realizado, percebeu-se que apesar de a literatura apontar uma relação positiva entre inovação, coproducão e desempenho, existem poucas evidências empíricas sobre o tema. Utilizou-se, portanto, uma DEA baseada no índice de produtividade de Malmquist para acessar o desempenho e a produtividade de bancos brasileiros no período de 2008 a 2015 utilizando inovação, coprodução e rede de atendimento como inputs e geração de valor e adimplência como outputs.

Os resultados confirmaram que o modelo DEA-BCC é mais adequado para analisar o desempenho de bancos brasileiros em virtude das grandes disparidades de escala, e que o modelo Malmquist-DEA se mostra robusto para análise da produtividade no setor. Além disso, verificou-se que no período considerado a produtividade do setor bancário brasileiro declinou. Contudo, observou-se que a maioria dos bancos apresentaram bons desempenhos e que a média de eficiência global foi elevada. Ainda, a maioria dos bancos apresentou melhoria de produtividade e apenas três apresentaram queda significativa. Finalmente, confirmaram-se as hipóteses da pesquisa, já que inovação e coproducão se mostraram bons estimadores estatísticos para explicar o desempenho bancário.

As contribuições do estudo se baseiam no pioneirismo de utilização dos investimentos em inovação e coprodução como insumos para DEA. Além disso, o trabalho fornece evidências empíricas acerca da relação positiva entre inovação, coprodução e desempenho.Do ponto de vista prático, o trabalho demonstrou que inovação e coprodução devem ser consideradas quando da análise e mensuração de desempenho, bem como tomada de decisão. Sugere-se, portanto, para fins de estudos futuros que se aprofunde a análise realizada com base na: aplicação de diferentes técnicas de DEA para corroborar os resultados 
encontrados; realização de diferentes técnicas estatísticas para evidenciar as relações entre inovação, coprodução e desempenho; construção de instrumentos de mensuração focados em captar inovação e coprodução e consequente refinamento do modelo apresentado; replicação do estudo em outras instituições do setor financeiro com o intuito de averiguar se as relações se mantêm; e reprodução do estudo em outros setores da economia para estabelecer análises comparativas. 


\section{CONCLUSÕES E RECOMENDAÇÕES}

Este capítulo sumariza as principais conclusões deste trabalho ao mesmo tempo em que apresenta as limitações do estudo, contribuições teóricas e de cunho prático e ainda destaca a agenda de pesquisa no intuito de sugerir diretrizes para estudos futuros sobre o tema. Em síntese, a presente tese teve como objetivo explicar as relações entre inovação, desempenho e coproducão no setor financeiro, o que foi possível por meio dos seguintes objetivos específicos: (1) discorrer sobre a relação entre inovação, desempenho e coprodução no setor financeiro e propor um modelo de articulação conceitual; (2) caracterizar a relação entre inovação, desempenho e coprodução no setor financeiro brasileiro; e (3) determinar o impacto da inovação e coprodução no desempenho de bancos brasileiros.

Observou-se que a recente crise do setor financeiro promoveu uma reformulação de toda a dinâmica, de forma que o papel da inovação foi questionado (Delimatsis, 2012). Dessa forma, diversos autores argumentaram que a inovação foi a responsável pela crise, visto que a criação de instrumentos financeiros obscuros que mascaravam o risco real acabou por eclodir em uma evasão em massa que comprometeu todo o sistema (Gai et al., 2008; Hutton \& Lee, 2012; Lenzer \& Zhao, 2012; Mullineux, 2010). Por outro lado, outros estudos demonstraram que a inovação no setor financeiro é responsável pelo crescimento econômico e melhoria do gerenciamento de riscos, e que, de forma geral, trata-se do mecanismo promotor da mudança, adaptação e sobrevivência das instituições financeiras no mercado (Bos, Kolari \& Lamoen, 2013; Delimatsis, 2013; Frame \& White, 2004; Rossignoli \& Arnaboldi, 2009; Tufano, 2003). Nesse âmbito destacou-se que as inovações envolvem riscos, que quando mal gerenciados ou regulados podem ocasionar impactos negativos para o sistema, mas que se deve buscar usufruir dos benefícios de tais artefatos (Delimatsis, 2013).

Paralelamente, destacou-se que a inovação é responsável por aumentar o nível de interatividade entre os atores do mercado, ao mesmo tempo em que há diversas evidências de que a inovação tem relação positiva com a coproducão (Chen, Tsou \& Ching, 2011; Cheung \& To, 2011; Martovoy, Mention \& Torkelli, 2015; Mende \& Doorn, 2014; Wu \& Lin, 2013; Vargo \& Lusch, 2004). Dessa forma, os parceiros e clientes tornam-se depósitos de conhecimento e, portanto, são fontes essenciais de informação, de tal modo que fornecem insumos diretos para a inovação (Chen, Tsou \& Ching, 2011; Tsou \& Chen, 2012). Finalmente, argumentou-se que o desempenho das instituições financeiras é tradicionalmente considerado como a medida de conversão de entradas em saídas, de tal modo que as instituições buscam 
reduzir as entradas e/ou maximizar as saídas a fim de aperfeiçoar tal proporção (Charnes, Cooper \& Rhodes, 1978; Farrell, 1957; Kopp, 1981; Leibenstein, 1966; Varian, 1990).

Com base nisso, foram identificadas convergências na literatura tendo em vista a abordagem de processo. Inicialmente, sob a óptica da abordagem integradora da inovação, um produto ou serviço foi caracterizado como um processo composto de competências e características que tem como objetivo a geração de entregas, onde a inovação ocorre sempre que há mudança em quaisquer desses componentes com o intuito de melhorar as entregas existentes ou criar novas (Gallouj, 2002; Gallouj \& Savona, 2009; Gallouj \& Weinstein, 1997). Nesse contexto, a coproducão é representada na forma da mobilização de competências entre instituição, parceiros e clientes, e o desempenho foi descrito como a medida de conversão de competências em características em entregas.

As premissas e proposições discutidas no capítulo 2 suscitaram questões acerca da articulação de tais constructos. Argumentou-se, primeiramente, que o ambiente tem relação direta com a inovação e coprodução uma vez que variáveis como regulação, limites de atuação, competitividade, dinamismo, tecnologias e demandas dos clientes atuam como moderadoras e mediadoras do processo (Blazevic \& Lievens 2004; Buzzacchi, Colombo \& Mariotti, 1995; Caselli, 2010; Delimatsis, 2013; Rossignoli \& Arnaboldi, 2009; Shahrokhi, 2008; Stevens \& Dimitriadis, 2005). Adicionalmente, defendeu-se que a coprodução tem relação positiva com a inovação posto que a prática de colaboração produz sinergias que induzem a melhoria de processos a partir da introdução de novo conhecimento (Chen, Tsou e Ching, 2011; Edvardsson et al., 2010; Ordanini, Miceli, Pizzetti \& Parasuraman, 2011; Wei, Wang, Tao \& Wang, 2006; Zhaoquan, Chen \& Xiande, 2013).

Na sequência, propôs-se que a inovação tem relação positiva com o desempenho posto que gere benefícios, reduz riscos e diversifica instrumentos financeiros (Bos, Kolari \& Lamoen, 2013; Delimatsis, 2012; Delimatsis, 2013; Frame \&White 2004; Rossignoli \& Arnaboldi, 2009). Finalmente, alegou-se que a coprodução também possui relação positiva com o desempenho pois a interatividade e rede de relacionamentos representa transferência de conhecimentos, sinergia de operações e vantagem competitiva para a organização (Edvardsson et al., 2010; Field, Xue\&Hitt, 2012; Lusch, Vargo \& O’Brien, 2007; Martovoy, Mention e Torkkeli, 2015; Mende \&Doorn, 2014).

Fundamentado em tais insumos, o Estudo I buscou investigar as três últimas proposições tendo como base 29 instituições financeiras brasileiras de capital aberto. Por meio da análise de conteúdo dos formulários de referência do ano de 2015, foram evidenciados relatos sobre as relações entre inovação, coprodução e desempenho. Os resultados 
demonstraram que as instituições financeiras brasileiras inovam principalmente para desenvolver novos produtos e serviços, melhorar produtos, serviços, processos e força de trabalho, estabelecer relacionamentos com parceiros e clientes, expandir a infraestrutura e investir em práticas socioambientais. Adicionalmente, observou-se que a relação entre inovação e desempenho é mediada por fatores internos tais como experiência da administração, flexibilidade organizacional, análise de viabilidade e melhoria contínua, ao mesmo tempo em que é moderada por fatores externos como taxa de juros, inflação, liquidez, inadimplência, tecnologias e demandas de mercado. Em suma, verificou-se que a inovação parte de um investimento inicial com intuito de gerar retorno positivo, onde que o sucesso da inovação ocorrerá sempre que o valor gerado superar o capital investido. Ainda, constatou-se que no setor financeiro brasileiro a inovação tende a apresentar impacto positivo no desempenho, uma vez que o setor é dominado por instituições de grande porte, que, por sua vez, possuem maturidade administrativa e reservas de capital suficientes para assumir riscos e inovar.

No tocante à coprodução, o Estudo I evidenciou que no setor financeiro brasileiro os relacionamentos colaborativos ocorrem principalmente entre instituições e parceiros de negócio, sendo que alguma atenção é dada ao estreitamento da relação com o cliente, governo e sociedade de forma geral. Nesse sentido, descobriu-se que a coprodução no setor financeiro é explicada com base em variáveis como proposta de valor agregado, envolvimento dos parceiros e clientes, sinergias no planejamento e execução e análise de viabilidade. Além disso, observou-se que a relação com o desempenho é moderada por fatores macroeconômicos externos e movimentos de mercado. Outro ponto relevante é que as companhias destacaram os riscos associados ao processo de coprodução, tais como exposição a novos riscos, resultados negativos de parceiros, interesses divergentes, dependência e risco reputacional e de imagem, elementos esses pouco explorados pela literatura (Chen, Tsou \& Ching, 2011; Cheung \& To, 2011; Dunston et al., 2009; Martovoy, Mention \& Torkkeli, 2015; Mende \& Doorn, 2014; Vargo \& Lusch, 2004; Wu \& Lin, 2013). Entretanto, as companhias no geral se mostraram dispostas a assumir os riscos associados a fim de alcançar os benefícios da coprodução, tais como legitimidade e confiança no mercado, incorporação de novo conhecimento, diversificação de produtos e serviços, rentabilização da base de clientes, fortalecimento da marca e acesso a melhores práticas. Ainda, evidenciou-se que a relação entre inovação e coprodução é positiva uma vez que a negociação de acordos e parcerias e a integração de esforços permite alcançar novos produtos e serviços e diversificar receitas.

Com base nessas informações, e com o intuito de dar continuidade à análise, o Estudo II foi desenhado para mensurar a mudança de produtividade de bancos brasileiros nos 
últimos anos tendo como apoio os investimentos em inovação e coprodução. No que se refere a esse assunto, a literatura demonstrou que existem poucas evidências empíricas acerca da relação entre inovação, coproducão e desempenho. Dessa forma, aplicou-se uma DEA tendo como base o índice de produtividade de Malmquist e seus componentes, mudança de eficiência e mudança de tecnologia. A análise comparou a aplicabilidade dos modelos CCR e BCC orientados a outputs e utilizou inovação, coproducão e rede de atendimento como inputs e geração de valor e adimplência como outputs. Os dados foram coletados das demonstrações financeiras de bancos brasileiros de capital aberto e abrangeu o período de 2008 a 2015.

De forma geral os resultados mostraram que há uma relação positiva entre inovação e geração de valor, mas destacaram que o desempenho dos bancos de forma geral é afetado adversamente por fatores externos e, portanto, a inovação sozinha não é capaz de sustentar a geração de riqueza. Na sequência, observou-se que a relação entre coproducão e geração de valor é não linear e fortemente impactada por fatores externos. Por outro lado, verificou-se o fortalecimento do relacionamento com o cliente favorece positivamente a geração de valor das instituições bancárias. Finalmente, observou-se que mesmo em face do aumento dos investimentos em inovação e coprodução, as instituições bancárias tendem a manter fixas suas reservas de capital, de forma que se argumentou que o impacto positivo da inovação e coprodução na redução de riscos e otimização do gerenciamento de riscos não impacta diretamente o montante de reservas de capital.

Verificou-se que o modelo DEA-BCC é mais adequado para analisar o desempenho de bancos brasileiros uma vez que no setor os bancos divergem consideravelmente em escala. Além disso, o modelo Malmquist-DEA se mostrou adequado para mensurar a produtividade no setor. Os resultados demonstraram que, apesar da produtividade do setor bancário brasileiro ter declinado no período, a maioria dos bancos apresentaram boas médias de eficiência global e melhoria de produtividade. Nesse contexto, a inovação e coproducão se mostraram bons estimadores de desempenho bancário. A inovação apresentou relação positiva com o desempenho uma vez que a DEA demonstrou ser viável a sua utilização como indicador de desempenho bancário. Da mesma forma, a coproducão foi capaz de explicar desempenho bancário uma vez que a medida de interação e relacionamento com parceiros e clientes demonstrou ser um bom estimador da geração de valor.

Ao se considerar os resultados dos dois estudos, verifica-se que ambos demonstraram que as relações entre inovação, coproducão e desempenho são positivas, o que vai ao encontro da literatura (Bos, Kolari \& Lamoen, 2013 Chen, Tsou e Ching, 2011; Delimatsis, 2012; Delimatsis, 2013; Edvardsson et al., 2010; Frame \&White 2004;Mullineux, 
2010; Ordaniniet al., 2011; Wei, Wang, Tao \& Wang, 2006; Zhaoquan, Chen \& Xiande, 2013). Contudo, a tese fornece insumos para discussão, posto que apontou que tais relações não são lineares. Tais relações são mediadas e moderadas por diversos fatores, o que pode mitigar em parte o debate sobre o impacto da inovação no desempenho (Delimatsis, 2012).

Uma vez que o processo de inovação é impactado por elementos internos e externos à organização, é possível justificar o porquê do fracasso de algumas inovações e a consequente crise financeira desencadeada em 2008. Enquanto alguns estudos procuraram destacar os aspectos negativos da inovação (Gai et al., 2008; Hutton \& Lee, 2012; Lenzer \& Zhao, 2012) outros se ativeram aos benefícios (Bos, Kolari \& Lamoen, 2013; Frame \& White, 2004; Rossignoli \& Arnaboldi, 2009). Ainda, houve evidências na literatura de que tal divergência de percepção se deu em virtude de falhas regulatórias, que por sua vez não acompanharam o ritmo da inovação no período (Delimatsis, 2013). Nesse ponto, argumenta-se que no geral a inovação gera benefícios para a organização uma vez que as instituições financeiras, em sua maioria de grande porte, possuem capital e recursos suficientes para assumir os riscos, bem como realizam planejamentos estruturados para garantir o retorno sobre o investimento. Contudo, mesmo em face dos retornos financeiros positivos, a inovação pode modificar o ambiente macroeconômico a tal ponto que este apresenta um efeito adverso sobre as organizações. Nesse caso, a análise de viabilidade e mapeamento dos riscos é fundamental.

Em síntese, o que se depreende dos dois estudos é que a relação entre inovação e desempenho é mediada/moderada por uma série de fatores externos, e que a inovação não é capaz de sustentar sozinha a geração de valor das companhias. Além disso, evidenciaram-se alguns aspectos negativos da coproducão, pouco explorados pela literatura, mas descobriu-se que, no geral, a coproducão contribui de forma positiva para os resultados da organização. A tese demonstrou que tanto a inovação quanto a coproducão requerem um planejamento prévio e uma análise de custo-benefício detalhada antes da implantação a fim de se garantir o retorno sobre o investimento. Ainda, reforça-se queambas devem ser considerados quando da tomada de decisão uma vez que são bons estimadores do desempenho da companhia.

Do ponto de vista acadêmico, esta tese forneceu evidências empíricas acerca das relações entre inovação, coproducão e desempenho no setor financeiro e, nesse ponto, mitigou em parte algumas lacunas da literatura ao evidenciar que no geral tais relações são positivas. Além disso, o trabalho apresentou novos elementos para discussão ao afirmar que fatores internos e externos à organização impactam diretamente o sucesso da inovação e coprodução. Ademais, foram sugeridas formas de operacionalização da inovação e coproducão como ferramentas de pesquisa, tanto qualitativamente quanto numericamente. Além disso, o trabalho 
contribui no sentido de que utilizou insumos de inovação e coproducão para compor um modelo DEA de análise do desempenho bancário.

\subsection{Recomendações Práticas}

Sob a óptica gerencial, esta investigação destaca insumos relevantes para a análise de desempenho e tomada de decisão no âmbito de instituições financeiras. Os resultados apontam que os investimentos em inovação e coproducão trazem benefícios para a companhia, de forma que a caracterização e correta análise do processo contribuem para a geração de resultados positivos. Neste âmbito, os dados apontam que inovações impactam positivamente o resultado operacional e a capacidade de gerar lucros, ao mesmo tempo em que compõem estratégias de expansão e diversificação. Contudo, deve-se observar fatores como experiência da administração, análise de viabilidade e custo-benefício antes de iniciar novos empreendimentos inovadores. Além disso, a economia do país, liquidez dos mercados, inflação e taxa de juros, novas tecnologias, regulação e novos modelos de negócio são elementos que impactam diretamente o sucesso da implementação de inovações, de forma que a correta mensuração destes elementos pode vir a potencializar a geração de valor.

Do lado da coproducão, os resultados apontam que investimentos em novas parcerias e fortalecimento do relacionamento com o cliente trazem resultados positivos para as instituições financeiras. Tais interações representam fontes de novos conhecimentos, melhoria da utilização de recursos e rentabilização da base de clientes. Cabe ressaltar, contudo, que coproduções podem expor a companhia a novos riscos e gerar conflitos. Portanto, ao estabelecer novos acordos e parcerias, as instituições financeiras devem considerar a proposta de valor agregado, delimitação de responsabilidades, análise de viabilidade, transparência, reputação, alinhamento e envolvimento dos parceiros. Paralelamente, ao investir em aprimoramento da relação com o cliente, as empresas do setor devem considerar as demandas específicas dos clientes, movimentos de mercado, restrições ao crédito, tendências de mercado e novas tecnologias.

Finalmente, sugere-se utilizar a DEA como ferramenta de análise de desempenho, posto que padroniza os escores de forma comparativa e permite o estabelecimento de estratégias para a tomada de decisão. Nesse contexto, propõe-se utilizar o modelo BCC para otimizar os resultados e melhor avaliar o desempenho de bancos no Brasil, ao mesmo tempo em que se recomenda explorar a técnica Malmquist-DEA para quantificar melhorias de produtividade, eficiência e tecnologia. 


\subsection{Limitações do Estudo}

As limitações identificadas podem ser apresentadas considerando os aspectos teóricos e metodológicos do presente estudo, a saber:

a) Dificuldade de acesso a dados específicos sobre inovação e coproducão no formulário de referências das empresas, uma vez que são construtos pouco trabalhados no ambiente corporativo e há um desalinhamento conceitual entre o que a literatura afirma e o que as organizações declaram (Estudo I);

b) Inexistência de relatos específicos sobre estes construtos nos documentos das empresas, de forma que as informações estão dispersas e mescladas em diferentes tópicos (Estudo I);

c) Caráter transversal do estudo, o que limita em parte a aferição de resultados comparativos (Estudo I);

d) Identificação de evidências de inovação e coproducão apenas com base nos dados divulgados publicamente pelas companhias, o que revela uma visão parcial e incompleta do fenômeno (Estudo I);

e) Obtenção dos dados e medidas de inovação e coproducão a partir unicamente das demonstrações financeiras e contábeis das companhias (Estudo II);

f) Pressuposto da DEA de que não há erros aleatórios e de mensuração (Estudo II);

g) Alta sensibilidade para os dados da análise DEA (Estudo II)

h) Amostra composta apenas de companhias de grande porte listadas na bolsa de valores, o que acarreta certo viés de escala (Estudos I e II);

i) O setor financeiro brasileiro foi o lócus de pesquisa, de forma que os resultados apresentados não podem ser generalizados para outros setores da economia.

\subsection{Agenda de Pesquisa}

Os seguintes estudos são sugeridos para o desenvolvimento teórico e prático do tema pesquisado na presente tese:

a) Definir e quantificar os efeitos das variáveis do ambiente (regulação, fronteiras, dinamismo, competitividade, tecnologias e demandas) na inovação, coprodução e desempenho; 
b) Descrever o processo de inovação no setor financeiro e determinar seus determinantes e barreiras;

c) Mapear as características, competências e entregas do processo de inovação no setor financeiro;

d) Caracterizar o processo de coproducão no setor financeiro e identificar formatos, determinantes, benefícios e ameaças;

e) Replicar os estudos realizados em outros setores da economia a fim de acessar um panorama geral da inovação e coproducão;

f) Verificar o impacto da inovação e coproducão no desempenho das pequenas e médias empresas do setor financeiro;

g) Realizar análises similares em setores financeiros de outros países a fim de estabelecer análises comparativas e verificar se as relações se mantêm;

h) Conduzir roteiros de entrevista para averiguar e aprofundar os efeitos da inovação e coproducão no desempenho das instituições financeiras;

i) Construir instrumentos de mensuração para otimizar a coleta de informações acerca de inovação e coproducão;

j) Fortalecer as evidências empíricas do presente trabalho através da aplicação de outras técnicas estatísticas de análise;

k) Explicar relações de mediação e moderação entre as variáveis estudadas na presente tese;

1) Descrever os impactos sociais e econômicos da inovação e coproducão no setor financeiro;

m) Ampliar o escopo da pesquisa para o nível setorial, nacional e internacional.

\section{REFERÊNCIAS}

Akamavi, R.K. (2005). A research agenda for investigation of product innovation in the financial services sector. Journal of Services Marketing, 19(6), 359 - 378.

Alford, J. (2002). Why Do Public-Sector Clients Coproduce: Toward a Contingency Theory Administration \& Society 34(1), 32-56.

Ali, A. I., \& Seiford, L. M. (1990). Translation invariance in data envelopment analysis. Operations Research Letters, 9(6), 403-405.

Annibal, C.A. (2009). Inadimplência do Setor Bancário Brasileiro: uma avaliação de suas medidas. Textos para discussão 192 - Banco Central do Brasil. 
Anthanassopoulos, A.D. (1998). Nonparametric Frontier Models for Assessing the Market and Cost Efficiency of Large-Scale Bank Branch Networks. Journal of Money, Credit and Banking, 30(2), 172-192.

Banco Central do Brasil. (1987). Circular 1.273, de 29 de dezembro de 1987. Recuperado em 10 de dezembro, 2016, de http://www.bcb.gov.br/pre/normativos/circ/1987/pdf/ circ_1273_v1_o.pdf

Banco Central do Brasil. (2012). Resolução n. 4.072, de 26 de abril de 2012. Recuperado em 10 de dezembro, 2016, de https://www.bcb.gov.br/pre/normativos/busca/download Normativo.asp?arquivo=/Lists/Normativos/Attachments/49206/Res_4072_v1_O.pdf

Banker, R.D.(1993). Maximum likelihood, consistency and data envelopment analysis: A statistical foundation. Management Science, 1265-1273.

Banker, T., Natarajan, R. (2008). Evaluating contextual variables affecting productivity using data envelopment analysis. Operations Research, 56 (1), 48-58.

Banker, R.D., Charnes, A., Cooper, W.W. (1984). Some Models for Estimating Technical and Scale Inefficiencies in Data Envelopment Analysis. Management Science, 30(9), 1078-1092.

Bardin, L. (2011). Análise de conteúdo. São Paulo: Edições 70.

Barras, R. (1986). Towards a theory of innovation in services. Research Policy, 15, 161-173.

Barras, R. (1990). Interactive Innovation in Financial and Business Services: The Vanguard of the Service Revolution. Research Policy, 19(3), 215-237.

Berger, A. N. \& Humphrey, D. B. (1997). Efficiency of financial institutions: International survey and directions for future research. European Journal of Operational Research, 98(2), $175-212$.

Blazevic, V. \& Lievens, A. (2004). Learning During the New Financial Service Innovation Process: Antecedents and Performance Effects. Journal of Business Research, 54, 374-391.

Boor, P., Oliveira, P. \& Veloso, F. (2014). Users as innovators in developing countries: The global sources of innovation and diffusion in mobile banking services. Research Policy, 43, 1594-1607.

Boot, A.W.A., \&Thakor, A.V. (2000). Can Relationship Banking Survive Competition? The Journal of Finance, 55(2), 679-713.

Bos, J.A.P., Kolari, J.W. \& Lamoen, R.C.R. (2013). Competition and Innovation: Evidence form Financial Services. Journal of Banking \& Finance, 37, 1590-1601.

Bovaird, T. (2007). Beyond Engagement and Participation: User and Community Coproduction of Public Services. Public Administration Review, 67(5), 846-860. 
Brudney, J.L., Robert, E. (1983). Toward a Definition of the Coproduction Concept. Public Administration Review, 43(1), 59-65.

Boyd, J.H., Levine, R., \& Smith, B.D. (2001). The Impact of Inflation on Financial Sector Performance. Journal of Monetary Economics, 47(2), 221-248.

Buzzacchi, L., Colombo, M.G. \&Mariotti, S. (1995). Technological Regimes and Innovation in Services: the Case of the Italian Banking Industry. Research Policy, 24, 151-168.

Caselli, S. (2010). Governance and Strategy Within the Financial System: Tradition and Innovation. Journal of Management Governance, 14, 241-271.

Charnes, A., Cooper, W.W. \& Rhodes, E. (1978). Measuring the efficiency of decision making units. European Journal of Operational Research, 2(6), 429-444.

Chen, J, Tsou, H.T. \& Ching, R.K.H. (2011). Co-production and its Effect on Service Innovation. Industrial Marketing Management, 40, 1331-1346.

Cheung, M.F.Y., \&To,W.M. (2011). Customer involvement and perceptions: The moderating role of customer co-production. Journal of Retailing and Consumer Services, 18(4), 271-277.

Clark, B.Y., Brudney, J. L., \& Jang, S. (2013).Coproduction of Government Services and the New Information Technology: Investigating the Distributional Biases. PublicAdministrationReview, 73(5), 687-701.

Comitê de Pronunciamentos Contábeis. (2010). Pronunciamento Técnico CPC 04 (R1): Ativo Intangível - Correlação às Normas Internacionais de Contabilidade - IAS 38. Recuperado em 10 de dezembro, 2016, de http://www.cpc.org.br/CPC/DocumentosEmitidos/Pronunciamentos/Pronunciamento?Id=35

Costa, A.C.A., Blum, D. (2008). Inadimplência no Setor Bancário Brasileiro: Uma Medida Alternativa. Tecnologia de Crédito, 9(65), 39-55.

Dantas, J.A., Medeiros, O.R., Capelletto, L.R. (2011). Determinantes do Spread BancárioExPost no Mercado Brasileiro. Trabalhos para discussão 242 - Banco Central do Brasil.

Delimatsis, P. (2012). Financial Innovation and Prudential Regulation: The New Basel III Rules, Journal of World Trade, 46(6), 1309-1342.

Delimatsis, P. (2013). Transparent Financial Innovation in a Post-Crisis Environment. Journal of International Economic Law, 16(1), 159-210.

Detragiache, E., Tressel, T., \& Gupta, P. (2008), Foreign Banks in Poor Countries: Theory and Evidence. The Journal of Finance, 63, 2123-2160.

Djellal, F. \& Gallouj, F. (2005). Mapping innovation dynamics in hospitals. Research Policy, $34,817-835$.

Djellal, F., \& Gallouj, F. (2010). Services, innovation and performance: general presentation. Journal of Innovation Economics, 0(1), 5-15. 
Djellal, F., Gallouj, F., \& Miles, I. (2013). Two decades of research on innovation in services: Which place for public services? Structural Change and Economic Dynamics, 27, 98-117.

Dunston, R., Lee, A., Boud, D., Brodie, P., \& Chiarella, M. (2009). Co-Production and Health System Reform - From Re-Imagining To Re-Making .The Australian Journal of Public Administration, 68 (1), 39-52.

Edvardsson, B., Gustafsson, A., Kristensson, P. \&Witell, L. (2010). Customer Integration in Service Innovation. In F. Gallouj, \& M. Savona, (2010). The Handbook of Innovation and Services: A Multidisciplinary Perspective (Vol. 1, Chap. 13, pp. 301-317). Massachusetts, USA: Edward Elgar Publishing Limited.

Farrell, M.J. (1957). The Measurement of Productive Efficiency. Journal of the Royal Statistical Society, 120: 253-281.

Fethi, M.D., Pasiouras F., 2010. Assessing bank efficiency and performance with operational research and artificial intelligence techniques: A survey. European Journal of Operational Research, 204(2), 189-198.

Field, J.M., Xue, M., \&Hitt, L.M. (2012). Learning by customers as co-producers in financial services: An empirical study of the effects of learning channels and customer characteristics. Operations Management Research, 5(1), 43-56.

Frame, W.S. \& White, L.J. (2004). Empirical studies of financial innovation: lots of talk, little action? Journal of Economic Literature, 42 (1), 116-144.

Fraser, D. R., Phillips, W., \& Rose, P. S.. (1974). A Canonical Analysis of Bank Performance. The Journal of Financial and Quantitative Analysis, 9(2), 287-295.

Gadrey, J. (1996). Services, la productivitéen question, Desclte de Brouwer, Paris.

Gadrey, J. (2000). The characterization of goods and services: an alternative approach. Review of Income and Wealth, 46(3), 369-387.

Gai, P., Kapadia, S., Millard, S. \& Perez, A. (2008). Financial Innovation, Macroeconomic Stability and Systemic Crises. The Economic Journal, 118(527), 401-426.

Gallouj, F. (2002). Innovation in the service economy: the new wealth of nations. Cheltenham. Edward Elgar.

Gallouj, F. \& Savona, M. (2009). Innovation in services: a review of the debate and the research agenda. Journal of Evolutionary Economics, 19(2), 149-172.

Gallouj, F, \& Savona, M. (2010). The Handbook of Innovation and Services: A Multidisciplinary Perspective. Massachusetts, USA: Edward Elgar Publishing Limited.

Gallouj, F., \& Toivonen, M. (2011). Elaborating the characteristics-based approach to service innovation: making the service process visible. Journal of Innovation Economics \& Management, 2(8), 33-58. 
Gallouj, F. \& Weinstein, O. (1997). Innovation in services. Research Policy, 26, 537-556.

Graff, M., \&Karmann, A. (2006). What Determines the Finance-growth Nexus? Empirical Evidence for Threshold Models. Journal of Economics, 87(2), 127-157.

Gropper, D.M., Jahera, J.S., \& Park, J.C. (2015). Political power, economic freedom and Congress: Effects on bank performance. Journal of Banking \& Finance, 60, 76-92.

Hsieh, J.-K., Chiu, H.-C., Wei, C.-P., Yen, H. R., \& Cheng, Y.-C. (2013). A practical perspective on the classification of service innovations. Journal of Services Marketing, 27(5), $371-384$.

Lei n. 6.404, de 15 de dezembro de 1976 (1976). Dispõe sobre as Sociedades por Ações. Brasília, DF. Recuperado em 10 de dezembro, 2016, de http://www.planalto.gov.br/ccivil_03/leis/L6404compilada.htm

Lei n. 11.941, de 27 de maio de 2009 (2009).Altera a legislação tributária federal relativa ao parcelamento ordinário de débitos tributários; concede remissão nos casos em que especifica; institui regime tributário de transição, alterando e revogando Decretos e Leis e dá outras providências. Recuperado em 10 de dezembro, 2016, de http://www.planalto.gov.br/ccivil_03/_ato2007-2010/2009/lei/111941.htm

Lenzer, J.H., \& Zhao, S.X. (2012). Roles of Financial Innovation and Information Technology: Lessons from US Sub-prime Mortgage Crisis and Its Implications for China. Chinese Geographical Science, 22(3), 343-355.

Hertog, P., Van der Aa, W., Jong, M.W. (2010). Capabilities for managing service innovation: towards a conceptual framework. Journal of Service Management, 21(4), 490-514.

Hill, P. (1977). On Goods and Services. The Review of Income and Wealth, 23(4), 315-338.

Hoffmann, A.O.I., Post, T. \& Pennings, J.M.E. (2013). Individual investor perceptions and behavior during the financial crisis. Journal of Banking \& Finance, 37(1), 60-74.

Hsieh, J.K., Chiu, H.C., Wei, C.P., Yen, H.R. \& Cheng, Y.C. (2013). A Practical Perspective on the Clssification of Service Innovations. Journal of Service Marketing, 27(5), 371-384.

Hutton, W. \& Lee, N. (2012). The City and the Cities: Ownership, Finance and the Geography of Recovery. Cambridge Journal of Regions, Economy and Society, 5, 325-337.

Johnson, S. \& Kwak, J. (2012). Is Financial Innovation Good for the Economy? Innovation Policy and the Economy, 12(1), 1-16.

Kopp, R.J. (1981). The Measurement of Productive Efficiency: A Reconsideration. Quarterly J Economics, 96(3), 477-503.

Leibenstein, H. (1966). Allocative efficiency vs. "X-efficiency". American Economic Review, $56,392-415$. 
Lenzer, J.H., Zhao, S.X. (2012). Roles of Financial Innovation and Information Technology: Lessons from US Sub-prime Mortgage Crisis and its Implications for China. Chinese Geographical Science, 22(3), 343-355.

Luo, X. (2003). Evaluating the profitability and marketability efficiency of large banks: An application of data envelopment analysis. Journal of Business Research, 56, 627-635.

Lusch, S.L., Vargo, R.F., \& O'Brien, M. (2007). Competing through service: Insights from service-dominant logic. Journal of retailing 83(1), 2-18.

Martovoy, A., Mention, A., \& Torkkeli, M. (2015). Inbound Open Innovation in Financial Services. Journal of Technology Management \& Innovation, 10(1), 117-131.

Mello, J.C.B.S., Meza, L.A., Gomes, E.G., Neto, L.B. (2005). Curso de Análise de Envoltória de Dados. Apresentado noXXXVIII Simpósio Brasileiro de Pesquisa Operacional, Gramado.

Mende, M., \& Doorn, J. (2014). Coproduction of Transformative Services as a Pathway to Improved Consumer Well-Being: Findings from a Longitudinal Study on Financial Counseling. Journal of Service Research, 1-18.

Meng, Y.H. \& Guo, H.H.B. (2013). Grey Relational Analysis on Service Innovation Performance in Commercial Banks. Service Systems and Service Management 10th International Conference(IEEE).

Mullineux, A.W. (2010). Financial innovation and social welfare. Journal of Financial Regulation and Compliance, 18(3), 243 - 256.

Niyama, J.K. (2001).Constituição da provisão para créditos de liquidação duvidosa de bancos e demais instiuições financeiras - principais alterações introduzidas pelo Conselho Monetário Nacional e o efeito das demonstraçõescontábeis. ConTexto1(1), 1-14.

Normas Internacionais de Contabilidade. (2014). IAS 38 IntangibleAssets. Recuperado em 10 de dezembro, 2016, de http://www.ifrs.org/IFRSs/Documents/Technical-summaries2014/IAS\%2038.pdf

Ordanini, A., Micel, A., Pizzetti,M., \& Parasuraman, A. (2011). Crowd-funding: transforming customers into investors through innovative service platforms, Journal of Service Management, 22(4), $443-470$

Ostrom, E. (1996). Crossing the Great Divide: Coproduction, Synergy and Development. World Development, 24(6), 1073-1087.

Ozbay, R.D., Dinçer, H. \& Hacioglu, U. (2011). Internet based Innovation Strategy for the Banks in the Era of 2008 Global Financial Crisis. International Journal of Business and Social Science, 2(22), 85-91.

Paradi, J. C., Zhu, H. (2013). A survey on bank branch efficiency and performance research with data envelopment analysis. Omega, 41(1), 61-79. 
Pastor, J. T. (1996). Translation invariance in data envelopment analysis: a generalization. AnnalsofOperationsResearch, 66(2), 93-112.

Resolução n. 2.682 de 21 de dezembro de 1999 (1999). Dispõe sobre critérios de classificação das operações de crédito e regras para constituição de provisão para créditos de liquidação duvidosa. Recuperado em 15 de dezembro, 2016, de http://www.bcb.gov.br/pre/normativos/ res/1999/pdf/res_2682_v2_L.pdf

Resti, A. (1997). Evaluating the cost-efficiency of the Italian Banking System: What can be learned from the joint application of parametric and non-parametric techniques. Journal of Banking and Finance, 21, 221-250.

Rossignoli, B. \& Arnaboldi, F. (2009). Financial Innovation: Theoretical Issues and Empirical Evidence in Italy and in the UK. International Review of Economics, 56, 275-301.

Salunke, S., Weerawardena, J., McColl-Kennedy, J.R. (2011). Towards a model of dynamics capabilities in innovation-based competitive strategy: Insights from project-oriented services firms. Industrial Marketing Management, 40(8), 1251-1263.

Sathye, M. (2001). X-efficiency in Australian Banking: Na Empirical Investigation. Journal of Banking and Finance, 32, 613-630.

Seiford, L.M., \& Thrall, R.M. (1990). Recent Developments in DEA: the Mathematical Programming Appoach to Frontier Analysis. Journal of Econometrics, (4), 7-38.

Shahrokhi, M. (2008). E-finance: status, innovations, resources and future challenges. Managerial Finance, 34(6), 365 - 398.

Soteriou, A.C., \&Zenios, S.A. (1997). Efficiency, profitability and quality of banking services. The Warthon Financial Institutions Center Working Paper Series, 97-28.

Sundbo, J. (1997). Management of innovation in service. The Service Industries Journal, 17(3), $432-455$.

Stevens, E., \& Dimitriadis, S. (2005). Learning during developing and implementing new bank offerings. International Journal of Bank Marketing, 23(1), 54-72.

Takami, M.Y., Tabak, B.M. (2007). Evaluation of Default Risk for the Brazilian Banking Sector. Wornking Paper Series 135 - Banco Central do Brasil.

Tsou, H.T., Chen, J.S. (2012). The influence of interfirm codevelopment competency on eservice innovation. Information \& Management, 49, 177-189.

Thakur, R., \& Hale, D. (2013). Service innovation: A comparative study of U.S. and Indian service firms. Journal of Business Research, 66(8), 1108-1123.

Tsou, H.T., Chen, J.C. (2012). The influence of interfirm codevelopment competency on eservice innovation. Information \& Management, 49, 177-189.

Tufano, P. (2003). The Handbook of the Economics of Finance: Financial Innovation (Cap. 6, pp. 307-355). Amsterdam: North-Holland. 
Vähämaa, E., \&Vähämaa, S. (2012). Did Good Corporate Governance Improve Bank Performance During the Financial Crisis? Journal of Financial Services Research, 41(1-2), 1935.

Vargo, S.L., \&Lusch, R.F. (2004). Evolving to a new dominant logic for marketing. Journal of Marketing, 68,1-17.

Vargo, R.F., \& Lusch, S.L. (2006). Service-dominant logic: reactions, reflections and refinements. Marketing theory 6 (3), 281-288.

Vargo, R.F., \& Lusch, S.L. (2008). Service-dominant logic: continuing the evolution. Journal of the Academy of marketing Science 36(1), 1-10.

Varian, H. R. (1990). Goodness-of-fit in optimizing models. Journal of Econometrics, 46(1-2), 125-140.

Wang, Y.M., \& Lan, Y.X. (2011). Measuring Malmquist productivity index: A new approach based on double frontiers data envelopment analysis. Mathematical and Computer Modelling, $54,2760-2771$.

Wang, W.K., Lu, W.M., \&Wang, Y.H. (2013). The relationship between bank performance and intellectual capital in East Asia.Quality and Quantity, 47(2), 1041-1062.

Wei, J., Wang, L., Tao, Y., \& Wang, T. (2006). Factor Analysis on the Performance of Financial Services Innovation: Empirical Study in China. Management of Innovation and Technology, 2006 IEEE International Conference, 2, 807-811.

Wu, L.W. \& Lin, J.R. (2013). Knowledge sharing and knowledge effectiveness: learning orientation and co-production in the contingency model of tacit knowledge. Journal of Business \& Industrial Marketing, 28(8), $672-686$.

Zaher, H.M., Zeineldin, A.R., \& Abdelshafy, G.M. (2015). Ranking Decision making units using Fuzzy Multi-Objective Approach. International Journal of Computer Applications 126(2), 1-6.

Zhaoquan, J., Chen, W., \& Xiande, Z. (2013). Network Competence's Impact on Service Innovation Performance: Mediating Role of Relationship Learning. Journal of Service Science and Management, 6(4), 256-265. 


\section{ANEXO 1 - PROTOCOLO PARA ANÁLISE DE DADOS SECUNDÁRIOS (NINE-UNB)}

\begin{tabular}{|c|c|c|c|c|}
\hline \multicolumn{5}{|c|}{ Tipos de Inovação } \\
\hline Categorias & Definição & Referência & Identificação & Palavras-Chave \\
\hline Inovação radical & $\begin{array}{c}\text { Criação de um produto } \\
\text { totalmente novo; descreve a } \\
\text { criação de um novo conjunto } \\
\text { de características } \mathrm{S}=\left\{\left[\mathrm{C}^{\prime *}\right] \text {, }\right. \\
\left.\left[\mathrm{C}^{*}\right],\left[\mathrm{X}^{*}\right],\left[\mathrm{X}^{*}\right],\left[\mathrm{Y}^{*}\right]\right\}\end{array}$ & $\begin{array}{l}\text { Gallouj e } \\
\text { Weinstein } \\
(1997)\end{array}$ & $\begin{array}{c}\text { Detecção de serviços que } \\
\text { não se relacionam com o } \\
\text { sistema antigo }\left\{[\mathrm{C}],\left[\mathrm{C}^{\prime}\right]\right. \\
\left.[\mathrm{X}],\left[\mathrm{X}^{\prime}\right],[\mathrm{Y}]\right\} \text { da } \\
\text { organização } \\
\end{array}$ & $\begin{array}{l}\text { Novo; novidade; } \\
\text { inédito; diferente }\end{array}$ \\
\hline $\begin{array}{l}\text { Inovação de } \\
\text { melhoria }\end{array}$ & $\begin{array}{c}\text { Melhoramento de certas } \\
\text { características sem alteração } \\
\text { do sistema }\end{array}$ & $\begin{array}{l}\text { Gallouj e } \\
\text { Weinstein } \\
(1997)\end{array}$ & $\begin{array}{l}\text { Detecção de serviços com } \\
\text { características [Y] } \\
\text { melhoradas como reflexo } \\
\text { do melhoramento de } \\
\text { competências }[\mathrm{C}] \mathrm{e} \\
\text { características técnicas }[\mathrm{X}]\end{array}$ & $\begin{array}{l}\text { Melhoramento; } \\
\text { otimização }\end{array}$ \\
\hline $\begin{array}{l}\text { Inovação } \\
\text { incremental }\end{array}$ & $\begin{array}{c}\text { Mudança marginal no } \\
\text { sistema por meio de novos } \\
\text { elementos adicionados para } \\
{[\mathrm{X}],\left[\mathrm{X}^{\prime}\right] \text { e/ou }[\mathrm{Y}] \text { ou pela }} \\
\text { substituição dos mesmos } \\
\end{array}$ & $\begin{array}{l}\text { Gallouj e } \\
\text { Weinstein } \\
(1997)\end{array}$ & $\begin{array}{c}\text { Detecção de serviços com } \\
\text { adição de ou substituição } \\
\text { de características finais [Y] } \\
\text { e/ou características técnicas } \\
{[\mathrm{X}]} \\
\end{array}$ & $\begin{array}{l}\text { Implementação; } \\
\text { adição; troca ou } \\
\text { substituição de } \\
\text { elementos }\end{array}$ \\
\hline $\begin{array}{l}\text { Inovação } \\
\text { recombinativa }\end{array}$ & $\begin{array}{l}\text { Reutilização sistemática de } \\
\text { certos elementos ou } \\
\text { componentes do serviço }\end{array}$ & $\begin{array}{l}\text { Gallouj e } \\
\text { Weinstein } \\
(1997)\end{array}$ & $\begin{array}{c}\text { Detecção de serviços com } \\
\text { características combinadas } \\
\text { de outros serviços } \\
\text { prestados }\end{array}$ & $\begin{array}{l}\text { Reutilização; } \\
\text { junção; } \\
\text { combinação de } \\
\text { características de } \\
\text { serviços já } \\
\text { existentes } \\
\end{array}$ \\
\hline Inovação ad hoc & $\begin{array}{l}\text { Construção interativa de uma } \\
\text { solução para um problema } \\
\text { particular colocado por um } \\
\text { determinado cliente }\end{array}$ & $\begin{array}{l}\text { Gallouj e } \\
\text { Weinstein } \\
(1997)\end{array}$ & $\begin{array}{l}\text { Detecção de ações com } \\
\text { características peculiares } \\
\text { referente à solução de um } \\
\text { problema particular a fím } \\
\text { de mudar a condição do } \\
\text { cliente }\end{array}$ & $\begin{array}{c}\text { Solução de } \\
\text { problema; } \\
\text { consultoria; } \\
\text { problema } \\
\text { particular; } \\
\text { correção de } \\
\text { falhas de sistema }\end{array}$ \\
\hline $\begin{array}{l}\text { Inovação de } \\
\text { formalização }\end{array}$ & $\begin{array}{c}\text { Implementação que dá } \\
\text { visibilidade e otimiza o grau } \\
\text { de padronização das várias } \\
\text { características dando forma e } \\
\text { tornando-as mais concretas e } \\
\text { menos confusas }\end{array}$ & $\begin{array}{l}\text { Gallouj e } \\
\text { Weinstein } \\
\text { (1997) }\end{array}$ & $\begin{array}{l}\text { Detecção de ações de } \\
\text { padronização, e criação de } \\
\text { método para execução de } \\
\text { certas atividades nas } \\
\text { experiências }\end{array}$ & $\begin{array}{l}\text { Padronização; } \\
\text { unificação; } \\
\text { clarificação e } \\
\text { ordenação de } \\
\text { características }\end{array}$ \\
\hline \multicolumn{5}{|c|}{ Lógicas de Inovação } \\
\hline Categorias & Definição & Referência & Identificação & Palavras-Chave \\
\hline Extensiva & $\begin{array}{c}\text { Adição de um ou mais } \\
\text { serviços constituintes (Si) à } \\
\text { oferta de serviços existentes }\end{array}$ & $\begin{array}{l}\text { Djellal e } \\
\text { Gallouj } \\
(2005)\end{array}$ & $\begin{array}{l}\text { Detecção de acréscimos de } \\
\text { serviços à oferta de } \\
\text { serviços. Normalmente se } \\
\text { refere a serviços periféricos } \\
\text { que complementam os } \\
\text { serviços centrais e está } \\
\text { relacionado à estratégias de } \\
\text { diferenciação e melhoria }\end{array}$ & $\begin{array}{c}\text { Adição; } \\
\text { acréscimo; } \\
\text { inovação; novo; } \\
\text { novidade; } \\
\text { inédito; diferente }\end{array}$ \\
\hline Intensiva & $\begin{array}{l}\text { Modificação de elementos } \\
\text { internos de um ou mais } \\
\text { vetores }[\mathrm{C}]\left[\mathrm{C}^{\prime}\right][\mathrm{X}] \text { a fim de } \\
\text { modificar uma entrega }[\mathrm{Y}]\end{array}$ & $\begin{array}{l}\text { Djellal e } \\
\text { Gallouj } \\
(2005)\end{array}$ & $\begin{array}{l}\text { Detecção de serviços com } \\
\text { características [Y] } \\
\text { modificadas como reflexo } \\
\text { da eliminação ou melhoria } \\
\text { de elementos internos de }\end{array}$ & $\begin{array}{l}\text { Melhoria; } \\
\text { otimização; } \\
\text { mobilização; } \\
\text { aprendizagem }\end{array}$ \\
\hline
\end{tabular}




\begin{tabular}{|c|c|c|c|c|}
\hline & & & $\begin{array}{l}\text { competências }[\mathrm{C}] \mathrm{e} \\
\text { características técnicas }[\mathrm{X}]\end{array}$ & \\
\hline Regressiva & $\begin{array}{l}\text { Remoção ou eliminação de } \\
\text { um ou mais serviços } \\
\text { constituintes ( } \mathrm{Si} \text { ) da oferta de } \\
\text { serviços existentes }\end{array}$ & $\begin{array}{l}\text { Djellal e } \\
\text { Gallouj } \\
(2005)\end{array}$ & $\begin{array}{c}\text { Detecção de reduções na } \\
\text { oferta de serviços. } \\
\text { Normalmente relacionado a } \\
\text { estratégias de refinamento e } \\
\text { otimização de processos ou } \\
\text { especializações }\end{array}$ & $\begin{array}{l}\text { Eliminação; } \\
\text { putificação; } \\
\text { refinamento; } \\
\text { regressão; } \\
\text { serviço mínimo; } \\
\text { especialização }\end{array}$ \\
\hline Combinação & $\begin{array}{l}\text { Fundamenta-se na associação } \\
\text { e/ou dissociação entre } \\
\text { serviços constituintes ( } \mathrm{Si} \text { ), } \\
\text { bem como entre tecnologias } \\
\text { e competências }\end{array}$ & $\begin{array}{l}\text { Djellal e } \\
\text { Gallouj } \\
(2005)\end{array}$ & $\begin{array}{c}\text { Detecção de serviços com } \\
\text { características combinadas } \\
\text { de outros serviços } \\
\text { prestados }\end{array}$ & $\begin{array}{l}\text { Combinação; } \\
\text { associação; } \\
\text { dissociação; } \\
\text { reutilização; } \\
\text { junção }\end{array}$ \\
\hline \multicolumn{5}{|c|}{ Tipos de Coprodução } \\
\hline Categorias & Definição & Referência & Identificação & Palavras-Chave \\
\hline Desenvolvedor & $\begin{array}{c}\text { Desenvolvedores assumem } \\
\text { um papel principal no } \\
\text { processo de inovação }\end{array}$ & $\begin{array}{l}\text { Edvardsson, } \\
\text { Gustafsson, } \\
\text { Kristensson } \\
\text { \&Witell } \\
(2010)\end{array}$ & $\begin{array}{l}\text { Detecção do papel do } \\
\text { coprodutor percebido como } \\
\text { agente principal no } \\
\text { processo de inovação }\end{array}$ & $\begin{array}{l}\text { Desenvolvedor; } \\
\text { responsável; } \\
\text { executor }\end{array}$ \\
\hline Codesenvolvedor & $\begin{array}{c}\text { Codesenvolvedores assumem } \\
\text { um papel participativo no } \\
\text { processo de inovação. }\end{array}$ & $\begin{array}{l}\text { Edvardsson, } \\
\text { Gustafsson, } \\
\text { Kristensson } \\
\text { \& Witell } \\
\text { (2010) }\end{array}$ & $\begin{array}{l}\text { Detecção do papel do } \\
\text { coprodutor percebido como } \\
\text { agente participativo no } \\
\text { processo de inovação }\end{array}$ & $\begin{array}{c}\text { Participação; } \\
\text { colaboração; } \\
\text { cooperação; } \\
\text { responsabilidade; } \\
\text { parceria; } \\
\text { relacionamento; } \\
\text { aliança; } \\
\text { associação; } \\
\text { acordo }\end{array}$ \\
\hline $\begin{array}{l}\text { Provedor de } \\
\text { informação }\end{array}$ & $\begin{array}{c}\text { Repassa informações } \\
\text { essenciais para o } \\
\text { desenvolvimento do processo } \\
\text { de inovação. }\end{array}$ & $\begin{array}{l}\text { Edvardsson, } \\
\text { Gustafsson, } \\
\text { Kristensson } \\
\text { \& Witell } \\
\text { (2010) }\end{array}$ & $\begin{array}{l}\text { Detecção do papel do } \\
\text { coprodutor percebido como } \\
\text { fornecedor de informações } \\
\text { essenciais ao processo de } \\
\text { inovação }\end{array}$ & $\begin{array}{l}\text { Fornecimento de } \\
\text { informação; } \\
\text { repasse; } \\
\text { suprimento, } \\
\text { provimento ou } \\
\text { municiamento. } \\
\end{array}$ \\
\hline \multicolumn{5}{|c|}{ Desempenho } \\
\hline Categorias & Definição & Referência & Identificação & Palavras-Chave \\
\hline Desempenho & $\begin{array}{l}\text { Lucro, Prejuízo, impactos } \\
\text { positivos e negativos }\end{array}$ & $\begin{array}{l}\text { Fethi \& } \\
\text { Pasiouras } \\
(2010)\end{array}$ & $\begin{array}{l}\text { Detecção dos impactos e } \\
\text { resultados financeiros } \\
\text { advindos das atividades da } \\
\text { organização }\end{array}$ & $\begin{array}{l}\text { lucro; prejuízo; } \\
\text { resultado; } \\
\text { desempenho }\end{array}$ \\
\hline
\end{tabular}

Quadro 15. Protocolo para Análise de Conteúdo de Dados Secundários (NINE-UnB). 
ANEXO 2 -ANÁLISE DA MELHORIA DE PRODUTIVIDADE, EFICIÊNCIA TÉCNICA E TECNOLOGIA DOS BANCOS BRASILEIROS DE CAPITAL ABERTO NO PERÍODO DE 2008 A 2015.

\begin{tabular}{|c|c|c|c|c|c|c|c|c|c|}
\hline DMU & 2008 & 2009 & 2010 & 2011 & 2012 & 2013 & 2014 & 2015 & Média \\
\hline Banestes & 0,708158 & 0,520189 & 0,506371 & 0,699128 & 0,701143 & 0,589954 & 0,796629 & 0,68574 & 0,64368 \\
\hline ABC Brasil & 0,853877 & 0,565715 & 0,54283 & 0,873446 & 0,939069 & 0,970585 & 0,990878 & 1 & 0,82121 \\
\hline Alfa & 0,970739 & 0,932873 & 0,926997 & 0,934266 & 0,941776 & 0,944706 & 0,945006 & 0,95621 & 0,94398 \\
\hline Amazônia & 0,970682 & 0,64757 & 0,220477 & 0,747528 & 0,856992 & 0,79724 & 0,820877 & 0,88135 & 0,68971 \\
\hline Bradesco & 0,096878 & 0,095982 & 0,006017 & 0,033667 & 0,072905 & 0,04843 & 0,055124 & 0,01556 & 0,03931 \\
\hline Brasil & 0,141882 & 0,109509 & 0,004657 & 0,060046 & 0,079571 & 0,073454 & 0,085807 & 0,06323 & 0,05853 \\
\hline BTG Pactual & 1 & 1 & 0,274541 & 0,612652 & 0,946619 & 0,999806 & 0,816812 & 0,30627 & 0,66837 \\
\hline Daycoval & 1 & 1 & 0,987609 & 1 & 1 & 1 & 1 & 1 & 0,99844 \\
\hline Banese & 0,645732 & 0,492844 & 0,228708 & 0,722377 & 0,82875 & 0,765167 & 0,777453 & 0,83664 & 0,61948 \\
\hline Banpará & 0,909301 & 0,785236 & 0,776095 & 0,887692 & 0,893688 & 0,877403 & 0,849588 & 0,93204 & 0,86221 \\
\hline Banrisul & 0,447046 & 0,350427 & 0,04528 & 0,372327 & 0,429944 & 0,339256 & 0,258564 & 0,18956 & 0,25675 \\
\hline Indusval & 1 & 1 & 1 & 1 & 0,98961 & 1 & 0,982155 & 1 & 0,99645 \\
\hline $\begin{array}{c}\text { Mercantil } \\
\text { (Inv.) }\end{array}$ & 1 & 0,996018 & 1 & 1 & 1 & 1 & 1 & 1 & 0,9995 \\
\hline Mercantil & 0,748114 & 0,519089 & 0,210941 & 0,757267 & 0,890238 & 0,841673 & 1 & 0,86548 & 0,66922 \\
\hline $\begin{array}{c}\text { BCO } \\
\text { Nordeste }\end{array}$ & 0,883306 & 0,6875 & 0,93997 & 0,965447 & 0,996225 & 0,955484 & 1 & 1 & 0,92252 \\
\hline Pan & 1 & 1 & 1 & 1 & 1 & 1 & 1 & 1 & 1 \\
\hline Pine & 1 & 0,696742 & 0,644691 & 0,94731 & 1 & 1 & 0,99731 & 0,98314 & 0,89649 \\
\hline Santander & 0,371344 & 0,167201 & 0,005902 & 0,064036 & 0,106771 & 0,098676 & 0,121502 & 0,07197 & 0,08258 \\
\hline $\mathrm{BRB}$ & 0,570458 & 0,444922 & 0,226672 & 0,702904 & 0,827653 & 0,773548 & 0,731127 & 0,76609 & 0,58908 \\
\hline Itaú & 0,70209 & 0,563021 & 0,005285 & 0,989738 & 1 & 1 & 1 & 1 & 0,46179 \\
\hline Paraná & 0,980019 & 0,938276 & 1 & 1 & 1 & 1 & 1 & 1 & 0,98957 \\
\hline Média & 0,666272 & 0,540698 & 0,203759 & 0,552565 & 0,634966 & 0,599353 & 0,613628 & 0,52262 & 0,51503 \\
\hline
\end{tabular}

Tabela 9. Eficiência das DMUs - Modelo CCR. 


\begin{tabular}{|c|c|c|c|c|c|c|c|c|c|}
\hline DMU & 2008 & 2009 & 2010 & 2011 & 2012 & 2013 & 2014 & 2015 & Média \\
\hline Banestes & 0,500674 & 0,520189 & 0,496336 & 0,443424 & 0,364873 & 0,309619 & 0,32382 & 0,30685 & 0,39908 \\
\hline ABC Brasil & 0,59973 & 0,565715 & 0,530143 & 0,485791 & 0,426762 & 0,394499 & 0,378413 & 0,33014 & 0,45503 \\
\hline Alfa & 0,919443 & 0,932873 & 0,922916 & 0,882658 & 0,880058 & 0,880861 & 0,885504 & 0,90058 & 0,90039 \\
\hline Amazônia & 0,131233 & 0,232495 & 0,176611 & 0,093538 & 0,084029 & 0,086656 & 0,0649 & 0,09559 & 0,11083 \\
\hline Bradesco & 0,006624 & 0,008975 & 0,005991 & 0,003488 & 0,003959 & 0,003186 & 0,003015 & 0,00243 & 0,00429 \\
\hline Brasil & 0,007157 & 0,0052 & 0,004646 & 0,003618 & 0,004099 & 0,003469 & 0,002989 & 0,00224 & 0,00395 \\
\hline BTG Pactual & 1 & 1 & 0,262384 & 0,196524 & 0,18373 & 0,123974 & 0,111009 & 0,07627 & 0,23697 \\
\hline Daycoval & 0,996443 & 1 & 0,980943 & 0,975183 & 0,981418 & 0,930975 & 0,997346 & 1 & 0,98255 \\
\hline Banese & 0,242337 & 0,21724 & 0,226453 & 0,211595 & 0,197393 & 0,161653 & 0,153509 & 0,15156 & 0,19234 \\
\hline Banpará & 0,88846 & 0,785236 & 0,763017 & 0,762447 & 0,733134 & 0,416391 & 0,291695 & 0,25777 & 0,55738 \\
\hline Banrisul & 0,05569 & 0,051597 & 0,045119 & 0,045467 & 0,045241 & 0,096308 & 0,08437 & 0,10176 & 0,06208 \\
\hline Indusval & 1 & 1 & 0,998686 & 0,679481 & 0,523048 & 0,872472 & 0,521466 & 0,91425 & 0,78732 \\
\hline $\begin{array}{c}\text { Mercantil } \\
\text { (Inv.) }\end{array}$ & 0,994902 & 0,995316 & 0,995078 & 0,995496 & 0,995498 & 0,994977 & 0,995195 & 0,99526 & 0,99522 \\
\hline Mercantil & 0,20222 & 0,190029 & 0,165457 & 0,172685 & 0,200809 & 0,215282 & 0,215346 & 0,1818 & 0,19215 \\
\hline $\begin{array}{c}\text { BCO } \\
\text { Nordeste }\end{array}$ & 0,618683 & 0,6875 & 0,727596 & 0,78179 & 0,827425 & 0,561676 & 0,517234 & 0,60052 & 0,6575 \\
\hline Pan & 0,660436 & 1 & 1 & 0,714598 & 0,707008 & 0,607402 & 0,382856 & 0,22015 & 0,60127 \\
\hline Pine & 0,75739 & 0,696742 & 0,630433 & 0,623624 & 0,612427 & 0,607552 & 0,603143 & 0,58874 & 0,63788 \\
\hline Santander & 0,006159 & 0,009011 & 0,005888 & 0,005023 & 0,004986 & 0,005102 & 0,005089 & 0,00528 & 0,0057 \\
\hline BRB & 0,322883 & 0,230379 & 0,224345 & 0,247663 & 0,275764 & 0,219998 & 0,101249 & 0,11331 & 0,20294 \\
\hline Itaú & 0,003545 & 0,004026 & 0,005284 & 0,004554 & 0,003794 & 0,003729 & 0,003228 & 0,00333 & 0,00389 \\
\hline Paraná & 0,921384 & 0,938276 & 0,939807 & 0,961861 & 0,923861 & 0,912723 & 0,951018 & 0,93684 & 0,9356 \\
\hline Média & 0,213541 & 0,221922 & 0,194639 & 0,170103 & 0,165598 & 0,156028 & 0,13517 & 0,13208 & 0,17078 \\
\hline
\end{tabular}

Tabela 10. Eficiência Global das DMUs - Modelo CCR. 


\begin{tabular}{|c|c|c|c|c|c|c|c|c|c|}
\hline DMU & 2008 & 2009 & 2010 & 2011 & 2012 & 2013 & 2014 & 2015 & Média \\
\hline Banestes & 0,904789 & 0,890759 & 0,896743 & 0,913222 & 0,874961 & 0,870209 & 1 & 0,87223 & 0,90204 \\
\hline ABC Brasil & 0,99701 & 0,983765 & 1 & 1 & 0,986474 & 0,998634 & 1 & 1 & 0,99572 \\
\hline Alfa & 0,988649 & 0,989402 & 0,988512 & 0,97236 & 0,979602 & 0,990028 & 0,983564 & 0,99637 & 0,98604 \\
\hline Amazônia & 1 & 0,899705 & 1 & 0,95499 & 0,89574 & 0,88441 & 0,920626 & 0,97888 & 0,94074 \\
\hline Bradesco & 857074 & 1 & 0,960468 & 0,790242 & 0,817302 & 0,718806 & 0,820041 & 0,52884 & 0,79878 \\
\hline Brasil & 1 & 1 & 1 & 1 & 1 & 1 & 1 & 1 & 1 \\
\hline BTG Pactual & 1 & 1 & 1 & 1 & 1 & 1 & 1 & 0,59065 & 0,9363 \\
\hline Daycoval & 1 & 1 & 1 & 1 & 1 & 1 & 1 & 1 & 1 \\
\hline Banese & 0,935893 & 0,897058 & 0,903737 & 0,922801 & 0,867371 & 0,868677 & 0,926333 & 0,93651 & 0,90692 \\
\hline Banpará & 0,974505 & 0,940502 & 0,922687 & 0,911475 & 0,915509 & 0,915428 & 0,851678 & 0,93501 & 0,92027 \\
\hline Banrisul & 0,94718 & 0,95312 & 0,985957 & 1 & 0,962986 & 1 & 0,960356 & 1 & 0,97597 \\
\hline Indusval & 1 & 1 & 1 & 1 & 0,994506 & 1 & 0,982677 & 1 & 0,99713 \\
\hline $\begin{array}{l}\text { Mercantil } \\
\text { (Inv.) }\end{array}$ & 1 & 1 & 1 & 1 & 1 & 1 & 1 & 1 & 1 \\
\hline Mercantil & 0,97422 & 0,89092 & 0,913231 & 0,909963 & 0,916693 & 0,892104 & 1 & 0,91269 & 0,92551 \\
\hline $\begin{array}{c}\text { BCO } \\
\text { Nordeste }\end{array}$ & 1 & 1 & 1 & 1 & 1 & 1 & 1 & 1 & 1 \\
\hline Pan & 1 & 1 & 1 & 1 & 1 & 1 & 1 & 1 & 1 \\
\hline Pine & 1 & 0,990281 & 0,999268 & 0,998899 & 1 & 1 & 0,997625 & 0,98346 & 0,99618 \\
\hline Santander & 1 & 1 & 1 & 0,998297 & 1 & 1 & 1 & 1 & 0,99979 \\
\hline BRB & 0,896413 & 0,896135 & 0,908062 & 0,909381 & 0,897305 & 0,896937 & 0,836513 & 0,88656 & 0,89064 \\
\hline Itaú & 0,8923 & 0,90004 & 0,923878 & 1 & 1 & 1 & 1 & 1 & 0,96338 \\
\hline Paraná & 1 & 0,99925 & 1 & 1 & 1 & 1 & 1 & 1 & 0,99991 \\
\hline Média & 0,968854 & 0,962283 & 0,970731 & 0,964206 & 0,955825 & 0,95098 & 0,963834 & 0,92283 & 0,95733 \\
\hline
\end{tabular}

Tabela 11. Eficiência das DMUs - Modelo BCC. 


\begin{tabular}{|c|c|c|c|c|c|c|c|c|c|}
\hline DMU & 2008 & 2009 & 2010 & 2011 & 2012 & 2013 & 2014 & 2015 & Média \\
\hline Banestes & 0,838188 & 0,86483 & 0,846887 & 0,829041 & 0,822468 & 0,826151 & 0,832473 & 0,83842 & 0,83721 \\
\hline ABC Brasil & 0,970538 & 0,970791 & 0,977801 & 0,978481 & 0,965678 & 0,961614 & 0,962274 & 0,9397 & 0,96579 \\
\hline Alfa & 0,968184 & 0,970988 & 0,972727 & 0,970439 & 0,970708 & 0,972391 & 0,96898 & 0,97019 & 0,97058 \\
\hline Amazônia & 0,855814 & 0,867923 & 0,871417 & 0,844831 & 0,851202 & 0,850923 & 0,855327 & 0,89381 & 0,86128 \\
\hline Bradesco & 0,584435 & 0,947917 & 0,849931 & 0,616067 & 0,718337 & 0,60473 & 0,589458 & 0,31454 & 0,62527 \\
\hline Brasil & 1 & 1 & 1 & 0,950136 & 1 & 1 & 0,931971 & 0,73382 & 0,94754 \\
\hline BTG Pactual & 1 & 1 & 0,974423 & 0,976998 & 1 & 1 & 0,804477 & 0,49298 & 0,88537 \\
\hline Daycoval & 0,99717 & 1 & 1 & 0,99489 & 1 & 0,991665 & 0,99096 & 1 & 0,99683 \\
\hline Banese & 0,85746 & 0,856043 & 0,861583 & 0,862607 & 0,857795 & 0,836331 & 0,827759 & 0,83488 & 0,84921 \\
\hline Banpará & 0,933442 & 0,895368 & 0,888692 & 0,891066 & 0,883685 & 0,848983 & 0,83084 & 0,85824 & 0,87828 \\
\hline Banrisul & 0,862519 & 0,876573 & 0,892025 & 0,917697 & 0,916618 & 0,966601 & 0,951054 & 0,97951 & 0,91947 \\
\hline Indusval & 1 & 1 & 1 & 0,935181 & 0,944882 & 0,933317 & 0,943232 & 0,92807 & 0,96009 \\
\hline $\begin{array}{l}\text { Mercantil } \\
\text { (Inv.) }\end{array}$ & 0,999637 & 0,999977 & 0,999701 & 1 & 1 & 0,999479 & 0,999742 & 1 & 0,99982 \\
\hline Mercantil & 0,8404 & 0,840891 & 0,842764 & 0,824776 & 0,839799 & 0,838347 & 0,818896 & 0,85424 & 0,83745 \\
\hline $\begin{array}{c}\text { BCO } \\
\text { Nordeste }\end{array}$ & 0,965353 & 0,992354 & 0,984749 & 1 & 1 & 0,983608 & 1 & 0,99372 & 0,98991 \\
\hline Pan & 0,969994 & 1 & 1 & 0,896877 & 0,838689 & 0,916072 & 0,917407 & 0,89038 & 0,92714 \\
\hline Pine & 0,985374 & 0,975273 & 0,969268 & 0,976459 & 0,97065 & 0,96691 & 0,960364 & 0,94097 & 0,96808 \\
\hline Santander & 0,934902 & 0,985254 & 0,940407 & 0,850313 & 0,931099 & 0,949663 & 1 & 1 & 0,94781 \\
\hline BRB & 0,817271 & 0,828462 & 0,834067 & 0,828436 & 0,846851 & 0,84772 & 0,835995 & 0,83664 & 0,83438 \\
\hline Itaú & 0,713837 & 0,746261 & 0,783559 & 0,855373 & 0,848758 & 1 & 0,919915 & 1 & 0,85243 \\
\hline Paraná & 0,976901 & 0,983696 & 0,978454 & 1 & 0,989435 & 0,985136 & 0,986607 & 0,96181 & 0,9827 \\
\hline Média & 0,901001 & 0,930384 & 0,924427 & 0,899693 & 0,910658 & 0,912503 & 0,895364 & 0,84482 & 0,90202 \\
\hline
\end{tabular}

Tabela 12. Eficiência Global das DMUs - Modelo BCC. 


\begin{tabular}{|c|c|c|c|c|c|c|c|c|}
\hline DMU & $2008 / 2009$ & $2009 / 2010$ & $2010 / 2011$ & $2011 / 2012$ & $2012 / 2013$ & $2013 / 2014$ & $2014 / 2015$ & Média \\
\hline Banestes & 1,031785 & 0,979252 & 0,978928 & 0,992072 & 1,004477 & 1,007653 & 1,007143 & 1,000039 \\
\hline ABC Brasil & 1,000261 & 1,007221 & 1,000696 & 0,986916 & 0,995791 & 1,000687 & 0,976538 & 0,995397 \\
\hline Alfa & 1,002896 & 1,001791 & 0,997648 & 1,000276 & 1,001734 & 0,996493 & 1,00125 & 1,000296 \\
\hline Amazônia & 1,014148 & 1,004025 & 0,969492 & 1,007541 & 0,999673 & 1,005175 & 1,044987 & 1,006224 \\
\hline Bradesco & 1,621937 & 0,896631 & 0,724844 & 1,166005 & 0,841848 & 0,974744 & 0,533603 & 0,915297 \\
\hline Brasil & 1 & 1 & 0,950136 & 1,052481 & 1 & 0,931971 & 0,787388 & 0,956751 \\
\hline BTG Pactual & 1 & 0,974423 & 1,002643 & 1,023543 & 1 & 0,804477 & 0,612792 & 0,903895 \\
\hline Daycoval & 1,002838 & 1 & 0,99489 & 1,005137 & 0,991665 & 0,999289 & 1,009123 & 1,000405 \\
\hline Banese & 0,998347 & 1,006471 & 1,001188 & 0,994422 & 0,974978 & 0,989751 & 1,0086 & 0,996194 \\
\hline Banpará & 0,959211 & 0,992544 & 1,002671 & 0,991717 & 0,96073 & 0,97863 & 1,032979 & 0,988072 \\
\hline Banrisul & 1,016294 & 1,017628 & 1,028779 & 0,998825 & 1,054529 & 0,983916 & 1,029924 & 1,018337 \\
\hline Indusval & 1 & 1 & 0,935181 & 1,010374 & 0,987761 & 1,010623 & 0,983923 & 0,989392 \\
\hline $\begin{array}{c}\text { Mercantil } \\
\text { (Inv.) }\end{array}$ & 1,00034 & 0,999724 & 1,000299 & 1 & 0,999479 & 1,000263 & 1,000258 & 1,000052 \\
\hline Mercantil & 1,000585 & 1,002228 & 0,978656 & 1,018215 & 0,998271 & 0,976798 & 1,043157 & 1,002336 \\
\hline $\begin{array}{c}\mathrm{BCO} \\
\text { Nordeste } \\
\end{array}$ & 1,02797 & 0,992337 & 1,015487 & 1 & 0,983608 & 1,016665 & 0,993718 & 1,004146 \\
\hline Pan & 1,030934 & 1 & 0,896877 & 0,935121 & 1,092267 & 1,001458 & 0,970542 & 0,98784 \\
\hline Pine & 0,98975 & 0,993843 & 1,007419 & 0,994051 & 0,996146 & 0,993231 & 0,97981 & 0,993435 \\
\hline Santander & 1,053858 & 0,954482 & 0,904196 & 1,095007 & 1,019938 & 1,053005 & 1 & 1,009663 \\
\hline BRB & 1,013694 & 1,006765 & 0,993248 & 1,022229 & 1,001026 & 0,986169 & 1,000776 & 1,003352 \\
\hline Itaú & 1,045422 & 1,049979 & 1,091651 & 0,992266 & 1,178193 & 0,919915 & 1,087057 & 1,049336 \\
\hline Paraná & 1,006956 & 0,994671 & 1,022021 & 0,989435 & 0,995655 & 1,001493 & 0,97487 & 0,997779 \\
\hline Média & 1,032611 & 0,993598 & 0,973244 & 1,012187 & 1,002027 & 0,981218 & 0,943553 & 0,990845 \\
\hline
\end{tabular}

Tabela 13. Índice Malmquist de Produtividade (MPI) de cada DMU - Modelo BCC 


\begin{tabular}{|c|c|c|c|c|c|c|c|c|}
\hline DMU & $2008 / 2009$ & $2009 / 2010$ & $2010 / 2011$ & $2011 / 2012$ & $2012 / 2013$ & $2013 / 2014$ & $2014 / 2015$ & Média \\
\hline Banestes & 0,984493 & 1,006718 & 1,018377 & 0,958102 & 0,994569 & 1,149149 & 0,872234 & 0,994779 \\
\hline ABC Brasil & 0,986715 & 1,016503 & 1 & 0,986474 & 1,012327 & 1,001368 & 1 & 1,000428 \\
\hline Alfa & 1,000761 & 0,999101 & 0,983661 & 1,007448 & 1,010642 & 0,993471 & 1,013018 & 1,001112 \\
\hline Amazônia & 0,899705 & 1,111475 & 0,95499 & 0,937958 & 0,98735 & 1,040949 & 1,063282 & 0,996956 \\
\hline Bradesco & 1,16676 & 0,960468 & 0,822768 & 1,034243 & 0,879486 & 1,140837 & 0,644895 & 0,933348 \\
\hline Brasil & 1 & 1 & 1 & 1 & 1 & 1 & 1 & 1 \\
\hline BTG Pactual & 1 & 1 & 1 & 1 & 1 & 1 & 0,59065 & 0,927541 \\
\hline Daycoval & 1 & 1 & 1 & 1 & 1 & 1 & 1 & 1 \\
\hline Banese & 0,958506 & 1,007445 & 1,021095 & 0,939933 & 1,001506 & 1,066372 & 1,010991 & 1,000095 \\
\hline Banpará & 0,965107 & 0,981059 & 0,987848 & 1,004426 & 0,999912 & 0,930361 & 1,097844 & 0,994107 \\
\hline Banrisul & 1,006272 & 1,034452 & 1,014243 & 0,962986 & 1,038436 & 0,960356 & 1,041281 & 1,007782 \\
\hline Indusval & 1 & 1 & 1 & 0,994506 & 1,005524 & 0,982677 & 1,017628 & 1 \\
\hline $\begin{array}{l}\text { Mercantil } \\
\text { (Inv.) }\end{array}$ & 1 & 1 & 1 & 1 & 1 & 1 & 1 & 1 \\
\hline Mercantil & 0,914495 & 1,025043 & 0,996421 & 1,007396 & 0,973176 & 1,120946 & 0,912687 & 0,990723 \\
\hline $\begin{array}{c}\text { BCO } \\
\text { Nordeste }\end{array}$ & 1 & 1 & 1 & 1 & 1 & 1 & 1 & 1 \\
\hline Pan & 1 & 1 & 1 & 1 & 1 & 1 & 1 & 1 \\
\hline Pine & 0,990281 & 1,009076 & 0,999631 & 1,001102 & 1 & 0,997625 & 0,985799 & 0,99762 \\
\hline Santander & 1 & 1 & 0,998297 & 1,001705 & 1 & 1 & 1 & 1 \\
\hline BRB & 0,99969 & 1,01331 & 1,001452 & 0,986721 & 0,99959 & 0,932633 & 1,059824 & 0,998422 \\
\hline Itaú & 1,008674 & 1,026485 & 1,082395 & 1 & 1 & 1 & 1 & 1,016412 \\
\hline Paraná & 0,99925 & 1,00075 & 1 & 1 & 1 & 1 & 1 & 1 \\
\hline Média & 0,993218 & 1,00878 & 0,993278 & 0,991308 & 0,994931 & 1,013516 & 0,957457 & 0,993071 \\
\hline
\end{tabular}

Tabela 14. Mudança de Eficiência (OEC) de cada DMU - Modelo BCC. 


\begin{tabular}{|c|c|c|c|c|c|c|c|c|}
\hline DMU & $\mathbf{2 0 0 8 / 2 0 0 9}$ & $\mathbf{2 0 0 9 / 2 0 1 0}$ & $\mathbf{2 0 1 0 / 2 0 1 1}$ & $\mathbf{2 0 1 1 / 2 0 1 2}$ & $\mathbf{2 0 1 2 / 2 0 1 3}$ & $\mathbf{2 0 1 3 / 2 0 1 4}$ & $\mathbf{2 0 1 4 / 2 0 1 5}$ & Média \\
\hline Banestes & 1,048037 & 0,972718 & 0,961263 & 1,035455 & 1,009962 & 0,876869 & 1,154671 & 1,005288 \\
\hline ABC Brasil & 1,013728 & 0,990868 & 1,000696 & 1,000448 & 0,983666 & 0,999319 & 0,976538 & 0,994972 \\
\hline Alfa & 1,002134 & 1,002692 & 1,01422 & 0,992881 & 0,991185 & 1,003042 & 0,988383 & 0,999185 \\
\hline Amazônia & 1,127201 & 0,903327 & 1,015185 & 1,074186 & 1,012481 & 0,965633 & 0,982794 & 1,009297 \\
\hline Bradesco & 1,390121 & 0,933535 & 0,880982 & 1,127399 & 0,957204 & 0,854411 & 0,827426 & 0,98066 \\
\hline Brasil & 1 & 1 & 0,950136 & 1,052481 & 1 & 0,931971 & 0,787388 & 0,956751 \\
\hline BTG Pactual & 1 & 0,974423 & 1,002643 & 1,023543 & 1 & 0,804477 & 1,037487 & 0,974507 \\
\hline Daycoval & 1,002838 & 1 & 0,99489 & 1,005137 & 0,991665 & 0,999289 & 1,009123 & 1,000405 \\
\hline Banese & 1,041567 & 0,999034 & 0,980505 & 1,057971 & 0,973512 & 0,928147 & 0,997635 & 0,9961 \\
\hline Banpará & 0,993891 & 1,011707 & 1,015006 & 0,987347 & 0,960814 & 1,051883 & 0,940916 & 0,99393 \\
\hline Banrisul & 1,00996 & 0,983736 & 1,014333 & 1,037216 & 1,015497 & 1,024533 & 0,989093 & 1,010473 \\
\hline Indusval & 1 & 1 & 0,935181 & 1,015955 & 0,982335 & 1,028438 & 0,966879 & 0,989392 \\
\hline Mercantil & 1,00034 & 0,999724 & 1,000299 & 1 & 0,999479 & 1,000263 & 1,000258 & 1,000052 \\
\hline Inv.) & 1,09414 & 0,977742 & 0,98217 & 1,01074 & 1,025786 & 0,871405 & 1,142951 & 1,011722 \\
\hline Mercantil & 1,02797 & 0,992337 & 1,015487 & 1 & 0,983608 & 1,016665 & 0,993718 & 1,004146 \\
\hline $\begin{array}{c}\text { BCO } \\
\text { Nordeste }\end{array}$ & 1,030934 & 1 & 0,896877 & 0,935121 & 1,092267 & 1,001458 & 0,970542 & 0,98784 \\
\hline Pan & 0,999464 & 0,984904 & 1,007791 & 0,992957 & 0,996146 & 0,995595 & 0,993925 & 0,995805 \\
\hline Pine & 1,053858 & 0,954482 & 0,905739 & 1,093143 & 1,019938 & 1,053005 & 1 & 1,009663 \\
\hline Santander & 1,014008 & 0,993541 & 0,991808 & 1,035986 & 1,001437 & 1,057404 & 0,944285 & 1,004938 \\
\hline BRB & 1,036432 & 1,022888 & 1,008552 & 0,992266 & 1,178193 & 0,919915 & 1,087057 & 1,032392 \\
\hline Itaú & 1,007711 & 0,993925 & 1,022021 & 0,989435 & 0,995655 & 1,001493 & 0,97487 & 0,997779 \\
\hline Paraná & 1,039662 & 0,98495 & 0,979831 & 1,021062 & 1,007131 & 0,968132 & 0,985478 & 0,997758 \\
\hline Média &
\end{tabular}

Tabela 15. Mudança de Tecnologia (OTC) de cada DMU - Modelo BCC. 